\title{
DISTÚRBIOS ANGIOPROLIFERATIVOS BUCAIS E CUTÂNEOS. CORRELAÇÕES HISTOPATOLÓGICAS E EXPRESSÃO DE MEDIADORES ANGIOGÊNICOS
}

MARIA RENATA SALES NOGUEIRA COSTA

Tese apresentada à Faculdade de Odontologia de Bauru, da Universidade de São Paulo, como parte dos requisitos para obtenção do título de Doutor em Odontologia, área de Patologia Bucal.

(Edição Revisada)

Bauru-SP

2006 
COSTA, MARIA RENATA SALES NOGUEIRA.

C823d Distúrbios Angioproliferativos Bucais e Cutâneos. Correlações

Histopatológicas e Expressão de Mediadores Angiogênicos / Maria

Renata Sales Nogueira Costa - Bauru 2006.

124p: il; $28 \mathrm{~cm}$.

Tese (Doutorado) - Faculdade de Odontologia de Bauru/USP.

Orientadora: PROFª .DR ${ }^{\text {a }}$ Vanessa Soares Lara

Autorizo, exclusivamente para fins acadêmicos e científicos, a reprodução total ou parcial desta Tese, por processos fotocopiadores e outros meios eletrônicos.

Maria Renata Sales Nogueira Costa

Comitê de Ética da FOB

№. do Processo: $21 / 2004$ 


\section{SUMÁRIO}

LISTA DE FIGURAS...................................................................

LISTA DE TABELAS.................................................................... $v$

LISTA DE ABREVIATURAS E SÍMBOLOS............................................. vii

RESUMO ..........................................................................

1 - INTRODUÇÃ

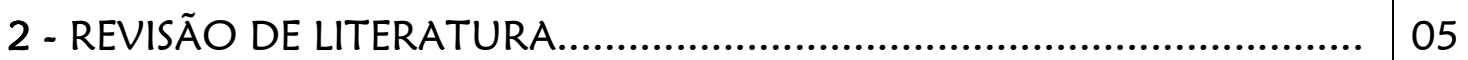

2.1 - Desenvolvimento vascular....................................................... 06

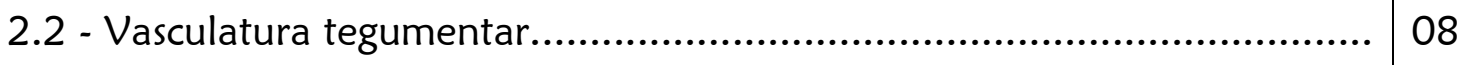

2.3 - Classificação das lesões angioproliferativas...................................... 10

2.4 - Lesões angioproliferativas bucais e cutâneas.................................... 13

2.5 - Fatores de crescimento fibroblástico e seus receptores...................... 30

2.6 - Neurotrofinas e seus receptores............................................... 35

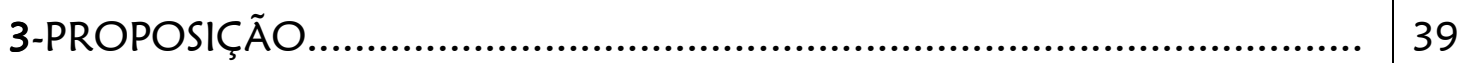

4-MATERIAL E MÉTODOS.............................................................. 41

4.1 - Amostragem...................................................................... 42

4.2 - Análise morfológica............................................................... 44

4.3 - Análise imuno-histoquímica....................................................... 45

4.4 - Análise estatística....................................................................... 49

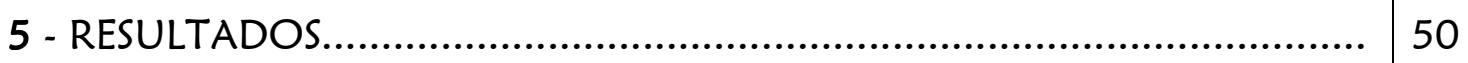

5.1 - Prevalência das lesões angioproliferativas...................................... 51

5.2 - Caracterização clínica da amostra............................................. 52

5.3 - Análise morfológica e imuno-histoquímica................................... 54

5.4 - Análise estatística comparativa................................................ 94

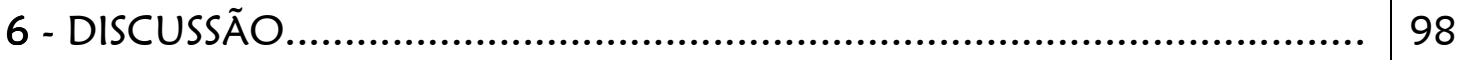

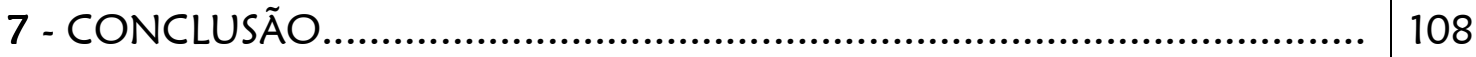

RFERÊNCIAS BIBLIOGRÁFICAS....................................................... 110

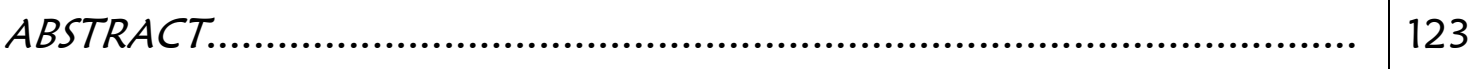




\section{LISTA DE FIGURAS}

Figura 1 - Classificação biológica das lesões vasculares, por Mulliken; Glowaki (2003).

Figura 2 - Classificação dos distúrbios angioproliferativos cutâneos, modificada de Sangüeza e Requena (2003)

Figura 3 - Critérios morfológicos empregados para a avaliação histopatológica dos espécimes.

Figura 4 - Malformação venosa bucal. HE e IHQ: FGFb.

Figura 5 - Malformação venosa cutânea. HE e IHQ: p75NTR

Figura 6 - Malformação linfática bucal. HE e IHQ: p75 NTR e FGFb.

Figura 7 - Malformação linfática cutânea. HE e IHQ.

Figura 8 - Granuloma piogênico bucal. HE e IHQ: FGFb. 68

Figura 9 - Granuloma piogênico bucal. HE e IHQ: FGFb. 69

Figura 10 - Granuloma piogênico cutâneo. HE e IHQ: p75 NTR

Figura 11 - Granuloma piogênico cutâneo. HE e IHQ: p75NTR

Figura 12 - Hemangioma capilar bucal. HE e IHQ: FGFb e p75NTR

Figura 13 - Hemangioma capilar bucal. HE e IHQ: p75NTR

Figura 14 - Hemangioma capilar cutâneo. HE e IHQ: p75 NTR 80

Figura 15 - Hemangioma capilar cutâneo. HE. 81

Figura 16 - Hemangioma arteriovenoso bucal. HE e IHQ: FGFb. 84

Figura 17 - Hemangioma arteriovenoso cutâneo. HE e IHQ: p75NTR. 87

Figura 18 - Sarcoma de Kaposi bucal. HE e IHQ: FGFb. 90

Figura 19 - Sarcoma de Kaposi cutâneo. HE e IHQ: p75 NTR 93

Gráfico 1 - Incidência das lesões angioproliferativas bucais. 52

Gráfico 2 - Incidência das lesões angioproliferativas cutâneas. 52

Gráfico 3 - Expressão de p75NTR nas lesões angioproliferativas bucais e cutâneas.. 96

Gráfico 4 - Expressão de FGFb nas lesões angioproliferativas bucais e cutâneas. 96 


\section{LISTA DE TABELAS}

Tabela 1 - Classificação etiopatogênica da amostra

Tabela 2 - Prevalência bianual das lesões angioproliferativas nos serviços de anatomopatologia da FOB-USP e do ILSL-SES/SP.

Tabela 3 - Dados clínicos das lesões angioproliferativas bucais e cutâneas selecionadas para o trabalho

Tabela 4 - Avaliação imuno-histoquímica da expressão de p75NTR e FGFb nos espécimes de malformação venosa bucal quanto à intensidade e distribuição.

Tabela 5 - Medianas dos critérios morfológicos analisados nos espécimes de malformação venosa bucal.

Tabela 6 - Avaliação imuno-histoquímica da expressão de p75NTR e FGFb nos espécimes de malformação venosa cutânea quanto à intensidade e distribuição.

Tabela 7 - Medianas dos critérios morfológicos analisados nos espécimes de malformação venosa cutânea...

Tabela 8 - Avaliação imuno-histoquímica da expressão de p75NTR e FGFb nos espécimes de malformação linfática bucal quanto à intensidade e distribuição.

Tabela 9 - Medianas dos critérios morfológicos analisados nos espécimes de malformação linfática bucal.

Tabela 10 - Avaliação imuno-histoquímica da expressão de p75NTR e FGFb nos espécimes de malformação linfática cutânea quanto à intensidade e distribuição.

Tabela 11 - Medianas dos critérios morfológicos analisados nos espécimes de malformação linfática.

Tabela 12 - Avaliação imuno-histoquímica da expressão de p75 NTR e FGFb nos espécimes de granuloma piogênico bucal quanto à intensidade e distribuição.

Tabela 13 - Medianas dos critérios morfológicos analisados nos espécimes de granuloma piogênico bucal.

Tabela 14 - Avaliação imuno-histoquímica da expressão de p75 NTR e FGFb nos espécimes de granuloma piogênico cutâneo quanto à intensidade e distribuição.

Tabela 15 - Medianas dos critérios morfológicos analisados nos espécimes de granuloma piogênico cutâneo. 
Tabela 16 - Avaliação imuno-histoquímica da expressão de p75NTR e FGFb nos espécimes de hemangioma capilar bucal quanto à intensidade e distribuição.

Tabela 17 - Medianas dos critérios morfológicos analisados nos espécimes de hemangioma capilar bucal.

Tabela 18 - Avaliação imuno-histoquímica da expressão de p75NTR e FGFb nos espécimes de hemangioma capilar cutâneo quanto à intensidade e distribuição.

Tabela 19 - Medianas dos critérios morfológicos analisados nos espécimes de hemangioma capilar cutâneo.

Tabela 20 - Avaliação imuno-histoquímica da expressão de p75NTR e FGFb nos espécimes de hemangioma arteriovenoso bucal quanto à intensidade $\mathrm{e}$ distribuição

Tabela 21 - Medianas dos critérios morfológicos analisados nos espécimes de hemangioma arteriovenoso bucal.

Tabela 22 - Avaliação imuno-histoquímica da expressão de p75 NTR e FGFb nos espécimes de hemangioma arteriovenoso cutâneo quanto à intensidade e distribuição

Tabela 23 - Medianas dos critérios morfológicos analisados nos espécimes de hemangioma arteriovenoso cutâneo.

Tabela 24 - Avaliação imuno-histoquímica da expressão de p75NTR e FGFb nos espécimes de sarcoma de Kaposi bucal quanto à intensidade e distribuição.

Tabela 25 - Medianas dos critérios morfológicos analisados nos espécimes de sarcoma de Kaposi bucal.

Tabela 26 - Avaliação imuno-histoquímica da expressão de p75NTR e FGFb nos espécimes de sarcoma de Kaposi cutâneo quanto à intensidade e distribuição.

Tabela 27 - Medianas dos critérios morfológicos analisados nos espécimes de sarcoma de Kaposi cutâneo.

Tabela 28 - Medianas dos escores morfológicos da amostra de lesões angioproliferativas bucais e cutâneas.

Tabela 29 - Escores da expressão de p75NTR nas lesões angioproliferativas bucais e cutâneas representados em valores percentuais.

Tabela 30 - Escores da expressão de FGFb nas lesões angioproliferativas bucais e cutâneas representados em valores percentuais 


\section{LISTA DE ABREVIATURAS E SÍMBOLOS}

34ßE12: anticorpo anti-citoqueratinas de alto peso molecular $(1,5,10,14)$

$35 \beta \mathrm{H} 11$ : anticorpo anti-citoqueratinas de baixo peso molecular $(5,6,17,19)$

AE1/AE3: anticorpo anti-citoqueratinas tipo I e II

ALK: anaplasic lymphoma kinase (quinase de linfoma anaplásico)

Ang: angiopoietin (angiopoietina)

ASMA ou $\alpha$-SMA: alpha smooth muscle actin (actina alfa de músculo liso)

AS-VEGF: anti-sense VEGF (VEGF anti-sentido)

BAD: BCL2-antagonist of cell death (antagonista de BCL2 de morte celular)

Bcl-2: B-cell CLL/lymphoma-2 (proteína 2 de CCL/linfoma de células B)

BDNF: brain derived neurotrophic factor (fator neurotrófico derivado do cérebro)

BSA: bovine albumin serum (albumina de soro bovino)

CAM: coryoalantoic membrane (membrana corioalantóica)

CD31: platelet/endothelial cell adhesion molecule 1 (molécula de adesão celular plaquetária/endotelial 1)

CD34: haematopoietic progenitor cell antigen (antígeno de célula progenitora hematopoiética)

cDNA: DNA complementar

C-terminal: término carboxila

DAB: diaminobenzidina

EMA: epithelial membrane antigen (antígeno de membrana epitelial)

FGF: fibroblastic growth factor (fator de crescimento fibroblástico)

FGFa: acid FGF (FGF ácido)

FGFb: basic FGF (FGF básico)

FGFR: FGF receptor (receptor de FGF)

FIF: interacting fibroblastic factor (fator de interação com fibroblastos)

GLUT1: glucose transporter 1 (transportador 1 de glicose)

GRB2: growth factor receptor-bound protein 2 (proteína 2 ligada a receptor de fator de crescimento)

HAM56: human alveolar macrophage 56 (macrófago alveolar humano 56) 
HBGF: heparin-binding growth factor (fator de crescimento associado à heparina) HE: hematoxilina-eosina

HEC-1B: human endometrial carcinoma $1 B$ (linhagem celular tipo um B de carcinoma endometrial humano)

HHF-35: muscle-specific actin (actina muscular específica)

HHSV-8: human herpes vírus 8 (vírus herpes simples humano tipo oito)

HHT1: hereditary hemorrhagic teleangiectasia type 1 (teleangectasia hemorrágica hereditária tipo um)

HHT2: hereditary hemorrhagic telangiectasia type 2 (teleangectasia hemorrágica hereditária tipo dois)

HIV: human immunodeficiency vírus (vírus da imunodeficiência humana)

HSPG: heparan-sulphate proteoglican (proteoglicana heparan sulfato)

HUVECS: human umbilical vein endothelial cells (células endoteliais de veias umbilicais humanas)

ICAM-1: intercellular adhesion molecule 1 (molécula 1 de adesão intercelular)

IHQ: imuno-histoquímica

INF- $\gamma$ : interferon gama

JNK: c-jun N-terminal protein kinase (proteína quinase $\mathrm{N}$-terminal c-jun)

KSV: Kaposi sarcoma virus (vírus do sarcoma de Kaposi)

LCA: light polypeptide A (polipeptídio A leve)

Lingo-1: leucine-rich repeat neuronal protein 1 (proteína neuronal rica em leucina)

MAE: células endoteliais aórticas murinas

MAPK: mitogen-activated protein kinase (proteína quinase ativadora mitogênica)

MHC: major histocompatibility complex (complexo principal de histocompatibilidade)

mRNA: RNA mensageiro

NADE: p75NTR-associated cell death executor (executor de morte celular associado a p75NTR)

NF: neurotrophin (neurotrofina)

NGF: neural growth factor (fator de crescimento neural)

NGFR: neural growth factor receptor (receptor de fator de crescimento neural) 
NRAGE: neurotrophin receptor-interacting MAGE homolog (receptor de neurotrofina homólogo a MACE)

NRIF: neurotrophin receptor interacting factor (fator de interação com neurotrofinas)

$\mathrm{N}$-terminal: término amino

p75 NTR: neurotrophin receptor p75 (receptor p75 de neurotrofina)

PBS: phosphate buffered salin (solução salina tamponada com fosfato)

PCNA: proliferating cell nuclear antigen (antígeno de proliferação nuclear)

TGF- $\beta$ : transforming growth factor beta (fator de crescimento e transformação beta)

TIE: tyrosine kinase with immunoglobulin-like and EGF-like domains (domínios imunoglobulina-like e EGF-like de tirosina quinase)

TNF- $\alpha$ : tumoral necrosis factor alpha (fator de necrose tumoral alfa)

TNFR: tumoral necrosis factor receptor (receptor de fator de necrose tumoral)

Trk: tropomyosin kinase related receptor (receptor quinase relacionado à tropomiosina)

VEGF: vascular endothelial growth factor (fator de crescimento vascular endotelial) VWF : fator de von Willebrand 


\section{RESUMO}

A mucosa bucal e a pele podem apresentar distúrbios vasculares proliferativos com comportamento biológico variado. Para classificar tais lesões foram adotados critérios etiopatogênicos e a avaliação desses critérios em grupos específicos de lesões angioproliferativas pode contribuir para o diagnóstico e tratamento das mesmas. O objetivo desse estudo retrospectivo foi caracterizar as principais lesões angioproliferativas da mucosa bucal, comparando-as com os mesmos tipos de lesões cutâneas, em relação aos achados histopatológicos e à expressão endotelial do fator de crescimento fibroblástico básico (FGFb) e do receptor p75 para neurotrofinas ( $p 75^{\mathrm{NTR}}$ ). Foram utilizados espécimes arquivados em blocos parafinados, divididos conforme o diagnóstico microscópico em seis grupos: (I) malformações venosas; (II) malformações linfáticas; (III) granulomas piogênicos; (IV) hemangiomas capilares; (V) hemangiomas arteriovenosos; (VI) sarcomas de Kaposi. Cada grupo foi subdividido em dois grupos quanto a sua localização bucal e cutânea. Os padrões microscópicos das lesões angioproliferativas bucais e cutâneas de nossa amostra são similares e podem ser classificadas sob os mesmos parâmetros. No entanto, alguns grupos apresentaram diferenças quanto ao estádio de maturação das lesões, em relação à incidência e principalmente em relação à expressão dos mediadores estudados. A diferença na expressão de FGFb e p75 NTR, observada entre os grupos bucais e cutâneos dos mesmos tipos de lesões, permitiunos concluir que a evolução da angiogênese na mucosa bucal e na pele não é necessariamente mediado pelos mesmos fatores. Tais diferenças abrem perspectivas para pesquisas futuras e abordagens terapêuticas baseadas em tecnologias moleculares. 


\section{1 - INTRODUÇÃO}




\section{1 - INTRODUÇÃO}

O processo de diferenciação e proliferação endotelial pode ser observado em diferentes fenômenos biológicos como a embriogênese, o processo de reparo e os distúrbios do desenvolvimento e do crescimento celular. Nos indivíduos em formação refere-se como vasculogênese. Eventos da mesma natureza, quando sediados em organismos adultos, recebem a designação de angiogênese ${ }^{83}$.

A angiogênese é modulada por vários estímulos biomoleculares em todas as suas etapas. Alterações que venham a interferir na interação entre os mediadores químicos envolvidos podem desencadear processos proliferativos além dos padrões fisiológicos, gerando lesões com características clínicas e patogênicas diversas 7, 8, 11, 29 , 37 .

$\mathrm{Na}$ literatura podem ser encontrados vários sinônimos para quase todo tipo de lesão angioproliferativa, bem como múltiplas classificações sob diferentes referenciais clínicos e microscópicos. Estes referenciais usados para classificar as lesões angioproliferativas, somados à sua diversidade, são obstáculos metodológicos na busca de respostas sobre seu comportamento biológico 19, 37, 41, 47, 76 .

MULLIKEN; GLOWACKI55 propuseram, em 1982, uma classificação das lesões angioproliferativas cutâneas. O propósito dos autores foi estabelecer uma linguagem comum aos diferentes especialistas envolvidos no manejo dessas lesões. Em 1996, a Sociedade Internacional para o Estudo das Anomalias Vasculares aceitou, com modificações, a classificação para lesões angioproliferativas de MULLIKEN e colaboradores 9 ,55, 56. A referida classificação se baseou na cinética das lesões angioproliferativas, enfatizando a distinção entre neoplasias e malformações vasculares, caracterizadas como anomalias das estruturas endoteliais capilares, venosas, linfáticas e arteriovenosas ${ }^{56}$. 
No espectro biológico dos distúrbios angioproliferativos encontram-se, ao lado das malformações vasculares, as ectasias e os hamartomas. No centro do espectro estão as hiperplasias vasculares e as neoplasias benignas, finalizando com os tumores malignos em seus graus de diferenciação. As lesões angioproliferativas podem acometer vários órgãos internos, além de regiões específicas como mucosa bucal e o tecido cutâneo ${ }^{51}$.

Algumas ferramentas de pesquisa são utilizadas no estudo das lesões vasculares proliferativas ${ }^{34,}$ 57. A diferenciação endotelial demonstrada pela morfologia microscópica pode ser confirmada por alguns marcadores imunofenotípicos como o CD31, VWF e GLUT154, 59. O receptor VEGFR-3 é capaz de distinguir o endotélio linfático do sanguíneo ${ }^{30}$. O processo de angiogênese pode ser estudado por meio da identificação de mediadores bioquímicos como o FGFb ${ }^{32}$, VEGF ${ }^{33}$, Ang-129, 97, NGF ${ }^{14,}{ }^{22}, \mathrm{TCF}_{-} \beta^{29}$ e TNF ${ }^{83}$. O desenvolvimento tecnológico permite que se acrescentem cada vez mais itens à ampla lista de moduladores angiogênicos que podem contribuir, entre outros aspectos, com a terapêutica das lesões angioproliferativas $26,53,83$.

Um dos primeiros mediadores angiogênicos descritos foi 0 fator de crescimento fibroblástico. Em 1985 foram determinadas as seqüências primárias de dois fatores de crescimento com alta afinidade por heparina: o FGF básico e o FGF ácido ${ }^{29}$. Posteriormente, o fator de crescimento fibroblástico básico e o fator de crescimento de células endoteliais - um precursor do FGF ácido - puderam ser clonados e suas respectivas seqüências de nucleotídeos caracterizadas, permitindo uma compreensão mais abrangente de seu emprego na pesquisa e terapêutica dos distúrbios angioproliferativos 31, 39, 84 .

A atividade angioproliferativa pode ser mediada alternativamente pela ação de mediadores pleiotrópicos como as neurotrofinas - NGF40, 66, BDNF²1, NF3, NF4 . Esses são fatores estratégicos no desenvolvimento, diferenciação e viabilidade neural, além de sua importância na fisiopatologia vascular. Sua ação é mediada por interações com os receptores de superfície celular do tipo p140 proto-trk (trK A, B, 
C) ${ }^{50,66}$ e p75 ${ }^{\mathrm{NTR}}, 77$, capazes de participar dos processos de proliferação e morte celular endotelial ${ }^{48}$.

Esse trabalho busca contribuir com o estudo dos aspectos patogênicos observados nas principais categorias de distúrbios angioproliferativos. Para tanto, foram avaliadas as características microscópicas das lesões angioproliferativas bucais em comparação com as cutâneas, bem como a participação dos mediadores FGFb e p75 ${ }^{\text {NTR }}$ no comportamento biológico dessas lesões. 
2 - REVISÃO DE LITERATURA 


\section{2 - REVISÃO DE LITERATURA}

\section{1 - DESENVOLVIMENTO VASCULAR}

Os processos pelos quais se formam os vasos sanguíneos e linfáticos são denominados vasculogênese, angiogênese e linfangiogênese. A vasculogênese envolve a diferenciação de células endoteliais a partir de precursores mesodérmicos denominados hemangioblastos. Tais células agregam-se para formar ilhotas endoteliais primárias nas quais as células da porção interna se diferenciam em progenitores hematopoiéticos e as da periferia em precursores endoteliais denominados angioblastos. Os angioblastos se reorganizam a fim de formar estruturas tubulares capilares que compõem o plexo vascular primário. Com o remodelamento do plexo primário se formam novos capilares, caracterizando o início do processo de angiogênese ${ }^{87,83,91,11}$.

Os novos capilares se originam principalmente da degradação da membrana basal de pequenas vênulas do plexo primário, seguida do movimento de células endoteliais em direção ao estímulo angiogênico. As células endoteliais se alongam e se alinham, formando um broto. Subseqüentemente forma-se o lume a partir de uma curvatura intracitoplasmática em cada uma das células endoteliais que proliferam aumentando o comprimento do broto. Dois brotos unidos pelas extremidades formam uma alça por onde se inicia novo fluxo sanguíneo. A estabilização da vasculatura recém-formada ocorre com a secreção de fatores angiogênicos e recrutamento de células periendoteliais como pericitos e células de músculo liso, que se posicionam ao longo da base da alça vascular, conduzindo o crescimento de novos brotos capilares ${ }^{29}$. As células periendoteliais são capazes de estabilizar os vasos neoformados por meio da inibição da migração e proliferação endotelial, do estímulo à secreção de matriz extracelular e pela formação de membrana basal ${ }^{87}$. 
Os vasos linfáticos se desenvolvem no organismo humano entre a sexta e sétima semana de vida intra-uterina, um mês após a formação dos primeiros vasos sanguíneos. A rede linfática se inicia pela formação de sacos linfáticos primários, dos quais surgem capilares que proliferam em sentido centrífugo. Possivelmente os sacos primários são produzidos a partir de vasos sanguíneos ou de linfangioblastos em um processo semelhante, porém independente, ao da vasculogênese sanguínea"l.

Os precursores morfogênicos das redes vasculares, sanguínea e linfática podem sofrer alterações e causar distúrbios do desenvolvimento classificados como malformações vasculares. Tanto nos distúrbios do desenvolvimento dos tecidos quanto na tumorigênese ${ }^{16}$, podem ocorrer alterações na expressão de genes específicos e na geração de sinais de diferenciação, além da produção de fatores de crescimento responsáveis pela sinalização de múltiplas funções celulares ${ }^{17}$. 


\section{2 - VASCULATURA TEGUMENTAR}

Os diferentes tecidos humanos apresentam variações anatômicas e fisiológicas inerentes aos sítios nos quais são formados. Assim ocorre com as redes vasculares. Conseqüentemente, os distúrbios vasculares proliferativos podem vir a demonstrar variáveis patológicas conforme as localidades nas quais são sediados. A avaliação das características vasculares de órgãos como a pele e a boca, permite que se verifiquem variáveis potencialmente úteis ao estudo dos tumores vasculares nessas regiões.

O suprimento sanguíneo da derme flui de um plexo localizado em profundidade na derme reticular. Essa rede se conecta com três plexos superficiais, denominados plexos subpapilares e pareados, localizados ao redor dos folículos pilossebáceos e glândulas écrinas. Pequenas arteríolas ascendem da derme reticular para se ramificarem em numerosos capilares que nutrem a derme papilar. As alças capilares de cada papila subepidérmica originam-se do plexo subpapilar. Cada alça consiste de um ramo arterial ascendente e de um ramo venoso descendente. $O$ ramo venoso drena sangue para vênulas progressivamente maiores que se esvaziam no plexo subcutâneo. As pequenas artérias do plexo subcutâneo e as arteríolas dérmicas possuem camadas, íntima, média e adventícia. A camada íntima é composta de células endoteliais e de uma lâmina elástica interna. A camada média é composta por células musculares lisas, circundadas por uma lâmina elástica externa e pela camada adventícia, com fibroblastos, colágeno do tipo III e fibras elásticas ${ }^{89}$. 76.

As arteríolas que precedem segmento capilar ascendente são revestidas externamente por pericitos circundados por membrana basal. As arteríolas da derme papilar possuem uma só camada de células endoteliais circundadas por uma camada descontínua de fibras elásticas e células musculares lisas. As metarteríolas são revestidas por uma camada de células endoteliais e circundadas por uma camada incompleta de pericitos. Os canais linfáticos formam uma rede complexa que segue a distribuição das arteríolas e vênulas. No espaço intersticial fornecem 
portais pelos quais trafegam moléculas que devem ser drenadas. Mesmo os menores capilares linfáticos são relativamente largos e achatados, revestidos por uma camada tênue de endotélio circundando por membrana basal indistinta e descontínua ${ }^{89}$.

A mucosa bucal possui um rico suprimento sanguíneo derivado de artérias que se dispõem paralelamente à superfície. Progressivamente esses vasos dão origem a pequenos feixes que anastomosam com os vasos adjacentes na submucosa antes de formarem uma extensa rede de capilares na lâmina própria que termina próxima à camada basal do epitélio. O sistema microvascular consiste de arteríolas, metarteríolas, capilares, vênulas circundadas por pericitos e miócitos. As arteríolas possuem uma a três camadas de musculatura lisa circular. As metarteríolas possuem algumas células musculares lisas esparsas. As vênulas pericíticas têm uma camada de pericitos e não têm musculatura lisa. As vênulas musculares são circundadas por uma a duas camadas de células musculares lisas ${ }^{86,88}$.

O arranjo vascular na mucosa bucal é mais profuso que na pele, onde as alças capilares se encontram associadas aos folículos pilossebáceos. O fluxo sanguíneo da mucosa bucal é mais intenso na gengiva, mas em todas as áreas da boca o mesmo fluxo é maior que o da pele. Diferente da pele, que desempenha um papel na regulação da temperatura corpórea, a mucosa bucal não possui anastomoses arteriovenosas. No entanto, é rica em anastomoses entre arteríolas e entre capilares que contribuem individualmente para a aceleração do processo de reparo na região, em comparação à derme ${ }^{86}$. 


\section{3 - CLASSIFICAÇÃO DAS LESÕES ANGIOPROLIFERATIVAS}

Em 1982, foi proposta por MULLIKEN; GLOWAKI ${ }^{55}$ uma classificação das anomalias vasculares, com base nas características patológicas do endotélio e na evolução natural dessas lesões (Figura 1). WANER; SUEN95 introduziram, em 1999, duas pequenas modificações na referida classificação. Os autores consideraram errôneo o termo malformação arteriovenosa, considerando tratar-se de malformações capilares associadas a pequenas conexões arteriovenosas próximas ao leito capilar. A segunda modificação introduz o termo malformação vascular venular em substituição a designação nevo flâmeo ou mancha "vinho do Porto". Os autores argumentaram que, microscopicamente, essas últimas lesões correspondem a vênulas pós-capilares ectásicas do plexo papilar5.

\begin{tabular}{|l|}
\hline HEMANGIOMAS \\
\hline \\
\hline Fase Proliferativa \\
\hline MALFORMAÇÕES \\
\hline \\
\hline Capilares \\
\hline Linfáticas \\
\hline Venosas \\
\hline Arteriais \\
\hline Combinadas \\
\hline
\end{tabular}

Figura 1 - Classificação biológica das lesões vasculares de Mulliken e Clowacki (1982)

CHILLER et al. ${ }^{19}$, em 2002, classificaram os hemangiomas de acordo com suas características clínico-anatômicas, categorizando-as em: (1) Localizadas ocupam só uma ou duas regiões do corpo; (2) Segmentares - apresentam localização linear ou topográfica, embora nem sempre sigam só um dermátomo e possam ser marcadores sindrômicos; (3) Indeterminadas; (4) Multifocais ${ }^{19}$.

As malformações vasculares podem, ainda, ser classificadas conforme suas características hemodinâmicas. Para o diagnóstico das malformações vasculares conforme esse critério é importante o emprego de métodos como a angiografia. 
Nesse âmbito as lesões são divididas em quatro categorias: [a] malformações isoladas sem drenagem periférica; [b] malformações com drenagem venular normal; [c] malformações com drenagem em veias ectásicas e [d] displasias venosas ${ }^{64}$.

A multiplicidade das lesões angioproliferativas já descritas torna árdua e fascinante a tarefa de categorizá-las. A classificação das lesões angioproliferativas cutâneas pode ser apreciada em estudos baseados em critérios etiopatogênicos como o publicado em 2003, por SANGÜEZA; REQUENA76 (Figura 2). As manifestações bucais dos distúrbios angioproliferativos podem ser encontradas entre as descrições de algumas das lesões angioproliferativas cutâneas. No entanto, não é de nosso conhecimento que haja, na literatura, um estudo classificatório exclusivo das lesões angioproliferativas bucais que poderia ser interessante para nortear pesquisas futuras. 


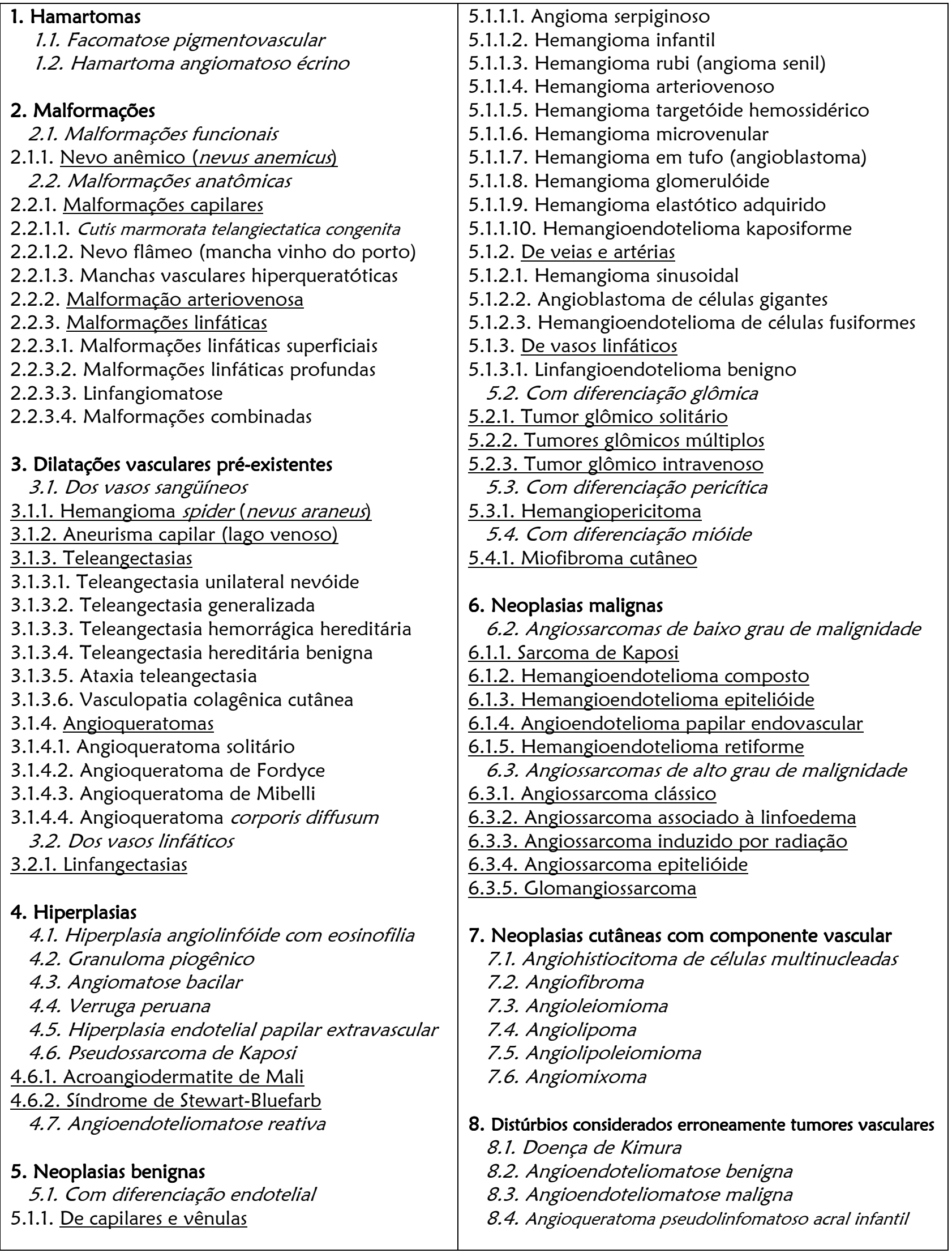

Figura 2 - Classificação dos distúrbios angioproliferativos cutâneos, modificada de Sangüeza e Requena (2003). 


\section{4 - LESÕES ANGIOPROLIFERATIVAS BUCAIS E CUTÂNEAS}

As lesões angioproliferativas podem se originar de distúrbios do desenvolvimento ou distúrbios do crescimento. Os primeiros são congênitos e apresentam alterações estruturais de vasos sanguíneos e/ou linfáticos ${ }^{11}{ }^{24}$. Os distúrbios do crescimento, designados de modo simplista como tumores vasculares, caracterizam-se como proliferações endoteliais hiperplásicas e neoplásicas ${ }^{53}$. Algumas das lesões angioproliferativas cutâneas referidas anteriormente apresentam equivalentes na região bucomaxilar e serão discutidas ${ }^{76}$.

\subsection{1 - Malformações vasculares}

Malformações vasculares resultam de alterações estruturais durante 0 desenvolvimento embriofetal. Estão associadas, em 35\% dos casos, a alterações esqueléticas, mas podem ser observadas distorções ósseas conseqüentes de malformações primárias dos tecidos moles. Quanto ao tipo de vaso envolvido, as malformações podem ser divididas em: capilares, venosas, arteriovenosas e linfáticas. Quando há mais de um tipo vascular envolvido são consideradas combinadas ou mistas. As lesões originadas nos capilares, veias e vasos linfáticos são classificadas clinicamente como de baixo fluxo, enquanto que as de origem arterial são de alto fluxo sangüíneo69.

\subsubsection{1 - Malformação capilar [nevo flâmeo]}

As malformações capilares são frequentemente localizadas nos territórios onde se localizam ramificações do nervo trigêmeo. Podem ser classificadas em variantes plana, teleangectásica, estrelada e senil. Não regridem espontaneamente e pode haver hipertrofia esquelética em lesões extensas. A síndrome de Sturge-Weber é um exemplo de angiomatose generalizada na qual se associam as malformações capilares $^{69,90}$. 
Nevo flâmeo é um termo genérico usado para descrever malformações vasculares congênitas. Envolvem a face e o pescoço, podendo, no entanto haver lesões em outras áreas do corpo como as mucosas. Aproximadamente $25-40 \%$ dos recém nascidos de todas as etnias, nascem com lesões maculares e avermelhadas envolvendo a linha média facial, principalmente a glabela que tendem a desaparecer durante a infância. Quando ocorrem na nuca persistem durante a vida adulta. Lesões em ambas as áreas citadas são designadas como "mordida de cegonha". A mancha "vinho do porto", um tipo menos freqüente de nevo flâmeo, consiste em uma mácula vascular grande envolvendo a face unilateralmente ${ }^{76}$.

Ainda há controvérsia quanto à patogenia da mancha "vinho do porto". Estudos detalhados sobre o tamanho, número de vasos e seu posicionamento, indicaram que não se tratam de proliferações vasculares, mas dilatações progressivas de vasos pré-existentes. Acredita-se que a etiologia dessas lesões deve-se principalmente às alterações funcionais, tendo como possível fator primário uma redução no componente fibrilar neural, observado por análise imuno-histoquímica da expressão da proteína $\mathrm{S}-100$ nos vasos ectásicos. A redução da inervação simpática leva a uma falha regulatória na vasoconstrição causando dilatação vascular perene ${ }^{69,76}$.

Microscopicamente, as malformações capilares são caracterizadas por um número aumentado de capilares e vênulas com paredes vasculares delgadas e dilatadas. Por vezes, em máculas pré-existentes formam-se nódulos angiomatosos compostos por agregados de vasos com paredes finas e lumes de diferentes calibres. Algumas lesões podem ocorrer secundariamente, entre elas, angioma em tufo, hiperplasia angiolinfóide com eosinofilia e carcinoma basocelular. Esta última lesão pode surgir em nevos flâmeos nos quais houve tentativa de tratamento por radioterapia 69,76 .

\subsubsection{2 - Malformação venosa}


As malformações venosas são consideradas, depois das capilares, o segundo tipo mais freqüente de anomalia vascular e representam mais de $50 \%$ dos pacientes referidos a centros especializados ${ }^{11}$. Malformações venosas e veno-capilares geralmente são relatadas como lesões congênitas, ainda que alguns estudos demonstrem o estabelecimento dessas lesões na primeira década e na vida adulta. O aparecimento tardio dessas lesões pode ser justificado pelo fato de seu curso seguir o desenvolvimento do indivíduo, ou por sofrerem influência de fatores hormonais e traumatismos 9,64 .

As malformações venosas podem ser assintomáticas, mas MATHES et al. ${ }^{53}$, 2004 , encontraram sintomatologia em $87 \%$ dos pacientes avaliados em seu estudo. Um número significativo de lesões bucais apresenta edema e sangramento, causando dificuldades na fala, deglutição e respiração. A maioria das lesões em extremidades é acompanhada de dor e diminuição da funcionalidade, em decorrência da compressão de terminações nervosas adjacentes ${ }^{53}$. Muitas das lesões aparentemente superficiais co-existem com alterações venosas profundas; a estrutura óssea e musculatura esquelética costumam apresentar-se distorcidas pelas dimensões da lesão. Em 34\% dos casos de malformações venosas nas extremidades, ocorre envolvimento ósseo ${ }^{90}$.

As malformações venosas apresentam-se clinicamente como lesões violáceas de temperatura fria e consistência elástica, localizadas principalmente na pele e mucosas. São compostas por vasos dilatados de paredes delgadas revestidas por células endoteliais achatadas, circundadas por musculatura lisa deficiente. Nessas lesões os vasos apresentam tamanhos e forma irregulares; envolvem planos médio e profundo da derme e mucosas. Estudos imuno-histoquímicos revelaram uma ausência relativa de células musculares lisas vasculares nessas malformações, provavelmente devido a alterações em moléculas de adesão intercelular e fatores quimiotáticos para miócitos 9 .

Algumas malformações venosas possuem número variável de células glômicas e podem ser denominadas como glomangiomas. Eventualmente os 
glomangiomas são confundidos com tumores glômicos, no entanto esses últimos referem-se a neoplasias e não a malformações. Os glomangiomas com apresentação bucal são extremamente incomuns, embora alguns casos já tenham sido relatados ${ }^{96}$. Os glomangiomas ocorrem com freqüência na infância e se apresentam como pequenos nódulos azulados distribuídos difusamente ${ }^{53,64}$.

A presença de glomangiomas pode ser observada em pacientes com Síndrome de Kasabach-Merritt ${ }^{96}$. Caracteristicamente, são compostos de canais vasculares dilatados, com pequenos agregados de células glômicas em suas paredes. O estroma adjacente pode demonstrar pequenos grupamentos de células glômicas em proliferação. As características subcelulares das células glômicas permitem qualificá-las como células musculares lisas modificadas. Essas lesões apresentam reatividade imuno-histoquímica para vimentina e actina alfa de músculo liso25, 96.

A maioria das malformações venosas é esporádica, embora algumas famílias apresentem um padrão de transmissão autossômico dominante por herança mendeliana. BOON et al. ${ }^{9}, 2004$, realizaram um cohort de 1685 pacientes com malformações vasculares, na qual 138 dessas eram hereditárias e 1547, esporádicas. Dos 138 pacientes com anomalias hereditárias, 33 eram portadores de malformações venosas mucocutâneas e 105 apresentavam malformações glomuvenosas 9 .

Foram demonstradas alterações nos cromossomos 9p21 e 1p21 que caracterizam, respectivamente, $\bigcirc$ fenótipo das malformações vasculares mucocutâneas e das malformações glomuvenosas ${ }^{9}$. As malformações mucocutâneas são geradas por um polimorfismo do códon R849W no locus VMCM1. O resultado dessa mutação foi identificado no receptor TIE-2 de células endoteliais, onde se observou um aumento na autofosforilação do receptor, independentemente da interação com 0 ligante ${ }^{88 .}$ 91. A distinção apropriada entre as variantes de malformações vasculares implica em precisão de diagnóstico e manejo adequado dos pacientes. 


\subsubsection{3 - Malformação arteriovenosa}

As malformações arteriovenosas são anomalias vasculares que representam grande risco aos pacientes. Manifestam-se clinicamente como máculas, placas e nódulos de coloração purpúrea, caracteristicamente pulsáteis. São lesões congênitas que tendem a aumentar de volume proporcionalmente ao desenvolvimento do indivíduo ${ }^{62}$. Sua etiologia está relacionada com a falta de interposição do leito capilar entre as arteríolas e vênulas. Apesar dos capilares normalmente formarem uma densa rede de pequenos vasos entre arteríolas e vênulas, em algumas ocasiões pequenas artérias podem formar nichos que são drenados diretamente por veias ${ }^{11}$.

Microscopicamente, as malformações arteriovenosas são compostas por artérias displásicas entremeadas e conectadas à veias com espessamento da camada íntima. Em culturas de células endoteliais extraídas de malformações arteriovenosas, observa-se alta capacidade proliferativa e redução do processo de apoptose, sugerindo um defeito celular intrínseco ${ }^{94}$. As células endoteliais derivadas das malformações arteriovenosas apresentam, ainda, um índice de proliferação elevado e ausência de sensibilidade a citocinas como IL-1, TNF $\alpha$, TGF $\beta$ e IFN $\gamma$. As malformações arteriovenosas não são hereditárias, embora façam parte de quadros sindrômicos como a Teleangectasia Hemorrágica Hereditária (HHT) ou RenduOsler-Weber. Alguns genes são candidatos potenciais a estar envolvidos na patogênese das malformações arteriovenosas entre os quais, o gene que codifica a proteína efrina B2 e seu receptor Eph-B4. A diversidade clínica das malformações vasculares reflete $\mathrm{O}$ envolvimento de múltiplos mediadores na regulação de vasculogênese e angiogênese $24,36,94$.

KOHOUT et al. ${ }^{47}$, revisaram em 1998, 81 pacientes portadores de malformação arteriovenosa localizadas na região de cabeça e pescoço. $O$ estudo enfocou a história natural e efetividade dos tratamentos instituídos. Observaram que em 59\% dos pacientes, as lesões apresentaram-se ao nascimento, em 10\% na infância, 10\% na adolescência e 21\% na vida adulta. Quando houve envolvimento ósseo, a maxila e mandíbula foram mais acometidas. Os autores caracterizaram as 
malformações arteriovenosas em estádios clínicos seguindo a classificação de Schobinger: quiescência (estádio I); expansão (estádio II); destruição (estádio III) e descompensação (estádio IV). Os autores constataram que o prognóstico não foi significantemente alterado pelas características clínicas e pelo tipo de tratamento adotado 47 .

Em 2000, foram revisados 200 casos de malformações arteriovenosas, por ENJOLRAS et al. ${ }^{24}$ Entre os aspectos observados, constataram a falsa caracterização dessas lesões como malformações capilares, podendo aumentar o risco da execução de um protocolo terapêutico inapropriado. Nos casos revisados, confirmaram-se fatores de exacerbação das lesões como puberdade, gestação e trauma. O padrão de crescimento observado demonstrou progressão expansiva regional. Ao analisarem os tratamentos, concluíram que a embolização não pode controlar definitivamente malformações superficiais e mesmo um tratamento combinado pode não ser suficiente para a cura das lesões ${ }^{24}$.

As malformações vasculares são divididas, para fins terapêuticos, em lesões de baixo e alto fluxo sanguíneo como as malformações arteriovenosas. Nas lesões de baixo fluxo, a terapia esclerosante pode ser a opção de escolha, acompanhada ou não de ressecção cirúrgica. Já nas lesões de alto fluxo, as condutas mais apropriadas são embolização pré-operatória seguida de excisão cirúrgica. A angiografia por ressonância magnética computadorizada tem grande valia no diagnóstico das malformações e são importantes quando a embolização faz parte do protocolo terapêutico 37 .

\subsubsection{4 - Malformação linfática}

Linfangiomas são distúrbios hamartomatosos benignos dos vasos linfáticos com predileção de ocorrência na região de cabeça e pescoço (75\%). Acredita-se que os linfangiomas desenvolvam-se como resultado da persistência de tecidos linfáticos embrionários que não chegam a formar anastomoses eficientes com os canais linfáticos maiores, caracterizando áreas de retenção de linfa. Tais áreas são 
classificadas como linfangioma circumscriptum e higroma cístico, embora o mais apropriado seja designá-las como malformações linfáticas superficiais e profundas ${ }^{10}$.

As malformações linfáticas podem envolver a mucosa bucal e expandir-se pelo periósteo e tecido ósseo adjacente. As alterações osteoporóticas mandibulares são fatores facilitadores da expansão dessas malformações em indivíduos senis. $\mathrm{Na}$ avaliação do fenótipo e comportamento biológico dessas lesões podem ser empregados, actina alfa de músculo liso ( $\alpha-S M A)$, fator de von Willebrand (VWF), angiogenina e receptor 3 para fator de crescimento vascular endotelial (VEGFR-3) como marcadores imuno-histoquímicos ${ }^{30,61}$.

As malformações linfáticas da cavidade bucal envolvem frequentemente a língua, mais raramente $\mathrm{O}$ palato e possuem grande potencial de recorrência ${ }^{20}$. Lesões linguais extensas participam da etiologia das macroglossias, limitando a qualidade de vida dos pacientes devido a alterações na fala, dificuldade de respiração e alimentação. Algumas malformações linfáticas podem se assemelhar às linfangiomatoses, englobando componentes vasculares sanguíneos e apresentando distribuição multicêntrica pela musculatura esquelética em associação a intensa fibrose intersticial 5 .

Pesquisas com microscopia eletrônica demonstraram o adelgaçamento e a descontinuidade da membrana basal no endotélio das malformações linfáticas, possivelmente responsáveis pelo insucesso da escleroterapia nessas lesões ${ }^{10}$.

\subsection{2 - Hiperplasias vasculares}

\subsubsection{1 - Granuloma piogênico}

O granuloma piogênico foi considerado inicialmente como um distúrbio de etiologia infecciosa causada por Botryomyces ou Staphylococcus. A presença de intenso infiltrado inflamatório misto e exuberante tecido de granulação sugeria resposta inflamatória secundária a um processo infeccioso. Sabe-se atualmente que 
se trata de uma hiperplasia vascular em resposta a agressões prévias e fatores hormonais. A patogenia do granuloma piogênico envolve crescimento rápido e regressão posterior sob a forma de fibrose. O granuloma piogênico é freqüente em crianças e adultos jovens, ocorrendo preferencialmente na mucosa bucal e na pele. Lesões eruptivas difusas são observadas como manifestações paraneoplásicas em pacientes com doença de Hodgkin ${ }^{25}$.

As lesões precoces do granuloma piogênico são microscopicamente idênticas a um tecido de granulação, com numerosos capilares e vênulas dispostas radialmente à superfície, geralmente ulcerada. No estroma, notam-se edema e intenso infiltrado inflamatório misto. Os granulomas piogênicos evoluídos apresentam-se como lesões polipóides com arquitetura lobular, devido à interposição septal de fibras colágenas. Lesões mais antigas apresentam reepitelização da área ulcerada e densa fibrose intersticial com redução progressiva das estruturas vasculares. Há granulomas piogênicos demonstram canais vasculares anastomosados tendendo a dissecar $o$ colágeno $e$ assumir um aspecto angiossarcomatoso. A variante intravenosa do granuloma piogênico é rara e apresenta-se ligada à parede de uma veia, formando uma área proliferativa com padrão lobular pouco proeminente $4,35,97$.

O granuloma piogênico bucal acomete mais mulheres do que homens, em uma proporção de 1,2:1 a 2,6:1. Em média a incidência varia entre 28 e 33 anos. A gengiva é mais afetada que outras áreas da mucosa bucal. A maioria das lesões é pediculada e ulcerada. Geralmente as lesões apresentam dimensões entre 10 e 12 $\mathrm{mm}$. Algumas delas crescem rapidamente e podem ser confundidas com tumores malignos. O tratamento de escolha é a excisão cirúrgica e o prognóstico é favorável 88,97 .

Entre as mulheres que apresentam granulomas piogênicos bucais, destaca-se a evolução dessas lesões durante o período de gestação, bem como regressão espontânea das mesmas após o parto. Os mecanismos moleculares envolvidos nessa regressão estão sendo estudados. Foi proposto que na ausência do fator 
angiogênico VEGF há regressão dos vasos sanguíneos mediada pela angiopoietina-2 (Ang-2). YUAN et al. ${ }^{97}$ avaliaram, em 2004, o aumento da expressão de Ang-2 em cultura de células endoteliais de granulomas piogênicos localizados em gengiva humana de pacientes gestantes, pós-parturientes e não gestantes. Observaram que níveis protéicos de Ang-2 e Tie-2 elevam-se durante a gestação em relação ao período pós-parto e à ausência de gravidez. Do mesmo modo, a expressão de VEGF aumenta durante o período gestacional e parece haver um efeito antiapoptótico na microvasculatura neoformada. Após o parto, a expressão de VEGF é quase imperceptível e possivelmente influencia a regressão dos granulomas piogênicos gravídicos ${ }^{97}$.

A diversidade histopatológica dos granulomas piogênicos em estádios evolutivos distintos pode ser notada em relação à celularidade dos elementos vasculares, bem como diferenças marcantes entre as áreas ulceradas e lobulares em uma mesma lesão. Essa diferença reflete o fato de que a área lobular representa essencialmente o granuloma piogênico e que a área ulcerada é composta por tecido de granulação em resposta a ulceração suprajacente. $\mathrm{Na}$ área lobular os elementos vasculares exibem uma uniformidade típica em relação ao diâmetro luminal e à proporção dos tipos celulares componentes da parede vascular. O endotélio vascular nas áreas lobulares consiste de uma camada interna de células endoteliais e uma ou várias camadas externas de células mesenquimais ASMA-positivas. Portanto as características morfológicas dessas áreas lobulares não correspondem à composição dos pequenos capilares uma vez que esses são formados por apenas uma camada de células endoteliais e lâmina basal com alguns pericitos associados, mas sem musculatura lisa 70,134 .

Considerando os aspectos microscópicos das áreas lobulares dos granulomas piogênicos, pode-se constatar que as mesmas possuem predominantemente segmentos vasculares pré e pós-capilares. Foi observado, ainda, que os pericitos dos capilares verdadeiros não expressam ASMA enquanto que os pericitos transicionais dos segmentos pré e pós-capilares expressam o referido antígeno. Conforme TOIDA et al. ${ }^{88}$, em 2003, as células mesenquimais positivas para ASMA nas áreas lobulares 
representam elementos microvenulares pericapilares (pré e pós), mas não verdadeiros capilares. Esses achados reforçam a idéia de que o termo hemangioma capilar lobular é inadequado. Apesar de a designação granuloma piogênico ser tão incorreta quanto a anterior, essa última sinonímia é vastamente adotada e não implica natureza neoplásica em seu desenvolvimento ${ }^{88}$.

\subsection{3 - Neoplasias benignas}

\subsubsection{1 - Hemangioma capilar}

As formas mais comuns de hemangiomas capilares são os infantis, que ocorrem em aproximadamente 10\% dos recém-nascidos. Caracterizam-se por lesões maculares que crescem rapidamente nos primeiros meses de vida, formando massas tumorais e posteriormente seguem em processo de remissão espontânea. A regressão dessas lesões ocorre acima de 50\% nas crianças com cinco anos de idade, acima de $70 \%$ aos sete anos e tendem a continuar regredindo após os 10 anos. Apresentam alta incidência na região de cabeça e pescoço. Frequentemente envolvem mucosas bucal e genital. Podem ser observadas lesões únicas ou múltiplas, sendo que as últimas ocorrem em $15 \%$ a $20 \%$ dos casos $^{2}$.

As características clínicas dos hemangiomas variam conforme o período evolutivo em que se encontram. Apresentam-se inicialmente como máculas róseas que, com o decorrer do tempo, formam placas purpúreas de superfície lobulada ou lisa. O início da fase de regressão é caracterizado pelo surgimento de estrias esbranquiçadas superficiais que podem vir a desaparecer completamente. Ainda durante a fase de proliferação dos hemangiomas infantis, podem ocorrer complicações como ulcerações que predispõem os pacientes à infecção secundária ou mesmo quadros de septicemia. Lesões extensas e generalizadas podem ser responsáveis por coagulopatias graves e fazer parte de síndromes como a de Kasabach-Merritt ${ }^{44}$. Nesta rara síndrome, descrita em 1940, observam-se quadros de púrpura trombocitopênica, coagulopatia crônica consumptiva e hemangiomas cutâneos extensos, localizados em tronco e membros ${ }^{44}$. Apesar da Síndrome de 
Kasabach-Merritt cursar com remissão dos hemangiomas, ainda há um percentual de mortalidade variável entre $20 \%$ a $30 \%$ dos casos em todos os grupos etários. Lesões viscerais elevam esse índice de mortalidade logo nos primeiros meses de vida e a condição hematológica precária de alguns pacientes impossibilita o tratamento cirúrgico ${ }^{45}$.

Da mesma forma que as características clínicas, os aspectos microscópicos dos hemangiomas infantis variam conforme sua fase evolutiva. Os hemangiomas precoces são abundantemente celularizados, compostos por células endoteliais volumosas revestindo espaços vasculares com lumes inconspícuos. A celularidade da lesão nessa fase pode obscurecer sua natureza vascular. Nota-se quantidade moderada de figuras mitóticas, bem como numerosos mastócitos de permeio ao estroma ${ }^{34}$. A presença de tais células nas lesões proliferativas reflete seu papel na secreção de fatores de crescimento e citocinas estimuladoras da angiogênese ${ }^{78}$. A maturação das lesões pode ser constatada pelo arredondamento das células endoteliais e pela composição de vasos com lumes bem definidos. $\mathrm{Na}$ fase regressiva, o aumento dos espaços vasculares dos hemangiomas pode conferir-lhes semelhança morfológica com as malformações vasculares. Além de fibrose do estroma nota-se, nos hemangiomas regredidos, metaplasia adiposa ${ }^{38}$.

Em todas as fases evolutivas os hemangiomas infantis expressam marcadores fenotípicos particulares, compartilhados apenas com a microvasculatura placentária. Os antígenos GLUT1 e Lewis $Y$ (LeY) caracterizam os hemangiomas infantis como processos patológicos únicos ${ }^{59}$. As três fases evolutivas dessas lesões podem, ainda, ser determinadas por antígenos de proliferação. O padrão de crescimento da fase proliferativa pode ser considerado agressivo, como demonstrado pela expressão do anticorpo para o antígeno de proliferação nuclear (PCNA), que revela a fase 61 tardia e $G 2$ precoce do ciclo celular e caracteriza o processo proliferativo em franca atividade ${ }^{116}$. Os níveis de expressão da molécula de adesão E-selectina se encontram elevados na fase proliferativa e a presença de colagenase IV demonstra lise colagênica, necessária para o crescimento dos capilares sanguíneos. O processo de apoptose marca o ápice da fase involutiva que também é caracterizada pela 
indução autócrina de inibidor tecidual de metaloproteinase. Nesta fase ainda persistem membranas basais multilaminadas e hialinização perivascular, uma característica típica da fase proliferativa dos hemangiomas. $O$ padrão multilaminado dessas lesões ocorre em conseqüência de ciclos sucessivos de proliferação e morte celular ${ }^{81}$.

Dentre os hemangiomas infantis, $10 \%$ caracterizam-se por formas de caráter familial, descritas sob trato autossômico dominante com alta penetrância. Estudos genômicos mapearam um locus no cromossomo 5q31-33 de algumas famílias, mas por enquanto não foi identificado o gene responsável pelo defeito nas células endoteliais. Nos hemangiomas esporádicos, não familiares, também foram descritas alterações no cromossomo 5q, sugerindo seu envolvimento em ambas as formas de hemangiomas infantis ${ }^{87}$.

Existem duas variantes que não seguem o padrão clássico de evolução e regressão dos hemangiomas infantis. Tais variantes são denominadas hemangiomas congênitos e apresentam características morfológicas e evolutivas diferentes dos hemangiomas infantis. Existem pelo menos dois grandes grupos de hemangiomas congênitos: hemangioma congênito rapidamente involutivo e hemangioma congênito não involutivo. $O$ crescimento do hemangioma congênito rapidamente involutivo é semelhante ao hemangioma infantil, porém apresenta um padrão de regressão bem mais acelerado. Ao regredir, o hemangioma congênito rapidamente involutivo deixa uma lesão residual com estruturas venosas proeminentes e raras áreas com tecido adiposo, o que contrasta com o hemangioma infantil em fase regressiva, que apresenta durante sua lenta regressão áreas evidentes de metaplasia adiposa. Apesar de parecidos, os aspectos microscópicos desses três tipos de lesões apresentam características que permitem distingui-las ${ }^{54,70}$.

O hemangioma congênito não involutivo foi descrito em 2001, por ENJOLRAS et al. ${ }^{23}$, como uma variante rara de tumor vascular cutâneo. Essas lesões não regridem e não apresentam predileção pelo gênero feminino, como os hemangiomas infantis, embora existam semelhanças quanto ao aspecto clínico e à 
distribuição anatômica. Os hemangiomas não involutivos são compostos por vasos intralobulares maiores e mais irregulares, com ausência de hialinização e poucas lâminas perivasculares de membrana basal. As células endoteliais apresentam núcleos arredondados, hipercromáticos e proeminentes, bem como a persistência de alta celularidade nos lóbulos vasculares. A presença de pequenas fístulas arteriovenosas chamou atenção dos autores para necessidade de diferenciação com hemangiomas arteriovenosos, que apresentam maiores riscos quanto a hemorragias e recidivas pós-cirúrgicas ${ }^{23}$.

NORTH et al.59, em 2001, propuseram-se a caracterizar os achados histopatológicos e imuno-histoquímicos de uma terceira variante de hemangioma congênito semelhante aos hemangiomas congênitos não involutivos. Os autores denominaram essa variante como hemangioma congênito não progressivo e compararam-na com hemangiomas infantis. Observaram que as lesões consistiam microscopicamente de múltiplos lóbulos formados por capilares proliferativos que lembravam os mesmos aspectos dos hemangiomas infantis, como células endoteliais volumosas, lumes diminutos, pericitos, algumas mitoses, ausência de atipia celular. Diferente dos hemangiomas infantis proliferativos, nos quais os lóbulos são separados por estroma com aparência normal, os hemangiomas congênitos não progressivos apresentavam septos de tecido conjuntivo densamente colagenizados, além de atrofia epitelial e ocasional esclerose dos lóbulos endoteliais. Foram observadas nas lesões estudadas características adicionais que permitiram a distinção entre as duas entidades patológicas, como trombos, grânulos de hemossiderina, ocasionais focos de calcificação distrófica e ausência de pseudo-invasão perineural. A despeito dos aspectos microscópicos citados, as principais diferenças fenotípicas foram dadas pela falta de reatividade imuno-histoquímica para os marcadores GLUT1 e LeY nos hemangiomas congênitos não progressivos. As células endoteliais e pericitos dessas lesões foram positivas os marcadores, CD34 e actina alfa de músculo liso. A proporção de mastócitos foi menor que nos hemangiomas infantis. Os autores também demonstraram nos espécimes estudados, infiltrado inflamatório crônico esparso com eosinófilos ocasionais e vasos dilatados com paredes 
endoteliais delgadas entre os lóbulos capilares, que não são observados nos hemangiomas infantis, além de características imaginológicas distintas ${ }^{59}$.

\subsubsection{2 - Hemangioma arteriovenoso}

Os hemangiomas arteriovenosos são lesões com alto fluxo sanguíneo e microscopia característica, demonstrando arteríolas e vênulas com densa musculatura lisa perivascular. Esse tipo de tumor vascular já foi denominado como aneurisma cirsóide e hemangioma arteriovenoso acral, embora não apresente localização exclusiva nas regiões acrais ${ }^{76}$. HASSARD; BYRNE ${ }^{36}$, em 1985, relataram pela primeira vez um caso de hemangioma arteriovenoso intrabucal. Posteriormente houve relatos mais extensos e detalhados dessas lesões na cavidade bucal, como descritos por BARRET et al. ${ }^{6}$, em 2000.

Dois tipos de hemangiomas arteriovenosos podem ser descritos: superficiais e profundos. A forma superficial envolve com freqüência a mucosa bucal, particularmente os lábios e a língua. Na pele, apresentam-se constantemente na área cutânea peribucal, nariz, cantos dos olhos e membros superiores. Geralmente, as lesões superficiais não causam implicações sistêmicas mais graves, em contraste com os hemangiomas arteriovenosos profundos que podem produzir sinais $e$ sintomas severos 6 .

Esses tumores geralmente apresentam-se como lesões solitárias e elevadas que aumentam de volume e podem durar meses ou anos. Notam-se, ainda, sinais clínicos como pulsação e aumento de temperatura. A arteriografia é considerada indispensável e o exame histopatológico revelará a inter-relação entre artérias e veias de calibres médio e grande, além do espessamento da camada íntima, indicando pressão sanguínea elevada na área ${ }^{46}$.

Entre os aspectos microscópicos dessas lesões, constantemente são observadas células endoteliais proliferativas, embora não seja claro se tais características sejam primárias ou resultantes da expansão vascular estimulada por 
mecanismos hemodinâmicos. Estímulos para a expansão dessas lesões como trauma, fatores hormonais e processo inflamatório, devem ser considerados ${ }^{6}$. As células com localização perivascular apresentam positividade imuno-histoquímica para desmina e miosina, caracterizando a presença e atividade de miofibroblastos ou mioblastos no local ${ }^{36}$.

\subsection{4 - Neoplasias malignas}

\subsubsection{1 - Sarcoma de Kaposi}

Em 1872, MORITZ KAPOSI ${ }^{43}$ relatou vários casos de sarcomas multifocais pigmentados nos membros inferiores em pacientes idosos de Viena/Áustria. Alguns desses pacientes sucumbiram ao tumor que atualmente é conhecido como sarcoma de Kaposi clássico, freqüente nas regiões mediterrânea e leste da Europa. Posteriormente à descrição inicial do sarcoma de Kaposi, foram identificadas três outras variantes da doença. O tipo endêmico/africano; o sarcoma de Kaposi associado aos transplantes e a forma epidêmica ou AIDS-correlata ${ }^{68}$. Com a epidemia da AIDS o sarcoma de Kaposi se tornou mais freqüente e sua etiologia foi relacionada, em 1994, ao vírus herpes tipo 8 (HHV-8 ou KSV), por CHANG et al ${ }^{16}$. Em todas as formas o fenótipo é similar e em quase todas pode ser identificado o HHV-8. Outras neoplasias parecem conter seqüências do mesmo vírus, como o linfoma primário de efusões relacionado à AIDS e a linfadenopatia angioimunoblástica'.

As formas clínico-epidemiológicas descritas são consideradas idênticas sob a óptica histopatológica. Podem ser estabelecidas três fases distintas, típicas do curso evolutivo da doença; as formas clínicas, macular, em placa e nodular. A forma macular demonstra proliferação de pequenos vasos irregulares, formados por células endoteliais discretamente atípicas, orientados paralelamente à superfície epitelial. Quando a lesão cursa para o aspecto em placa, notam-se basicamente os mesmos elementos do tipo macular, porém com exuberância de células fusiformes e glóbulos eosinofílicos intracitoplasmáticos. O aspecto típico dessas lesões é o sinal 
de promontório [sm. Cabo formado de rochas ou alcantis (rocha escarpada)]. Por fim, as lesões de aspecto nodular apresentam-se sob forma de domo ou podem ser polipóides com predominância de células fusiformes. É comum observar nas neoplasias, espaços vasculares em forma de fendas, pequenos vasos de contornos entalhados, eritrócitos extravasados, plasmócitos e linfócitos. As células fusiformes geralmente possuem lumes citoplasmáticos abortivos, algumas vezes com hemácias e glóbulos eosinofílicos em seu interior ${ }^{76}$.

O sarcoma de Kaposi presente na mucosa bucal é localmente agressivo e raramente letal, ocorre mais frequentemente em pacientes com AIDS, sendo raro em indivíduos sem imunocomprometimento. Seus diagnósticos diferenciais clínicos incluem angiomatose bacilar, granuloma piogênico e algumas variantes de hemangiomas capilares. Esses diferenciais são microscopicamente descartados com certa facilidade, no entanto existem alguns tipos de lesões vasculares proliferativas mais agressivas capazes de gerar incertezas durante a análise microscópica, como o hemangioendotelioma kaposiforme e o angiossarcoma epitelióide ${ }^{68}$.

Diferentes linhagens celulares já foram implicadas na histogênese do sarcoma de Kaposi como as células endoteliais, musculares lisas e mesenquimais indiferenciadas. $\mathrm{Na}$ identificação imuno-histoquímica do sarcoma de Kaposi podem ser empregados marcadores tais como CD31, vimentina, AE1/AE3, S-100. No entanto, a origem do sarcoma de Kaposi está nas células endoteliais dos vasos linfáticos, como demonstrado pela expressão de VEGFR-3, um membro da família dos receptores para fator de crescimento vascular endotelial, presente exclusivamente no endotélio linfático. Este receptor do tipo tirosina-quinase pode ser utilizado para diferenciação de lesões angioproliferativas com mais especificidade e sensibilidade que outros atualmente adotados. Alguns autores atribuem e reforçam a origem vascular linfática do sarcoma de Kaposi com base na ausência de pericitos, na descontinuidade da lâmina basal e na fraca reatividade para o fator de von Willebrand. Alternativamente, postula-se que o sarcoma de Kaposi possa conter um fenótipo de células endoteliais imaturas, justificando a positividade para VEGFR-3 $3^{30}$. 
Foi sugerido que a patogênese do sarcoma de Kaposi fosse sediada em um processo inflamatório desregulado, entretanto estudos demonstraram alternâncias de monoclonalidade, oligoclonalidade e policlonalidade em vários espécimes analisados. Um outro aspecto relevante é o fato de que já foram isoladas três linhagens celulares neoplásicas do sarcoma de Kaposi. Não se descarta a possibilidade da lesão se iniciar como uma proliferação hiperplásica que acaba por gerar uma população celular monoclonal sob circunstâncias especiais, como a imunossupressão. O sarcoma de Kaposi poderia evoluir do mesmo modo que os distúrbios linfoproliferativos pós-transplante, os quais se caracterizam por proliferações clonais de células B vírus-induzidas que resultam em linfomas não Hodgkin'.

Os distúrbios angioproliferativos descritos acima se manifestam na cavidade bucal, em graus diferentes de importância clínica e prevalência. Mesmo os tumores vasculares mais raros devem ser compreendidos e caracterizados a fim de não tornarem-se surpresas desagradáveis aos profissionais encarregados de diagnosticálos e tratá-los. As semelhanças e diferenças entre lesões angioproliferativas bucais e suas correspondentes cutâneas permitem correlações morfológicas e prognósticas que podem ser consideradas no embasamento para condutas estomatológicas futuras.

Um aspecto a ser considerado quando se pesquisa tumores vasculares referese ao desmembramento dos fenômenos presentes na neoformação vascular e os mediadores químicos responsáveis pelas interações angiogênicas. Desse modo, serão descritas a seguir as funções de dois dos fatores que medeiam o desenvolvimento dos vasos. 


\section{5 - FATORES DE CRESCIMENTO FIBROBLÁSTICO E SEUS RECEPTORES}

Os fatores de crescimento fibroblástico ou fatores de crescimento ligados à heparina, compõem uma extensa família de mediadores que participam direta e indiretamente da formação de vasos sanguíneos e linfáticos, agindo em parceria com uma variedade de outras moléculas indutoras ${ }^{79}$. Os dois protótipos dessa família de fatores de crescimento são o FGF-1, precursor da forma ácida e FGF-2, precursor da forma básica. A partir dos precursores foram identificadas outras formas como FGF-4, FGF-5, FGF-6 e KGF, que estão entre os 23 isotipos alternativos de FGFs localizados em diversas regiões intracelulares. O potencial transformador desses protótipos habilita-os como reguladores de diferenciação, proliferação e sobrevivência celular, participando ainda da composição da matriz extracelular, quimiotaxia e adesão intercelular de células mesodérmicas e neuroectodérmicas ${ }^{82}$. Muitas das isoformas de FGF exibem, ainda, características oncogênicas ${ }^{31}$.

O protótipo FGF-2 é produzido por diferentes tipos de células, entre as quais as células endoteliais, miócitos de musculatura lisa, fibroblastos, mastócitos e macrófagos $^{80}$. Quatro isoformas de FGF-2 ou FGFb são geradas a partir de transcritos distintos provenientes de um mesmo gene e podem ser mantidas no meio intracelular após sua síntese. Essas isoformas geradas por alternative splicing possuem alto peso molecular e contêm uma seqüência $\mathrm{N}$-terminal adicional que funciona como sinal de retenção para alvos nucleares, permitindo que atuem sobre - crescimento celular independentemente da interação com receptores de superfície ${ }^{39}$.

Os mastócitos são considerados as principais fontes de produção e secreção de FGFb na angiogênese ${ }^{65,75}$. Alterações no status biológico dessas células e no microambiente em que se encontram foram demonstradas em estudos sobre os tumores vasculares ${ }^{34,84}$. Os mastócitos podem ser descritos como células granulares metacromáticas, abundantes no interstício perivascular dérmico e mucoso, principalmente durante alterações inflamatórias ${ }^{78}$. Ao serem estimulados, 
solubilizam e liberam o conteúdo de seus grânulos intracitoplasmáticos, bem como fatores de crescimento e citocinas importantes para a fisiopatologia endotelial. O aumento na densidade de mastócitos ${ }^{75}$ e da concentração de mediadores angiogênicos como FGFb, pode fazer parte da patogenia de doenças que envolvem proliferação vascular. As aminas vasoativas e as proteases neutras liberadas pelos mastócitos também participam das alterações do endotélio e da matriz extracelular subendotelial nas lesões angioproliferativas ${ }^{69}$.

Os fatores de crescimento fibroblástico influenciam, ainda, a estabilização vascular devido à relação com a proteoglicana heparan sulfato. VLODAVSKY et al.92, demonstraram, em 1987, que parte do FGFb produzido pelas células endoteliais permanece no interior das mesmas e que mais de $30 \%$ é secretado e se acumula na matriz extracelular subjacente ao endotélio. Acredita-se que 0 armazenamento do FGFb funciona como um mecanismo de preservação, estimulando prontamente a proliferação endotelial nas ocasiões necessárias. Nas neoplasias vasculares, a degradação enzimática da matriz pode ser um recurso rápido para que fatores de crescimento angiogênicos, como o FGF, sejam disponibilizados ${ }^{74,92}$.

Quatro tipos de receptores de alta afinidade são responsáveis pelas interações dos FGFs na superfície celular. Os receptores FGFR-1, 2, 3 e 4 compartilham uma estrutura protéica geral, caracterizada por uma seqüência $\mathrm{N}$ terminal de sinalização com três domínios extracelulares, do tipo imunoglobulina, relacionados a uma região transmembrana simples e um domínio C-terminal intracelular do tipo tirosina-quinase. Do mesmo modo que os ligantes, esse grupo de receptores caracteriza-se por produzir múltiplas isoformas geradas por sítios alternativos de edição de RNA mensageiro. Cada um dos protótipos desses receptores divide-se em três subtipos $(a, b, c)^{93}$.

Os subtipos dos receptores de FGF não possuem a região transmembrana nem o domínio tirosina-quinase característicos, conferindo-lhes afinidades distintas pelos mesmos ligantes ${ }^{82}$. Nas interações dos complexos FGF/FGFR são necessários, 
ainda, co-receptores como proteoglicanas do tipo heparan sulfato (HSPG), proteína 2 ligada a receptor para fator de crescimento (GRB2) e as proteínas da via MAPK, essenciais na morfogênese vascular ${ }^{39}$.

Alguns modelos experimentais podem ser utilizados para demonstrar o efeito angiogênico das isoformas de FGF e seus receptores. Entre eles há o sistema Tetoff para modular a expressão de FGF-2 durante a angiogênese e tumorigênese experimental. Nesse sistema, a produção de FGF-2 é controlada por um promotor gênico responsivo à tetraciclina. A adição da droga ao sistema leva à interrupção na expressão de FGF-2 em células transfectadas ${ }^{32}$. Com essa metodologia, GIAVAZZI et al.32, em 2003, geraram células tumorais com expressão diferenciada de FGF-2. Utilizaram uma linhagem de células de adenocarcinoma endometrial humano (HEC-1B) transfectadas com o sistema Tetoff para FGF-2 (células Tet-FGF-2) e com DNA complementar (CDNA) VEGF anti-sense (AS-VEGF). As células tumorais foram transplantadas em tecido subcutâneo de camundongos nude. $\mathrm{O}$ estudo demonstrou que FGF-2 e VEGF atuam na angiogênese e na tumorigênese sinergicamente e que a inibição de um desses fatores altera a progressão desses processos. A expressão simultânea de FGF-2 e VEGF resultou em lesões de crescimento rápido, caracterizadas por alta densidade, canalização e permeabilidade vascular. A inibição de FGF-2, mesmo na presença de VEGF, levou a um decréscimo significante na densidade e heterogeneidade dos vasos, bem como na restrição de crescimento tumoral. Em contraste, a restrição de VEGF alterou a microvascularização de forma drástica, tanto em relação à densidade, quanto à patência e permeabilidade vascular ${ }^{32}$.

A organização das estruturas que determinam o padrão de permeabilidade endotelial também é modulada pelos fatores de crescimento FGF, VEGF e seus receptores. Entre essas estruturas estão, vesículas plasmalemais, fenestrações e gaps intercelulares. CAO et $a^{15}{ }^{15}$ em 2004, realizaram uma análise quantitativa da estrutura e permeabilidade macromolecular de capilares sanguíneos e linfáticos induzidos pelos fatores de crescimento FGF-2, VEGF-A e VEGF-C, utilizando ensaio angiogênico em córneas murinas. Demonstraram que VEGF-A estimulou o 
crescimento de microvasculatura difusa com alta densidade de capilares, arteríolas e vênulas que se fundiam em um plexo vascular primitivo. Por outro lado, constatouse que VEGF-C estimulou a formação das mesmas quantidades de vasos sanguíneos e linfáticos compondo redes vasculares bem definidas com micro vasos dilatados. Do mesmo modo, os vasos sanguíneos induzidos por FGF-2 consistiam de estruturas bem definidas e individualizadas. A análise ultra-estrutural demonstrou que os capilares induzidos por VEGF-A continham várias fenestrações resultando em alta permeabilidade. As redes vasculares formadas pela estimulação de VEGF-C apresentaram algumas fenestrações nos capilares tornando-os moderadamente permeáveis. FGF-2 estimulou a formação de vasos sanguíneos com maior densidade em comparação aos demais fatores testados. A quantidade de fenestrações observada foi mínima, o que conferiu a esses vasos grau inferior de permeabilidade ${ }^{15}$.

A proliferação endotelial desequilibrada presente nas lesões angioproliferativas é um reflexo de alterações funcionais em moléculas responsáveis pela programação morfogenética dos vasos sanguíneos e linfáticos. Sozinhos, os FGFs não são capazes de regular o processo de angiogênese. RIBATI et al. ${ }^{72}$, em 1999, demonstraram a formação de tumores vasculares em membranas corioalantóicas (CAM) embrionárias de galinhas, incubadas com células endoteliais aórticas murinas com aumento na expressão de FGF-2. Os autores não conseguiram produzir tumores vasculares nas CAMs somente com FGF-2 recombinante e na ausência de células endoteliais murinas. Os resultados indicaram que outros fatores provenientes do endotélio, além do FGF-2, participam da gênese vascular normal e tumoral ${ }^{72}$.

A correlação entre o comportamento clínico e as alterações bioquímicas durante o desenvolvimento dos tumores vasculares pode ser demonstrada pela expressão diferencial entre FGFb e VEGF, fatores de crescimento cruciais para a angiogênese. O FGFb encontra-se expresso durante a fase proliferativa e o início da regressão dos hemangiomas capilares, enquanto que o VEGF está mais expresso na fase proliferativa dos mesmos. Propostas terapêuticas interessantes para a redução 
de hemangiomas extensos baseiam-se na utilização de fatores de crescimento associados com substâncias tóxicas, corticosteróides e especialmente interferon $\beta^{90}$.

Apesar da importância de fatores de crescimento como FGF e VEGF, sabe-se cada vez mais que esses não são os únicos mediadores responsáveis pela proliferação dos vasos. As neurotrofinas e seus receptores estão entre as moléculas com potencial angiogênico mais recentemente estudadas, e serão discutidas adiante. 


\section{6 - NEUROTROFINAS E SEUS RECEPTORES}

Dentre as várias famílias de fatores de crescimento com características angiogênicas, destacam-se seis tipos de neurotrofinas: $O$ fator de crescimento neural ou NGF, o fator neurotrófico derivado do cérebro ou BDNF, o fator neurotrófico derivado da glia ou GDNF e as neurotrofinas 3, 4 e 6 (NF3, NF4, NF6). Tais polipeptídios estruturalmente relacionados podem mediar suas próprias ações ligando-se a duas classes de receptores de superfície. O receptor p75 para neurotrofinas ( $\mathrm{7} 75^{\mathrm{NTR}}$ ou NGFR) interage com todas as neurotrofinas e modula a sinalização iniciada por uma segunda classe de receptores do tipo tirosina quinase trkA, trkB e trkC. Esses últimos ligam-se seletivamente as neurotrofinas NCF, BDNF e NF321.

A princípio, o padrão de expressão e a interação das neurotrofinas com seus receptores não era totalmente conhecido, principalmente em relação ao desempenho de algumas de suas funções mais importantes, como por exemplo, a organização de fibras nervosas subepidérmicas ${ }^{17}$. Posteriormente observou-se que tais funções eram mediadas por diferentes tipos de interações entre essas moléculas. O fator de crescimento neural, que foi uma das primeiras neurotrofinas estudadas, destacou-se por sua capacidade de prevenir morte celular pela ativação do receptor trkA, uma função potencializada pela interação de trkA com o receptor multifuncional $\mathrm{p} 75^{\mathrm{NTR}} 77$.

O mediador $p 75^{\text {NTR }}$ foi o primeiro receptor de neurotrofinas identificado ${ }^{40}$. Além de modular e modificar a sinalização de trkA, o p75 ${ }^{\text {NTR }}$ participa de respostas celulares variadas, agindo como co-receptor em uma variedade de complexos protéicos em diferentes tipos celulares. Sua participação em processos biológicos como a sobrevivência e morte celular, foi também demonstrada por meio de sinais independentes mediados por proteínas trans-membrana e fatores de transcrição. $\mathrm{O}$ p75 ${ }^{\text {NTR }}$ pode, por exemplo, iniciar o processo de apoptose interagindo com a proteína transmembrana sortilina - receptor 3 de neurotensina - ou com o ligante pró-NGF ${ }^{50}$. Seguindo-se a essa interação ligante/complexo receptor, ocorre ativação 
da proteína quinase $\mathrm{N}$-terminal c-Jun (JNK). Alguns substratos subseqüentes à ativação de JNK implicados na cascata de interações que precede a apoptose são: a proteína BAD da família $B \mathrm{cl} 2$, a proteína derivada do gene supressor de tumor p53 e o fator de transcrição NRIF. LINGGI et al. ${ }^{50}$ demonstraram, em 2005, as correlações entre NRIF, JNK e p53 como sinalizadores da cascata de indução à morte celular via p $75^{\text {NTR, } 50}$.

Algumas famílias de moléculas relacionadas a apoptose, como Fas e os receptores para TNF, são homólogas ao P75 NTR, 48. Como algumas dessas moléculas apoptóticas, foi demonstrado que p75 ${ }^{\mathrm{NTR}}$ é capaz de promover morte celular em lesões tumorais, delegando ao p75 NTR a função de supressor de tumor ${ }^{67}$. Foi demonstrado aumento da expressão de p75 NTR após lesões isquêmicas em tecidos neurais ${ }^{58}$, bem como a participação desse receptor na regulação da resposta inflamatória em eventos que vão desde a supressão de moléculas de $\mathrm{MHC}$ até o controle da apresentação de antígenos em células dendríticas ${ }^{28}$.

O envolvimento do receptor $\mathrm{p} 75^{\mathrm{NTR}}$ como indutor morfogênico foi evidenciado em diferentes tipos de modelos experimentais e a maneira pela qual essa molécula e seus co-fatores promovem seus efeitos biológicos em células neurais e não neurais vem sendo estudada extensivamente ${ }^{13}$.

O receptor P75 ${ }^{\text {NTR }}$ foi evidenciado na superfície de células endoteliais, eosinófilos, linfócitos e mastócitos que sabidamente participam dos processos de inflamação e reparo. Pode-se, portanto, incluir algumas das neurotrofinas e seus receptores no hall dos mediadores químicos secretados por células inflamatórias e vasculares durante a angiogênes $\mathrm{e}^{14}$. As neurotrofinas e seus receptores, além de influenciar a biologia endotelial, estimulam a multiplicação de queratinócitos. Em neoplasias de origem ectodérmica, como carcinomas cutâneos, foi observado que os queratinócitos imortalizados desprendem o complexo p75 NTR/TNFR da membrana celular, o que não acontece com os queratinócitos normais. Devido à alta afinidade de $\mathrm{p} 75^{\mathrm{NTR}}$ com o ligante TNF, a liberação desse complexo receptor pelas células neoplásicas pode representar um mecanismo de escape à resposta 
imune anti-tumoral ${ }^{17}$, uma vez que a falta de receptores específicos limitaria a ação anti-tumoral de TNF. Um mecanismo similar poderia permitir o crescimento de tumores vasculares.

A participação das células endoteliais no processo inflamatório e de reparo pode ser influenciada pela estimulação autócrina de NGF bioativo e pela expressão dos receptores trkA e p75 ${ }^{\mathrm{NTR}}$. Em cultura de células endoteliais de veias umbilicais humanas demonstrou-se a ação autócrina angiogênica de NGF mediada pelos receptores trkA e p75 NTR, 14. Em 2002, EMANUELI et al. ${ }^{22}$ investigaram o envolvimento do NGF na angiogênese reparadora em tecidos extraneurais. Observaram que a suplementação exógena de NGF acelerou o processo de angiogênese durante a reparação tecidual em membros isquêmicos de animais experimentais. Em contrapartida, o bloqueio de NGF aumentou significantemente a apoptose de miócitos perivasculares, conferindo ao NGF um papel chave na sobrevivência dessas células em condições adversas como a falta de irrigação. Devido a suas propriedades pró-angiogênicas, os autores sugeriram a utilização terapêutica desse fator de crescimento em quadros de isquemia periférica ${ }^{22}$.

TANAKA et al. ${ }^{85}$, em 2004, estudaram a expressão de NGF e seus receptores em células endoteliais de aorta de ratos estimuladas pela citocina pró-inflamatória IL-1ß. Os autores observaram que a adição exógena de NGF aumenta a fosforilação de trkA e induz proliferação endotelial, indicando que esse fator de crescimento participe da manutenção e viabilidade endotelial frente a fenômenos inflamatórios 85. O fator de crescimento neural também participa do processo inflamatório como quimiotáticos para leucócitos e estimulam a expressão de moléculas de adesão intercelular. RAICHAUDHURI et al. ${ }^{66}$, em 2001, avaliaram o efeito de NGF sobre a expressão de ICAM-1 em cultura de células endoteliais dérmicas desafiadas com TNF e INF- $\gamma$. Os autores indicaram NGF como um potente indutor de ICAM-1 nas células endoteliais ${ }^{66}$.

Os fatores de crescimento envolvidos na angiogênese e ativação endotelial, bem como suas isoformas e receptores participam das variações de comportamento 
biológico nos distúrbios angioproliferativos. Esse grupo de lesões pode se manifestar disseminadamente ou acometer órgãos específicos como a boca e a pele, causando limitações para o desenvolvimento e a qualidade de vida dos pacientes. A caracterização clínico-microscópica para fins de diagnóstico e pesquisa, bem como sua relação com moduladores angiogênicos, visa promover perspectivas futuras em termos de tratamento e prognóstico. 
3 - PROPOSIÇÃO 


\section{3 - PROPOSIÇÃO}

Caracterizar as malformações venosas e linfáticas, granulomas piogênicos, hemangiomas capilares e sarcomas de Kaposi bucais comparando-os com seus análogos cutâneos, quanto à morfologia microscópica e quanto ao padrão de expressão dos mediadores angiogênicos, FGFb e p75 ${ }^{\text {NTR }}$. 
4 - MATERIAL E MÉTODOS 


\section{4 - MATERIAL E MÉTODOS}

\section{1 - AMOSTRAGEM}

A prevalência das lesões angioproliferativas bucais e cutâneas registradas nos serviços de Anatomopatologia da Faculdade de Odontologia de Bauru Universidade de São Paulo (FOB-USP) e do Instituto Lauro de Souza Lima Secretaria de Estado da Saúde / São Paulo (ILSL-SES/SP) foi estimada entre os anos de 1971 e 2002.

Foram adotados, na definição da amostra, os seguintes critérios:

A. Critérios de Inclusão

$\rightarrow$ Lesões vasculares de caráter proliferativo

$\rightarrow$ Lesões mais freqüentes na mucosa bucal e na pele

$\rightarrow$ Lesões com o mínimo de três espécimes do mesmo tipo de lesão

$\rightarrow$ Lesões em condições de análise microscópica

$\rightarrow$ Lesões fixadas em formol a 10\% tamponado

$\rightarrow$ Lesões processadas para inclusão em blocos de parafina

B. Critérios de Exclusão

$\rightarrow$ Lesões proliferativas perivasculares

$\rightarrow$ Lesões cutâneas nas quais os vasos estivessem associados a qualquer outro componente dérmico (e.g.: angiofibroma, angiolipoma, angioleiomioma)

$\rightarrow$ Mais de uma lesão biopsia de um mesmo paciente

\subsection{1 - Definição da Amostra}

A amostra foi definida pela seleção de 110 espécimes de lesões angioproliferativas dos arquivos dos serviços de Anatomopatologia da Faculdade de Odontologia de Bauru (FOB-USP) e do Instituto Lauro de Souza Lima (ILSLSES/SP). Esses espécimes foram obtidos de biópsias de mucosa bucal e pele humana, processadas para inclusão em parafina. Os espécimes selecionados foram 
classificados conforme critérios etiopatogênicos previamente estabelecidos ${ }^{56,76} \mathrm{e}$ divididos em cinco grupos de 20 espécimes e um grupo de 10 espécimes (Tabela 1). Cada grupo foi dividido em dois subgrupos contendo 10 lesões bucais e 10 cutâneas. Somente o grupo dos sarcomas de Kaposi foi subdividido de modo diferente por dispor de menos espécimes que os demais grupos.

Tabela 1 - Classificação etiopatogênica da amostra conforme Sangüeza \& Requena ${ }^{76}$

\begin{tabular}{c|c|c}
\hline \multirow{2}{*}{ CLASSIFICAÇÃO } & DIAGNÓSTICO MICROSCÓPICO & GRUPOS \\
\hline \multirow{2}{*}{ Malformação Vascular } & Hemangioma Cavernoso (Malformação Venosa) & Grupo I / MV \\
\cline { 2 - 3 } & Linfangioma (Malformação Linfática) & Grupo II / ML \\
\hline \multirow{2}{*}{ Hiperplasia Vascular } & Granuloma Piogênico & Grupo III / GP \\
\hline \multirow{2}{*}{ Neoplasia Benigna } & Hemangioma Capilar & Grupo IV / HCP \\
\cline { 2 - 3 } & Hemangioma Arteriovenoso & Grupo V / HAV \\
\hline \multirow{2}{*}{ Neoplasia Maligna } & Sarcoma de Kaposi & Grupo VI / SK \\
\hline
\end{tabular}

A caracterização clínica da amostra foi obtida com o registro de todos os subgrupos quanto à localização da lesão, idade e gênero dos pacientes. 


\section{2 - ANÁLISE MORFOLÓGICA}

Foi realizada avaliação de cortes microscópicos corados por HematoxilinaEosina. Os dados microscópicos foram registrados em quadros específicos como o exemplo que segue abaixo (Figura 3). Os critérios morfológicos receberam escores semi-quantitativos variando entre zero (ausente), um (escasso), dois (moderado) e três (freqüente).

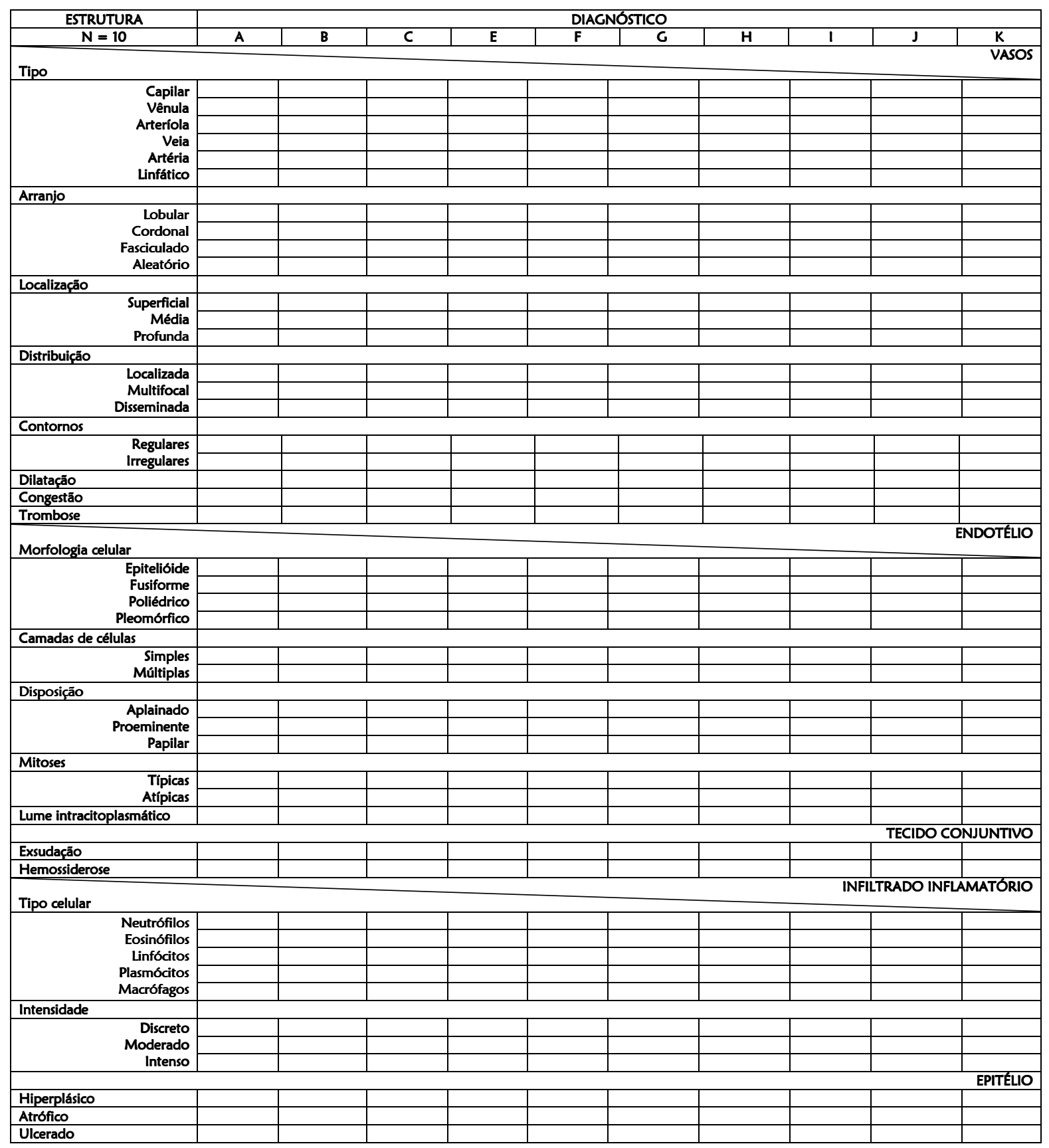

Figura 3 - Critérios morfológicos empregados para a avaliação histopatológica dos espécimes 


\section{3 - ANÁLISE IMUNO-HISTOQUÍMICA}

A técnica imuno-histoquímica foi empregada com a finalidade de avaliar a presença e distribuição endotelial dos marcadores para fator de crescimento fibroblástico básico (FGFb) e receptor p75 para fator de crescimento neural (p75 NTR). A intensidade e a distribuição dos marcadores para fator de FGFb e p75 NTR também foram consideradas conforme escores semi-quantitativos: $0=$ ausente/ausente; $1=$ discreta/localizada; $2=$ moderada/multifocal e $3=$ intensa/difusa.

Como controles positivos externos para FGFb e p75 NTR foram utilizados cortes microscópicos de cistos do ducto nasopalatino, cisto periodontal apical e neurofibromas em cada bateria de reação imuno-histoquímica. Os controles positivos internos foram analisados em cada corte microscópico de cada espécime. As estruturas adotadas no controle interno incluíram a camada basal dos epitélios bucal e cutâneo, epineuro e perineuro das terminações nervosas superficiais. Os controles negativos foram realizados em cortes extras de cada grupo, nos quais os anticorpos primários para p75 NTR e FGFb foram substituídos por soro normal de camundongo e de cabra, respectivamente.

\subsection{1 - Seqüência técnica:}

\subsubsection{1 - Desparafinização}

Cortes de três $\mu \mathrm{m}$ em lâminas silanizadas

Estufa a $60^{\circ} \mathrm{C}-30$ minutos

Xilol - três banhos de cinco minutos

Total $=45$ minutos

\subsubsection{2 - Hidratação}

Álcool absoluto - três banhos de cinco minutos

Álcool 95\% - um banho de cinco minutos

Água destilada - um banho

PBS com Triton X-100 - três lavagens 
Total $=21$ minutos

\subsubsection{3 - Bloqueio de peroxidase endógena}

$\mathrm{H}_{2} \mathrm{O}_{2}$ a $3 \%$ em PBS - incubar por 40 minutos

Água destilada - um banho

PBS com Triton X-100 - três lavagens

Total $=40$ minutos

\subsubsection{4 - Exposição antigênica}

Tampão citrato a $95^{\circ} \mathrm{C}$ - incubar por 20 minutos

Aguardar resfriamento por 20 minutos

Água destilada - um banho

PBS com Triton X100 - três lavagens

Total $=40$ minutos

\subsubsection{5 - Bloqueio de reação cruzada}

Leite em pó a 5\% - incubar por 20 minutos

Não lavar em PBS

Remover o excesso de solução ao redor do corte

Circundar os cortes com caneta especial

Total $=20$ minutos

\subsubsection{6 - Anticorpo primário}

Seguidas as instruções do fabricante

Incubar por 18 horas a $4^{\circ} \mathrm{C}$

Água destilada - um banho

PBS com Triton X100 - três lavagens

Remover o excesso ao redor do corte

Total $=18$ horas

\subsubsection{7 - Anticorpo secundário e Substrato cromogênico}

Seguidas as instruções do fabricante (DAKO - Kit LSAB)

Incubar por 30 a 60 minutos com o anticorpo secundário biotinilado 
Água destilada - um banho

PBS com Triton X100 - três lavagens

Remover excesso ao redor do corte

Incubar por 30 minutos com streptavidina conjugada a peroxidase

Água destilada - um banho

PBS com Triton X100 - três lavagens

Remover excesso ao redor do corte

Total $=60$ a 90 minutos

\subsubsection{8 - Revelação}

Incubar os cortes com DAB - aguardar o tempo padronizado para cada anticorpo primário

Água destilada - duas lavagens

Total $=20$ minutos

\subsubsection{0 - Contra-coloração}

Hematoxilina de Harris - sete minutos

Lavar em água corrente

Diferenciador - um banho

Lavar em água corrente - 10 minutos

Álcool 95\% - um banho

Álcool absoluto - quatro banhos

Xilol - quatro banhos

Total $=20$ minutos

\subsubsection{1 - Montagem}

Montar lâminas em meio resinoso (Resina Permonunt - Fisher)

\subsection{2 - Preparo das soluções:}

$$
\begin{aligned}
& \text { 4.3.2.1 - PBS } \\
& \mathrm{H}_{2} \mathrm{O}-1 \mathrm{~L} \\
& \mathrm{NaH}_{2} \mathrm{PO}_{4} \mathrm{H}_{2} \mathrm{O} \text { (Merck) - 1,38g }
\end{aligned}
$$


$\mathrm{K}_{2} \mathrm{H}_{2} \mathrm{PO}_{4}$ (Merck) - 6,96g

$\mathrm{NaCl}$ (Merck) - 7,2g

$\mathrm{pH}: 7,2-7,4$

\subsubsection{2 - TRITON X-100}

PBS - 1L

Triton X-100 (Sigma-Aldrich) - 0,5ml

\subsubsection{3 $-\mathrm{H}_{2} \mathrm{O}_{2}$ a $3 \%$ em PBS}

PBS $-180 \mathrm{ml}$

$\mathrm{H}_{2} \mathrm{O}_{2} 30 \mathrm{~V}-20 \mathrm{ml}$

\subsubsection{4 - Tampão citrato}

$\mathrm{H}_{2} \mathrm{O}$ destilada $-200 \mathrm{ml}$

Duas pastilhas de tampão citrato (Sigma-Aldrich)

\subsubsection{5 - Leite em pó a $4 \%$}

$\mathrm{H}_{2} \mathrm{O}$ destilada $-200 \mathrm{ml}$

Leite em pó (Molico ${ }^{\circledR}$ - Nestlé) - 8g

\subsubsection{6 - BSA a $1 \%$}

PBS - 100ml

BSA (American Pharmacia Biotechnology) - pastilha de 1g

\subsubsection{7 - Anticorpo primário}

FGFb - clone FGF-2, \#sc79G (Santa Cruz Biotechnology):

Anticorpo policlonal de cabra

Diluição de trabalho (padronizada em 1:200)

$1 \mu \mathrm{l}$ da solução de estoque: $199 \mu$ l de PBS com BSA a $1 \%$.

p75 NTR - clone NGFR-5, \#M3507 (DAKO Corporation):

Anticorpo monoclonal de camundongo

Diluição de trabalho (padronizada em 1:2000)

$1 \mu \mathrm{l}$ da solução de estoque: $1999 \mu \mathrm{l}$ de PBS com BSA a $1 \%$. 
4.3.2.8 - DAB

PBS $-5 \mathrm{ml}$

Uma pastilha de DAB (DAKO Corporation)

Uma pastilha de $\mathrm{H}_{2} \mathrm{O}_{2}$ (Merck)

4.3.2.9 - Hematoxilina de Harris63

Hematoxilina (Merck) $-5 g$

Etanol (Merck) a 100\% - 50ml

Alume de potássio (Merck) - 100g

Água destilada $-1000 \mathrm{ml}$

Óxido de mercúrio (Merck) - 2,5g

4.3.2.10 - Soro normal:

Cabra - controle negativo para FGFb

Soro $-8,3 \mu 1$

PBS/BSA 1\%-50ml

Camundongo - controle negativo para NGFR

Soro $-2,8 \mu 1$

PBS/BSA $1 \%-500 \mathrm{ml} /$

\section{4 - ANÁLISE ESTATÍSTICA}

Nos resultados morfológicos e imuno-histoquímicos obtidos foram aplicados os testes, não paramétrico de Kruskal Wallis para $\mathrm{N}$ variáveis independentes e de Dunn para comparações individuais com nível de significância estabelecido em $5 \%$. 
5 - RESULTADOS 


\section{5 - RESULTADOS}

\section{1 - Prevalência das Lesões Angioproliferativas}

As lesões angioproliferativas bucais e cutâneas compiladas ao longo de vinte e um anos (1971-2002) nos serviços de anatomia patológica das duas instituições que participaram dessa pesquisa estão apresentadas na tabela 2.

Tabela 2 - Prevalência bianual das lesões angioproliferativas nos serviços de anatomopatologia da FOB-USP e do ILSL-SES/SP

\begin{tabular}{|c|c|c|c|c|c|c|c|c|c|c|c|c|c|c|}
\hline \multirow{2}{*}{ Biênio } & \multicolumn{7}{|c|}{ FOB } & \multicolumn{7}{|c|}{ ILSL } \\
\hline & GPB & HAVB & HCPB & MVB & MLB & SKB & TOTAL & GPC & HAVC & HCPC & MVC & MLC & SKC & TOTAL \\
\hline $1971 / 72$ & 0 & 0 & 2 & 3 & 0 & 0 & 5 & 0 & 0 & 0 & 0 & 1 & 0 & 1 \\
\hline $1973 / 74$ & 6 & 0 & 3 & 0 & 0 & 0 & 9 & 0 & 0 & 0 & 1 & 0 & 0 & 1 \\
\hline $1975 / 76$ & 7 & 0 & 1 & 1 & 0 & 0 & 9 & 0 & 0 & 0 & 0 & 1 & 0 & 1 \\
\hline $1977 / 78$ & 3 & 0 & 0 & 5 & 0 & 0 & 8 & 1 & 0 & 0 & 0 & 0 & 0 & 1 \\
\hline $1979 / 80$ & 7 & 0 & 0 & 1 & 0 & 0 & 8 & 0 & 0 & 0 & 0 & 0 & 0 & 0 \\
\hline 1981/82 & 7 & 0 & 0 & 1 & 0 & 0 & 8 & 3 & 0 & 0 & 1 & 0 & 0 & 4 \\
\hline $1983 / 84$ & 9 & 0 & 3 & 2 & 1 & 0 & 15 & 2 & 0 & 0 & 1 & 0 & 0 & 3 \\
\hline $1985 / 86$ & 4 & 0 & 2 & 2 & 0 & 0 & 8 & 4 & 0 & 1 & 2 & 1 & 0 & 8 \\
\hline 1987/88 & 14 & 1 & 2 & 1 & 0 & 0 & 18 & 9 & 0 & 6 & 2 & 1 & 0 & 18 \\
\hline $1989 / 90$ & 20 & 0 & 0 & 2 & 2 & 0 & 24 & 7 & 0 & 1 & 0 & 1 & 0 & 9 \\
\hline 1991/92 & 10 & 0 & 2 & 2 & 2 & 1 & 17 & 7 & 0 & 8 & 2 & 5 & 5 & 27 \\
\hline $1993 / 94$ & 26 & 3 & 3 & 6 & 1 & 0 & 39 & 11 & 1 & 5 & 3 & 1 & 0 & 21 \\
\hline 1995/96 & 29 & 0 & 0 & 5 & 4 & 0 & 38 & 19 & 7 & 9 & 2 & 3 & 2 & 42 \\
\hline 1997/98 & 36 & 1 & 4 & 7 & 4 & 0 & 52 & 24 & 7 & 12 & 4 & 2 & 0 & 49 \\
\hline 1999/00 & 48 & 3 & 5 & 7 & 2 & 1 & 66 & 16 & 9 & 21 & 17 & 2 & 0 & 65 \\
\hline 2001/02 & 47 & 2 & 3 & 12 & 9 & 1 & 74 & 37 & 16 & 17 & 12 & 3 & 5 & 90 \\
\hline TOTAL & 273 & 10 & 30 & 57 & 25 & 3 & 398 & 140 & 40 & 80 & 47 & 21 & 12 & 340 \\
\hline
\end{tabular}

$\mathrm{GPB}=$ granuloma piogênico bucal; $\mathrm{HAVB}=$ hemangioma arteriovenoso bucal; $\mathrm{HCPB}=$ hemangioma capilar bucal; $\mathrm{MVB}=$ hemangioma cavernoso bucal; $\mathrm{MLB}=$ linfangioma bucal; SKB = sarcoma de Kaposi bucal. $\mathrm{CPC}=$ granuloma piogênico cutâneo; HAVC= hemangioma arteriovenoso cutâneo; $\mathrm{HCPC}=$ hemangioma capilar cutâneo; $\mathrm{MVC}=$ hemangioma cavernoso cutâneo; $\mathrm{MLC}=$ linfangioma cutâneo; SKC = sarcoma de Kaposi cutâneo.

A prevalência das lesões compiladas de 1971 a 2002 foi registrada sob forma de gráficos percentuais (Gráficos 1 e 2 ) relativos ao total de lesões angioproliferativas na mucosa bucal $(n=398)$ e no tecido cutâneo $(n=340)$. A partir de um universo de 738 espécimes, foram escolhidos 110 para compor a amostra desse trabalho. 


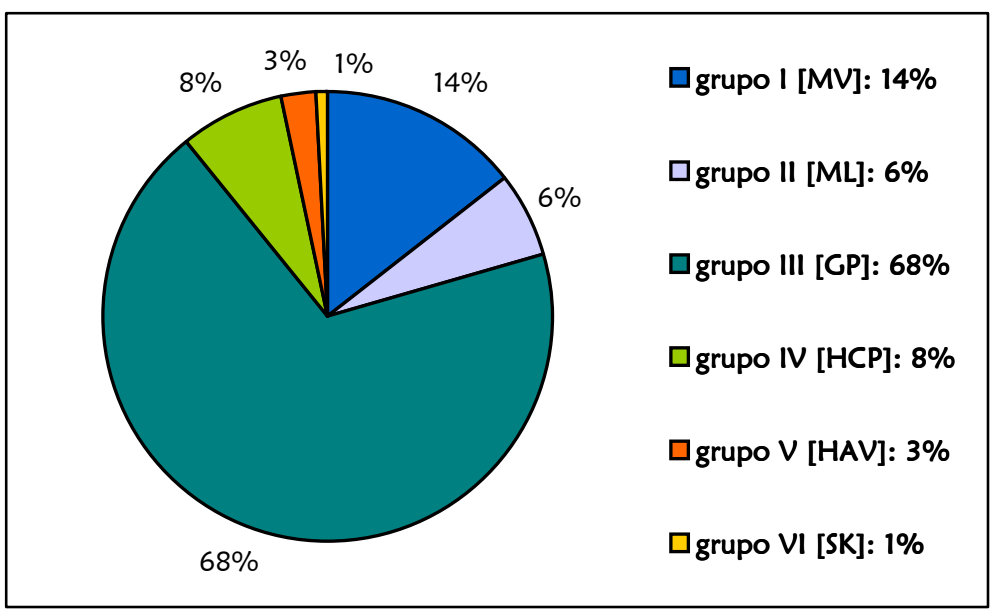

Gráfico 1 - Prevalência das lesões angioproliferativas bucais, estimada entre os anos de 1971-2002: [I] malformação venosa (14\%); [II] malformação linfática (6\%); [III] granuloma piogênico (68\%); [IV] hemangioma capilar (8\%); [V] hemangioma arteriovenoso (3\%); [VI] sarcoma de Kaposi (1\%)

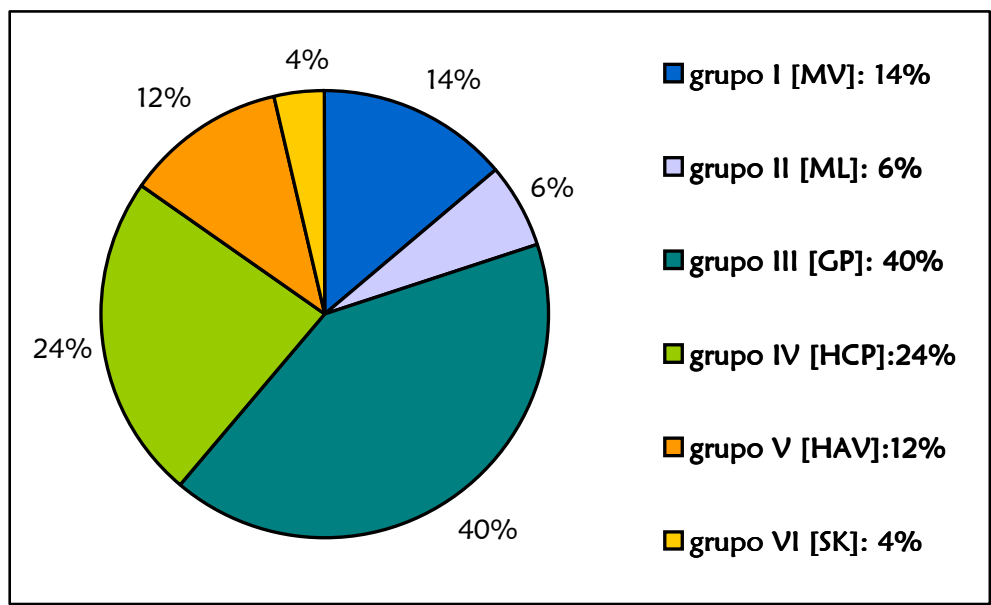

Gráfico 2 - Prevalência das lesões angioproliferativas cutâneas, estimada entre os anos de 1971-2002: [I] malformação venosa (14\%); [II] malformação linfática (6\%); [III] granuloma piogênico (40\%); [IV] hemangioma capilar (24\%); [V] hemangioma arteriovenoso (12\%); [VI] sarcoma de Kaposi (4\%)

\section{2 - Caracterização Clínica da Amostra}


Após a seleção dos espécimes da amostra, foram analisados os dados clínicos das lesões quanto à localização e dos pacientes à idade e gênero (Tabela 3).

Tabela 3 - Dados clínicos das lesões angioproliferativas bucais e cutâneas

\begin{tabular}{|c|c|c|c|c|c|c|c|c|}
\hline \multirow{2}{*}{ GRUPOS } & \multicolumn{4}{|c|}{ LESÕES BUCAIS } & \multicolumn{4}{|c|}{ LESÕES CUTÃNEAS } \\
\hline & $\mathrm{N}$ & LOCAL & IDADE & GÊNERO & $\mathrm{N}$ & LOCAL & IDADE & GÊNERO \\
\hline \multirow{10}{*}{$\underset{\sum}{\stackrel{\sum}{\Xi}}$} & 1 & língua & 40 & $\mathrm{~F}$ & 1 & antebraço & $S / D^{* *}$ & $M$ \\
\hline & 2 & lábio inferior & 81 & $M$ & 2 & braço & S/D & $M$ \\
\hline & 3 & mucosa jugal & 65 & $\mathrm{~F}$ & 3 & braço & $S / D$ & $M$ \\
\hline & 4 & comissura & 14 & $\mathrm{~F}$ & 4 & nariz & 62 & $\mathrm{~F}$ \\
\hline & 5 & lábio superior & $S / D$ & $\mathrm{~F}$ & 5 & antebraço & 66 & M \\
\hline & 6 & lábio inferior & 76 & $\mathrm{~F}$ & 6 & pescoço & 44 & $\mathrm{~F}$ \\
\hline & 7 & língua & $S / D$ & $M$ & 7 & face & $S / D$ & $M$ \\
\hline & 8 & mucosa jugal & 24 & $M$ & 8 & clavícula & $S / D$ & $M$ \\
\hline & 9 & língua & 66 & M & 9 & tórax & 49 & M \\
\hline & 10 & lábio inferior & 57 & $\mathrm{~F}$ & 10 & S/D & $S / D$ & $S / D$ \\
\hline \multirow{10}{*}{$\stackrel{\vec{\Sigma}}{\equiv}$} & 1 & língua & 5 & $M$ & 1 & Lombar & 4 & $\mathrm{~F}$ \\
\hline & 2 & lábio inferior & 59 & $M$ & 2 & mama & 14 & $\mathrm{~F}$ \\
\hline & 3 & língua & 28 & $\mathrm{~F}$ & 3 & lombar & 12 & $M$ \\
\hline & 4 & língua & 22 & $\mathrm{~F}$ & 4 & abdômen & 27 & $\mathrm{~F}$ \\
\hline & 5 & S/D & S/D & $M$ & 5 & abdômen & 24 & $\mathrm{~F}$ \\
\hline & 6 & língua & $S / D$ & M & 6 & $S / D$ & S/D & $S / D$ \\
\hline & 7 & língua & $S / D$ & $\mathrm{~F}$ & 7 & $S / D$ & S/D & $S / D$ \\
\hline & 8 & S/D & $S / D$ & $S / D$ & 8 & $S / D$ & $S / D$ & $S / D$ \\
\hline & 9 & língua & $S / D$ & $\mathrm{~F}$ & 9 & $S / D$ & $S / D$ & S/D \\
\hline & 10 & língua & $S / D$ & S/D & 10 & S/D & $S / D$ & S/D \\
\hline \multirow{10}{*}{$\stackrel{\text { v }}{\supseteqq}$} & 1 & palato & S/D & $\mathrm{F}$ & 1 & dedo & 13 & $M$ \\
\hline & 2 & palato & $S / D$ & $\mathrm{~F}$ & 2 & dedo & 29 & $\mathrm{~F}$ \\
\hline & 3 & língua & 15 & $M$ & 3 & cabeça & S/D & M \\
\hline & 4 & gengiva & $S / D$ & M & 4 & face & $S / D$ & $\mathrm{~F}$ \\
\hline & 5 & gengiva & 44 & M & 5 & pele & S/D & S/D \\
\hline & 6 & lábio superior & $S / D$ & $\mathrm{~F}$ & 6 & pele & 31 & $\mathrm{~F}$ \\
\hline & 7 & & $S / D$ & $S / D$ & 7 & face & $S / D$ & M \\
\hline & 8 & $S / D$ & S/D & $S / D$ & 8 & pele & 50 & $M$ \\
\hline & 9 & língua & $S / D$ & $M$ & 9 & perna & $S / D$ & $M$ \\
\hline & 10 & gengiva & 32 & $\mathrm{~F}$ & 10 & braço & $S / D$ & $M$ \\
\hline \multirow{10}{*}{ 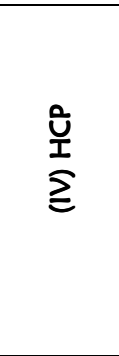 } & 1 & lábio inferior & 20 & $\mathrm{~F}$ & 1 & tórax & 41 & $M$ \\
\hline & 2 & comissura labial & $S / D$ & $\mathrm{~F}$ & 2 & dorso & $S / D$ & $\mathrm{~F}$ \\
\hline & 3 & lábio inferior & 30 & $M$ & 3 & nariz & 53 & $\mathrm{~F}$ \\
\hline & 4 & rebordo alveolar & 1 & $M$ & 4 & dorso & $S / D$ & $M$ \\
\hline & 5 & lábio inferior & 13 & $\mathrm{~F}$ & 5 & antebraço & 51 & $\mathrm{~F}$ \\
\hline & 6 & comissura labial & 60 & $S / D$ & 6 & dorso & 35 & M \\
\hline & 7 & lábio inferior & $S / D$ & $\mathrm{~F}$ & 7 & couro cabeludo & 67 & $M$ \\
\hline & 8 & língua & $S / D$ & $M$ & 8 & ombro & 77 & $M$ \\
\hline & 9 & $S / D$ & $S / D$ & $S / D$ & 9 & pele & $S / D$ & $M$ \\
\hline & 10 & $S / D$ & $S / D$ & $S / D$ & 10 & pele & $S / D$ & $M$ \\
\hline \multirow{10}{*}{$\frac{\text { 主 }}{\text { 至 }}$} & 1 & lábio inferior & 47 & $M$ & 1 & face & 26 & $\mathrm{~F}$ \\
\hline & 2 & lábio & $S / D$ & $S / D$ & 2 & colo & 40 & $\mathrm{~F}$ \\
\hline & 3 & lábio inferior & 66 & $\mathrm{~F}$ & 3 & braço & $S / D$ & $M$ \\
\hline & 4 & lábio & $S / D$ & $S / D$ & 4 & dedo & 27 & $M$ \\
\hline & 5 & lábio & $S / D$ & $S / D$ & 5 & dorso & 36 & $\mathrm{~F}$ \\
\hline & 6 & lábio superior & 75 & $\mathrm{~F}$ & 6 & S/D & $S / D$ & $\mathrm{~F}$ \\
\hline & 7 & língua & 69 & M & 7 & face & 66 & $\mathrm{~F}$ \\
\hline & 8 & língua & $S / D$ & $S / D$ & 8 & face & $S / D$ & $\mathrm{~F}$ \\
\hline & 9 & lábio & $S / D$ & $S / D$ & 9 & face & 66 & $\mathrm{~F}$ \\
\hline & 10 & língua & $S / D$ & S/D & 10 & face & 42 & $\mathrm{~F}$ \\
\hline \multirow{8}{*}{$\stackrel{\text { 并 }}{\sum}$} & 1 & palato & 47 & $M$ & 1 & pé & 72 & $\mathrm{~F}$ \\
\hline & 2 & língua & 62 & $M$ & 2 & pele & 75 & $\mathrm{~F}$ \\
\hline & & & & & 3 & membro inferior & 78 & M \\
\hline & & & & & 4 & mão & 53 & M \\
\hline & & & & & 5 & coxa & 79 & $\mathrm{~F}$ \\
\hline & & & & & 6 & pele & 77 & $\mathrm{~F}$ \\
\hline & & & & & 7 & pé & 25 & M \\
\hline & \multicolumn{4}{|c|}{$* * S / D=$ sem dados } & 8 & antebraço & 53 & $M$ \\
\hline
\end{tabular}




\section{3 - Análise Morfológica e Imuno-Histoquímica}

\subsection{1 - MALFORMAÇÃO VENOSA}

A localização das malformações venosas na mucosa bucal foi predominantemente superficial e média. Observaram-se amplos espaços vasculares com contornos irregulares e paredes delgadas, revestidas por células endoteliais planas. Em alguns seguimentos os vasos apresentaram contornos papilares, trombos em organização e discreto infiltrado inflamatório mononuclear. As malformações venosas cutâneas apresentaram padrão arquitetural semelhante ao das lesões bucais. $\mathrm{Na}$ análise imuno-histoquímica dos espécimes de lesões bucais utilizando o anticorpo para FGFb, observou-se marcação citoplasmática e nuclear de intensidade moderada e distribuição multifocal (Figura 4). Em alguns cortes de malformações venosas bucais, o anticorpo anti-p75 ${ }^{\mathrm{NTR}}$ evidenciou a musculatura lisa vascular $\mathrm{e}$ terminações nervosas perivasculares. Nas malformações venosas cutâneas o mediador FGFb foi negativo. $O$ sinal imuno-histoquímico para $\mathrm{p} 75^{\mathrm{NTR}}$ foi focal $e$ predominantemente perivascular (Figura 5).

Tabela 4 - Avaliação imuno-histoquímica da expressão de p75 NTR e FGFb nos espécimes de malformação venosa bucal quanto à intensidade e distribuição. Valores demonstrados em medianas dos escores

\begin{tabular}{|c|c|c|c|c|}
\hline \multicolumn{5}{|c|}{ Malformação Venosa Bucal } \\
\hline Data de Registro & P75 ${ }^{\mathrm{NTR}}$ - intensidade & P75NTR - distribuição & FGFb - intensidade & FGFb - distribuição \\
\hline 2002 & 2 & 1 & 2 & 3 \\
\hline 2002 & 1 & 1 & 2 & 3 \\
\hline 2002 & 0 & 0 & 2 & 2 \\
\hline 2002 & 1 & 1 & 2 & 1 \\
\hline 2001 & 0 & 0 & 3 & 2 \\
\hline 2001 & 0 & 0 & 0 & 0 \\
\hline 2000 & 1 & 1 & 1 & 2 \\
\hline 2000 & 1 & 1 & 1 & 1 \\
\hline 1999 & 0 & 0 & 1 & 2 \\
\hline 1999 & 1 & 1 & 2 & 2 \\
\hline
\end{tabular}


Tabela 5 - Medianas dos critérios morfológicos analisados nos espécimes de malformação venosa bucal

\begin{tabular}{|c|c|c|c|c|c|c|c|c|c|c|}
\hline ESTRUTURA & \multicolumn{10}{|c|}{ MALFORMAÇÃO VENOSA BUCAL } \\
\hline $\mathrm{N}=10$ & A & B & C & $E$ & $\mathrm{~F}$ & $\mathrm{G}$ & $\mathrm{H}$ & 1 & $\mathrm{~J}$ & $\mathrm{~K}$ \\
\hline \multicolumn{11}{|l|}{ Tipo } \\
\hline \multirow{6}{*}{$\begin{array}{r}\text { Capilar } \\
\text { Vênula } \\
\text { Arteríola } \\
\text { Veia } \\
\text { Artéria } \\
\text { Linfático }\end{array}$} & 2 & 2 & 3 & 1 & 2 & 1 & 2 & 1 & 2 & 2 \\
\hline & 3 & 3 & 3 & 3 & 3 & 3 & 3 & 3 & 3 & 3 \\
\hline & 1 & 1 & 1 & 1 & 1 & 1 & 2 & 1 & 1 & 2 \\
\hline & 0 & 2 & 2 & 0 & 0 & 0 & 0 & 0 & 0 & 0 \\
\hline & 0 & 0 & 0 & 0 & 0 & 0 & 0 & 0 & 0 & 0 \\
\hline & 0 & 0 & 0 & 0 & 0 & 0 & 0 & 0 & 0 & 0 \\
\hline \multicolumn{11}{|l|}{ Arranjo } \\
\hline \multirow{4}{*}{$\begin{array}{r}\text { Lobular } \\
\text { Cordonal } \\
\text { Fasciculado } \\
\text { Aleatório }\end{array}$} & 0 & 3 & 0 & 0 & 2 & 0 & 2 & 0 & 0 & 2 \\
\hline & 3 & 0 & 3 & 3 & 0 & 3 & 0 & 3 & 0 & 0 \\
\hline & 0 & 0 & 0 & 0 & 0 & 0 & 0 & 0 & 0 & 0 \\
\hline & 2 & 0 & 3 & 0 & 2 & 0 & 0 & 0 & 3 & 0 \\
\hline \multicolumn{11}{|l|}{ Localização } \\
\hline \multirow{3}{*}{$\begin{array}{r}\text { Superficial } \\
\text { Média } \\
\text { Profunda }\end{array}$} & 2 & 0 & 3 & 0 & 0 & 3 & 3 & 3 & 2 & 2 \\
\hline & 3 & 3 & 3 & 3 & 2 & 2 & 2 & 2 & 3 & 2 \\
\hline & 0 & 0 & 0 & 0 & 2 & 0 & 0 & 2 & 2 & 0 \\
\hline \multicolumn{11}{|l|}{ Distribuição } \\
\hline \multirow{3}{*}{$\begin{array}{r}\text { Localizada } \\
\text { Multifocal } \\
\text { Disseminada }\end{array}$} & 3 & 3 & 0 & 3 & 0 & 0 & 0 & 0 & 3 & 2 \\
\hline & 0 & 0 & 0 & 0 & 3 & 3 & 3 & 3 & 0 & 0 \\
\hline & 0 & 0 & 3 & 0 & 0 & 0 & 0 & 0 & 0 & 0 \\
\hline \multicolumn{11}{|l|}{ Contornos } \\
\hline \multirow{2}{*}{$\begin{array}{r}\text { Regulares } \\
\text { Irregulares }\end{array}$} & 0 & 0 & 0 & 0 & 0 & 0 & 0 & 0 & 0 & 0 \\
\hline & 3 & 3 & 3 & 3 & 3 & 3 & 3 & 3 & 3 & 3 \\
\hline Dilatação & 3 & 3 & 3 & 3 & 3 & 3 & 3 & 3 & 3 & 3 \\
\hline Congestão & 3 & 3 & 3 & 2 & 3 & 3 & 3 & 3 & 3 & 3 \\
\hline Trombose & 0 & 0 & 0 & 0 & 0 & 0 & 3 & 0 & 3 & 0 \\
\hline
\end{tabular}

\section{Morfologia celular}

\begin{tabular}{|c|c|c|c|c|c|c|c|c|c|c|}
\hline Epitelióide & 0 & 0 & 2 & 0 & 2 & 0 & 0 & 0 & 0 & 0 \\
\hline Fusiforme & 3 & 3 & 3 & 2 & 3 & 3 & 3 & 3 & 3 & 3 \\
\hline Poliédrico & 1 & 1 & 1 & 3 & 2 & 2 & 2 & 2 & 0 & 1 \\
\hline Pleomórfico & 0 & 0 & 0 & 0 & 0 & 0 & 0 & 0 & 0 & 0 \\
\hline
\end{tabular}

de células

\begin{tabular}{c|c|c|c|c|c|c|c|c|c|c|}
\hline Simples & 3 & 3 & 3 & 3 & 3 & 3 & 3 & 3 & 3 & 3 \\
\cline { 2 - 9 } Múltiplas & 1 & 0 & 1 & 0 & 1 & 0 & 2 & 0 & 2 & 0 \\
\hline
\end{tabular}

Disposição

Aplainado

Proeminente

Papilar

\begin{tabular}{|c|c|c|c|c|c|c|c|c|c|c|}
\hline \multirow[b]{2}{*}{ Papilar } & & & & & & & & & & \\
\hline & 0 & 2 & 0 & 2 & 2 & 2 & 2 & 0 & 2 & 0 \\
\hline \multicolumn{11}{|l|}{ Mitoses } \\
\hline \multirow{2}{*}{$\begin{array}{r}\text { Típicas } \\
\text { Atípicas } \\
\end{array}$} & 0 & 0 & 1 & 0 & 0 & 0 & 0 & 0 & 0 & 0 \\
\hline & 0 & 0 & 0 & 0 & 0 & 0 & 0 & 0 & 0 & 0 \\
\hline $\begin{array}{l}\text { Lume } \\
\text { intracitoplasmático }\end{array}$ & 0 & 1 & 0 & 0 & 0 & 0 & 0 & 0 & 0 & 0 \\
\hline
\end{tabular}

intracitoplasmático

Exsudação

Hemossiderose

Tipo celular

\begin{tabular}{|c|c|c|c|c|c|c|c|c|c|c|}
\hline \multirow{5}{*}{$\begin{array}{r}\text { Neutrófilos } \\
\text { Eosinófilos } \\
\text { Linfócitos } \\
\text { Plasmócitos } \\
\text { Macrófagos }\end{array}$} & 0 & 0 & 0 & 0 & 0 & 0 & 0 & 0 & 2 & 0 \\
\hline & 0 & 0 & 0 & 0 & 0 & 0 & 0 & 0 & 0 & 0 \\
\hline & 2 & 2 & 2 & 0 & 0 & 0 & 0 & 0 & 2 & 0 \\
\hline & 0 & 0 & 0 & 0 & 0 & 0 & 0 & 0 & 0 & 0 \\
\hline & 0 & 0 & 0 & 0 & 0 & 0 & 0 & 0 & 0 & 0 \\
\hline \multicolumn{11}{|l|}{ Intensidade } \\
\hline \multirow{3}{*}{$\begin{array}{r}\text { Discreto } \\
\text { Moderado } \\
\text { Intenso }\end{array}$} & 2 & 2 & 2 & 0 & 0 & 0 & 0 & 0 & 2 & 0 \\
\hline & 0 & 0 & 0 & 0 & 0 & 0 & 0 & 0 & 0 & 0 \\
\hline & 0 & 0 & 0 & 0 & 0 & 0 & 0 & 0 & 0 & 0 \\
\hline
\end{tabular}

Hiperplásico

Atrófico

Ulcerado

TECIDO CONJUNTIVO

Escores: 0 = ausente; 1 = escasso; 2 = moderado; 3 = freqüente. 


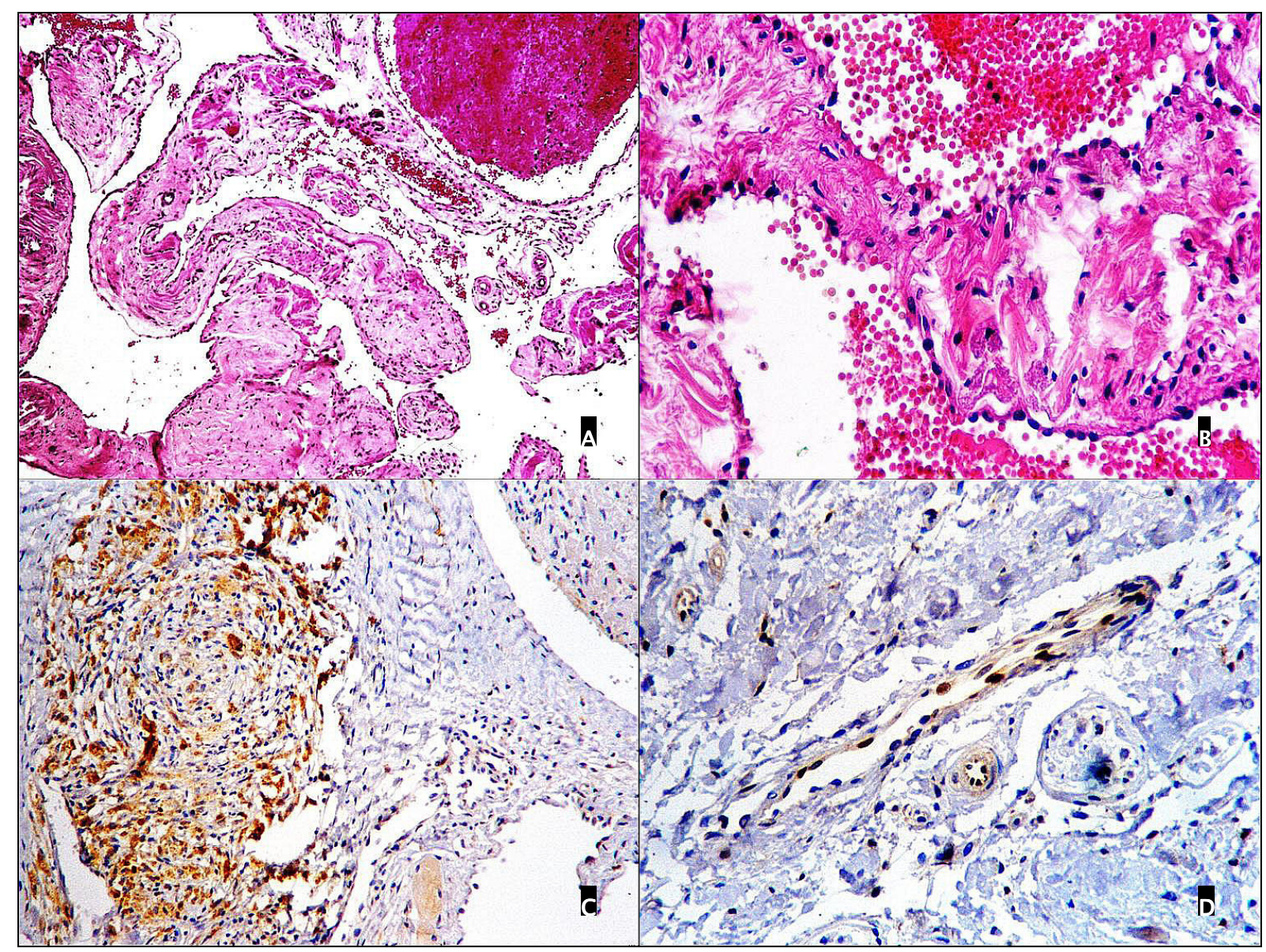

Figura 4 - Malformação venosa bucal. Em (A) e (B) os cortes corados por HE demonstram espaços vasculares irregulares e descontínuos associados a trombos em organização. O tecido conjuntivo apresenta-se hialinizado, com discreto infiltrado inflamatório mononuclear. As imagens (C) e (D) apresentam coloração imunohistoquímica positiva para FGFb no trombo e nos núcleos das células endoteliais de uma vênula. [HE ( $A$ e $B$ ) e IHQ (C e D). Objetivas 10X ( $A$ e $C$ ) e 40X (B e D)] 
Tabela 6 - Avaliação imuno-histoquímica da expressão de p75 NTR e FGFb nos espécimes de malformação venosa cutânea quanto à intensidade e distribuição. Valores demonstrados em medianas dos escores

\begin{tabular}{|c|c|c|c|c|}
\hline \multicolumn{5}{|c|}{ Malformação Venosa Cutânea } \\
\hline Data de Registro & P75 ${ }^{\text {NTR }}$ - intensidade & P75NTR - distribuição & FGFb - intensidade & FGFb - distribuição \\
\hline 2002 & 2 & 2 & 1 & 2 \\
\hline 2002 & 2 & 1 & 0 & 0 \\
\hline 2001 & 1 & 1 & 0 & 0 \\
\hline 2000 & 3 & 1 & 0 & 0 \\
\hline 1997 & 3 & 2 & 0 & 0 \\
\hline 1996 & 2 & 2 & 0 & 0 \\
\hline 1995 & 3 & 2 & 0 & 0 \\
\hline
\end{tabular}


Tabela 7 - Medianas dos critérios morfológicos analisados nos espécimes de malformação venosa cutânea

\begin{tabular}{|c|c|c|c|c|c|c|c|c|c|c|}
\hline ESTRUTURA & \multicolumn{10}{|c|}{ MALFORMAÇÃO VENOSA CUTÂNEA } \\
\hline $\mathrm{N}=10$ & $\mathbf{A}$ & B & $\mathrm{C}$ & $E$ & $\mathrm{~F}$ & G & $\mathrm{H}$ & 1 & $\mathrm{~J}$ & $\mathrm{~K}$ \\
\hline \multicolumn{10}{|l|}{ Tipo } & VASOS \\
\hline \multirow{6}{*}{$\begin{array}{r}\text { Capilar } \\
\text { Vênula } \\
\text { Arteríola } \\
\text { Veia } \\
\text { Artéria } \\
\text { Linfático }\end{array}$} & 1 & 3 & 2 & 2 & 2 & 1 & 2 & 2 & 2 & 2 \\
\hline & 2 & 3 & 3 & 3 & 3 & 3 & 3 & 3 & 3 & 3 \\
\hline & 1 & 2 & 2 & 1 & 1 & 2 & 2 & 1 & 1 & 1 \\
\hline & 0 & 1 & 1 & 0 & 0 & 2 & 0 & 0 & 2 & 0 \\
\hline & 0 & 0 & 1 & 0 & 0 & 0 & 0 & 0 & 0 & 0 \\
\hline & 0 & 0 & 1 & 0 & 0 & 2 & 0 & 2 & 0 & 0 \\
\hline \multicolumn{11}{|l|}{ Arranjo } \\
\hline \multirow{4}{*}{$\begin{array}{r}\text { Lobular } \\
\text { Cordonal } \\
\text { Fasciculado } \\
\text { Aleatório }\end{array}$} & 0 & 2 & 0 & 0 & 0 & 2 & 2 & 3 & 0 & 2 \\
\hline & 0 & 0 & 0 & 3 & 0 & 0 & 0 & 0 & 3 & 2 \\
\hline & 0 & 0 & 0 & 0 & 0 & 0 & 0 & 0 & 0 & 0 \\
\hline & 0 & 2 & 3 & 0 & 3 & 2 & 2 & 0 & 0 & 0 \\
\hline \multicolumn{11}{|l|}{ Localização } \\
\hline \multirow{3}{*}{$\begin{array}{r}\text { Superficial } \\
\text { Média } \\
\text { Profunda }\end{array}$} & 3 & 0 & 3 & 3 & 3 & 3 & 3 & 3 & 3 & 3 \\
\hline & 0 & 3 & 3 & 0 & 2 & 2 & 0 & 3 & 3 & 3 \\
\hline & 0 & 2 & 2 & 0 & 0 & 0 & 0 & 3 & 0 & 3 \\
\hline \multicolumn{11}{|l|}{ Distribuição } \\
\hline \multirow{3}{*}{$\begin{array}{r}\text { Localizada } \\
\text { Multifocal } \\
\text { Disseminada }\end{array}$} & 3 & 0 & 0 & 3 & 0 & 0 & 0 & 0 & 0 & 0 \\
\hline & 0 & 3 & 0 & 0 & 3 & 3 & 3 & 0 & 3 & 0 \\
\hline & 0 & 0 & 3 & 0 & 0 & 0 & 0 & 3 & 0 & 3 \\
\hline \multicolumn{11}{|l|}{ Contornos } \\
\hline \multirow{2}{*}{$\begin{array}{r}\text { Regulares } \\
\text { Irregulares } \\
\end{array}$} & 0 & 3 & 0 & 0 & 0 & 0 & 0 & 2 & 0 & 0 \\
\hline & 3 & 0 & 3 & 3 & 3 & 3 & 3 & 3 & 3 & 3 \\
\hline Dilatação & 3 & 3 & 3 & 3 & 3 & 3 & 3 & 3 & 3 & 3 \\
\hline Congestão & 3 & 3 & 3 & 3 & 3 & 3 & 3 & 3 & 3 & 3 \\
\hline Trombose & 3 & 3 & 3 & 0 & 3 & 0 & 3 & 2 & 2 & 2 \\
\hline \multicolumn{11}{|l|}{ Morfologia celular } \\
\hline \multirow{4}{*}{$\begin{array}{r}\text { Epitelióide } \\
\text { Fusiforme } \\
\text { Poliédrico } \\
\text { Pleomórfico }\end{array}$} & 2 & 3 & 2 & 2 & 2 & 0 & 1 & 0 & 1 & 2 \\
\hline & 3 & 2 & 3 & 3 & 3 & 3 & 3 & 3 & 3 & 3 \\
\hline & 0 & 2 & 0 & 0 & 0 & 2 & 2 & 1 & 2 & 2 \\
\hline & 1 & 1 & 0 & 0 & 0 & 0 & 0 & 0 & 0 & 0 \\
\hline \multicolumn{11}{|l|}{ Camadas de células } \\
\hline \multirow{2}{*}{$\begin{array}{r}\text { Simples } \\
\text { Múltiplas }\end{array}$} & 3 & 3 & 3 & 3 & 3 & 3 & 3 & 3 & 3 & 3 \\
\hline & 0 & 2 & 0 & 0 & 2 & 1 & 1 & 1 & 2 & 2 \\
\hline \multicolumn{11}{|l|}{ Disposição } \\
\hline \multirow{3}{*}{$\begin{array}{r}\text { Aplainado } \\
\text { Proeminente } \\
\text { Papilar }\end{array}$} & 3 & 3 & 3 & 3 & 3 & 3 & 3 & 3 & 3 & 3 \\
\hline & 0 & 2 & 0 & 0 & 0 & 0 & 0 & 0 & 2 & 0 \\
\hline & 0 & 0 & 0 & 0 & 0 & 0 & 0 & 0 & 2 & 3 \\
\hline \multicolumn{11}{|l|}{ Mitoses } \\
\hline \multirow{2}{*}{$\begin{array}{r}\text { Típicas } \\
\text { Atípicas } \\
\end{array}$} & 0 & 0 & 0 & 0 & 0 & 0 & 0 & 0 & 0 & 0 \\
\hline & 0 & 0 & 0 & 0 & 0 & 0 & 0 & 0 & 0 & 0 \\
\hline $\begin{array}{l}\text { Lumes } \\
\text { intracitoplasmáticos }\end{array}$ & 0 & 2 & 0 & 0 & 2 & 0 & 0 & 0 & 1 & 1 \\
\hline
\end{tabular}

\begin{tabular}{ll}
\hline & TECIDO CONJUNTIVO
\end{tabular}

\begin{tabular}{l|l|l|l|l|l|l|l|l|l|l}
\hline Exsudação & 3 & 3 & 2 & 0 & 2 & 0 & 2 & 2 & 1 & 1 \\
\hline Hemossiderose & 0 & 2 & 2 & 0 & 2 & 2 & 2 & 2 & 1 & 1 \\
\hline
\end{tabular}

Tipo celular

\begin{tabular}{|c|c|c|c|c|c|c|c|c|c|c|}
\hline \multirow{5}{*}{$\begin{array}{r}\text { Neutrófilos } \\
\text { Eosinófilos } \\
\text { Linfócitos } \\
\text { Plasmócitos } \\
\text { Macrófagos }\end{array}$} & 2 & 2 & 0 & 0 & 0 & 0 & 0 & 0 & 0 & 0 \\
\hline & & & & & & & & & & \\
\hline & 2 & 2 & 2 & 0 & 2 & 0 & 2 & 2 & 2 & 2 \\
\hline & & & & & & & & & & \\
\hline & & & & & & & & & & \\
\hline \multicolumn{11}{|l|}{ Intensidade } \\
\hline \multirow{3}{*}{$\begin{array}{r}\text { Discreto } \\
\text { Moderado } \\
\text { Intenso }\end{array}$} & 3 & 3 & 3 & 0 & 3 & 0 & 0 & 0 & 0 & 0 \\
\hline & 0 & 0 & 0 & 0 & 0 & 0 & 3 & 3 & 3 & 3 \\
\hline & 0 & 0 & 0 & 0 & 0 & 0 & 0 & 0 & 0 & 0 \\
\hline
\end{tabular}

\begin{tabular}{l|l|l|l|l|l|l|l|l|l|l}
\hline Hiperplásico & 2 & 0 & 3 & 2 & 0 & 0 & 2 & 0 & 0 & 0 \\
\hline Atrófico & 0 & 0 & 0 & 0 & 0 & 0 & 0 & 2 & 0 & 2 \\
\hline Ulcerado & 2 & 3 & 0 & 0 & 0 & 0 & 2 & 0 & 0 & 0 \\
\hline
\end{tabular}

Escores: 0 = ausente; 1 = escasso; 2 = moderado; 3 = freqüente. 


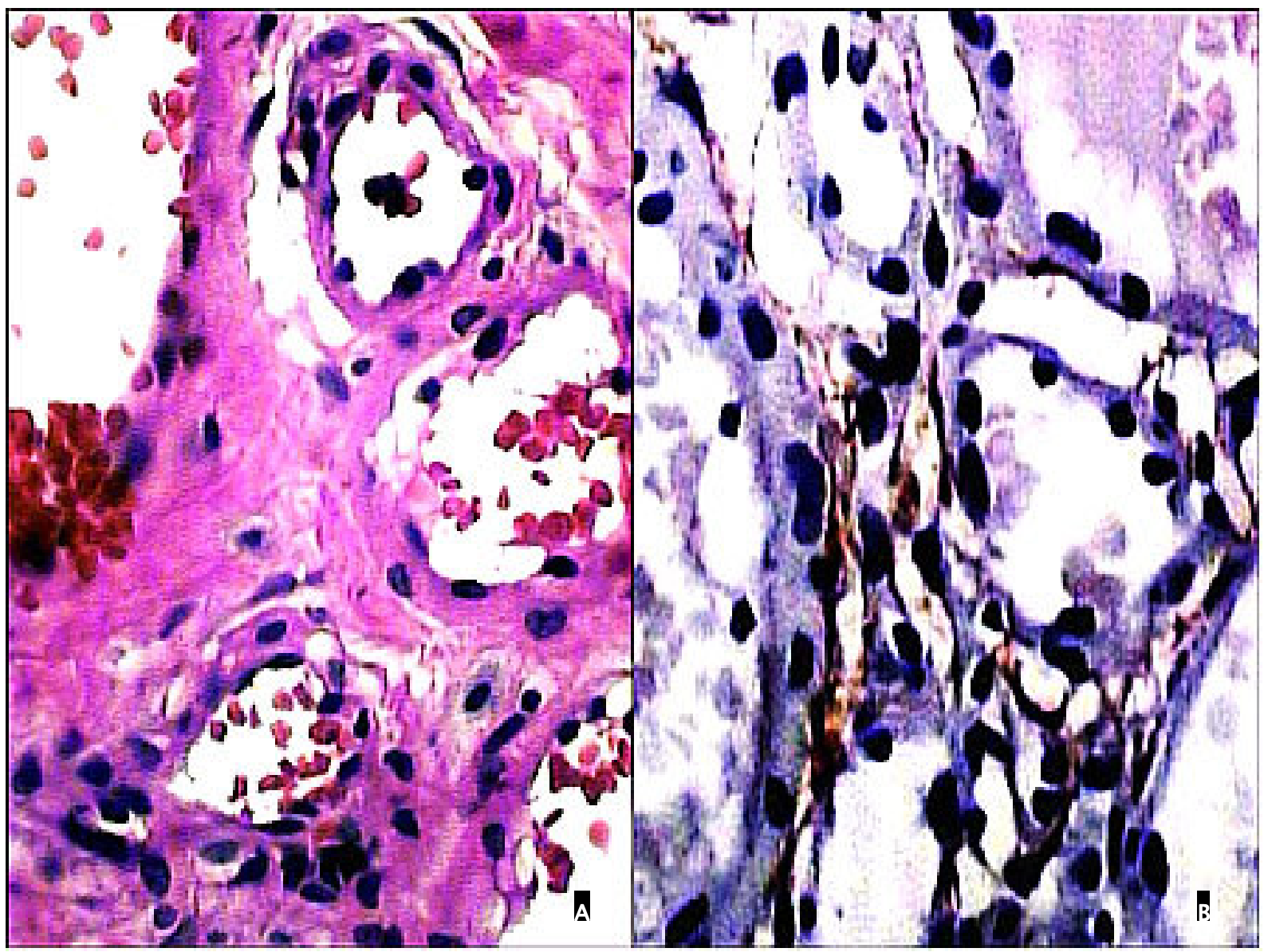

Figura 5 - Malformação venosa cutânea. Em (A) o corte microscópico demonstra vasos congestos revestidos por camadas simples de células. No interstício nota-se densa colagenização e ausência de infiltrado inflamatório. O corte (B) demonstra sinal imuno-histoquímico focal para p75 ${ }^{\mathrm{NTR}}$ no endotélio de algumas vênulas. [HE (A) e IHQ (B). Objetiva 100X (A e B)] 


\subsection{2 - MALFORMAÇÃO LINFÁTICA}

Os vasos linfáticos das malformações linfáticas bucais da amostra apresentaram paredes irregulares com endotélio extremamente delgado desprovido de musculatura lisa. No tecido conjuntivo subjacente observou-se acúmulo de exsudato seroso associado a moderado infiltrado inflamatório mononuclear. A análise imuno-histoquímica das lesões bucais demonstrou reatividade discreta e focal para os mediadores $\mathrm{p} 75^{\mathrm{NTR}}$ e FGFb em pequenos vasos sanguíneos associados aos linfáticos (Figura 6). As lesões cutâneas demonstraram espaços vasculares subepiteliais dispostos em grupamentos, revestidos por células planas com núcleos proeminentes. Não se observou sinal imuno-histoquímico nas lesões cutâneas (Figura 7).

Tabela 8 - Avaliação imuno-histoquímica da expressão de p75 NTR e FGFb nos espécimes de malformação linfática bucal quanto à intensidade e distribuição. Valores demonstrados em medianas dos escores

\begin{tabular}{|c|c|c|c|c|}
\hline \multicolumn{5}{|c|}{ Malformação Linfática Bucal } \\
\hline Data de Registro & P75 ${ }^{\text {TTR }}$ - intensidade & P75 NTR - distribuição & FGFb - intensidade & FGFb - distribuição \\
\hline 2002 & 1 & 1 & 1 & 1 \\
\hline 1999 & 0 & 0 & 1 & 1 \\
\hline 2002 & 1 & 1 & 1 & 1 \\
\hline 2001 & 1 & 2 & 1 & 1 \\
\hline 1995 & 1 & 1 & 1 & 1 \\
\hline 1997 & 1 & 1 & 2 & 2 \\
\hline 1995 & 1 & 1 & 3 & 2 \\
\hline 2002 & 1 & 1 & 2 & 1 \\
\hline 2002 & 1 & 1 & 1 & 1 \\
\hline 1995 & 1 & 1 & 0 & 0 \\
\hline
\end{tabular}


Tabela 9 - Medianas dos critérios morfológicos analisados nos espécimes de malformação linfática bucal

\begin{tabular}{|c|c|c|c|c|c|c|c|c|c|c|}
\hline \multirow{2}{*}{$\begin{array}{r}\text { ESTRUTURA } \\
\mathrm{N}=9 \\
\end{array}$} & \multicolumn{10}{|c|}{ MALFORMAÇÃO LINFÁTICA BUCAL } \\
\hline & $\mathbf{A}$ & B & $C$ & $\mathrm{E}$ & $\mathrm{F}$ & $G$ & $\mathrm{H}$ & 1 & $\mathrm{~J}$ & \\
\hline \multicolumn{10}{|l|}{ Tipo } & VASOS \\
\hline \multirow{6}{*}{$\begin{array}{r}\text { Capilar } \\
\text { Vênula } \\
\text { Arteríola } \\
\text { Veia } \\
\text { Artéria } \\
\text { Linfático }\end{array}$} & 2 & 3 & 2 & 1 & 2 & 2 & 2 & 2 & 3 & \\
\hline & 2 & 2 & 2 & 2 & 1 & 2 & 2 & 2 & 3 & \\
\hline & 0 & 1 & 0 & 0 & 1 & 0 & 0 & 0 & 1 & \\
\hline & 0 & 1 & 0 & 0 & 0 & 0 & 0 & 0 & 0 & \\
\hline & 0 & 0 & 0 & 0 & 0 & 0 & 0 & 0 & 0 & \\
\hline & 3 & 3 & 3 & 3 & 3 & 3 & 3 & 3 & 3 & \\
\hline \multicolumn{11}{|l|}{ Arranjo } \\
\hline \multirow{4}{*}{$\begin{array}{r}\text { Lobular } \\
\text { Cordonal } \\
\text { Fasciculado } \\
\text { Aleatório } \\
\end{array}$} & 0 & 3 & 0 & 0 & 0 & 3 & 0 & 0 & 2 & \\
\hline & 0 & 0 & 0 & 0 & 0 & 0 & 0 & 0 & 0 & \\
\hline & 0 & 0 & 0 & 0 & 0 & 0 & 0 & 0 & 0 & \\
\hline & 3 & 0 & 3 & 3 & 3 & 0 & 3 & 3 & 0 & \\
\hline \multicolumn{11}{|l|}{ Localização } \\
\hline \multirow{3}{*}{$\begin{array}{r}\text { Superficial } \\
\text { Média } \\
\text { Profunda }\end{array}$} & 3 & 3 & 3 & 2 & 3 & 3 & 3 & 3 & 3 & \\
\hline & 0 & 0 & 2 & 3 & 3 & 3 & 2 & 0 & 0 & \\
\hline & 0 & 0 & 0 & 0 & 2 & 0 & 0 & 0 & 0 & \\
\hline \multicolumn{11}{|l|}{ Distribuição } \\
\hline & 3 & 3 & 0 & 0 & 0 & 0 & 0 & 3 & 0 & \\
\hline \multirow{2}{*}{$\begin{array}{r}\text { Multifocal } \\
\text { Disseminada }\end{array}$} & 0 & 0 & 3 & 3 & 3 & 3 & 3 & 0 & 3 & \\
\hline & 0 & 0 & 0 & 0 & 0 & 0 & 0 & 0 & 0 & \\
\hline \multicolumn{11}{|l|}{ Contornos } \\
\hline \multirow{2}{*}{$\begin{array}{r}\text { Regulares } \\
\text { Irregulares }\end{array}$} & 0 & 0 & 0 & 0 & 0 & 2 & 0 & 0 & 0 & \\
\hline & 3 & 3 & 3 & 3 & 3 & 2 & 3 & 3 & 3 & \\
\hline Dilatação & 3 & 3 & 3 & 3 & 3 & 3 & 3 & 3 & 3 & \\
\hline Congestão & 0 & 3 & 2 & 3 & 2 & 3 & 2 & 2 & 3 & \\
\hline Trombose & 0 & 0 & 0 & 0 & 0 & 0 & 0 & 0 & 2 & \\
\hline \multicolumn{11}{|l|}{ Morfologia celular } \\
\hline \multirow{4}{*}{$\begin{array}{r}\text { Epitelióide } \\
\text { Fusiforme } \\
\text { Poliédrico } \\
\text { Pleomórfico }\end{array}$} & 1 & 2 & 1 & 1 & 0 & 0 & 0 & 0 & 2 & \\
\hline & 3 & 3 & 3 & 3 & 3 & 3 & 3 & 3 & 3 & \\
\hline & 0 & 0 & 1 & 2 & 0 & 0 & 0 & 0 & 0 & \\
\hline & 0 & 0 & 0 & 0 & 0 & 0 & 0 & 0 & 0 & \\
\hline \multicolumn{11}{|l|}{ Camadas de células } \\
\hline \multirow{2}{*}{$\begin{array}{r}\text { Simples } \\
\text { Múltiplas } \\
\end{array}$} & 3 & 3 & 3 & 3 & 3 & 3 & 3 & 3 & 3 & \\
\hline & 0 & 2 & 0 & 2 & 0 & 0 & 0 & 0 & 0 & \\
\hline \multicolumn{11}{|l|}{ Disposição } \\
\hline \multirow{3}{*}{$\begin{array}{r}\text { Aplainado } \\
\text { Proeminente } \\
\text { Papilar }\end{array}$} & 3 & 3 & 3 & 3 & 3 & 3 & 3 & 3 & 3 & \\
\hline & 0 & 0 & 0 & 0 & 0 & 0 & 0 & 0 & 0 & \\
\hline & 0 & 0 & 0 & 0 & 0 & 0 & 0 & 0 & 0 & \\
\hline \multicolumn{11}{|l|}{ Mitoses } \\
\hline Típicas & 0 & 0 & 0 & 0 & 0 & 0 & 0 & 0 & 2 & \\
\hline Atípicas & 0 & 0 & 0 & 0 & 0 & 0 & 0 & 0 & 0 & \\
\hline $\begin{array}{l}\text { Lumes } \\
\text { intracitoplasmáticos }\end{array}$ & 0 & 0 & 0 & 0 & 0 & 0 & 0 & 0 & 0 & \\
\hline
\end{tabular}

\begin{tabular}{lr}
\hline & TECIDO CONJUNTIVO \\
\hline
\end{tabular}

\begin{tabular}{l|l|l|l|l|l|l|l|l|l|l}
\hline Exsudação & 0 & 3 & 1 & 3 & 2 & 3 & 3 & 1 & 3 & \\
\hline Hemossiderose & 0 & 0 & 0 & 0 & 0 & 0 & 0 & 1 & 2 & \\
\hline
\end{tabular}

Tipo celular

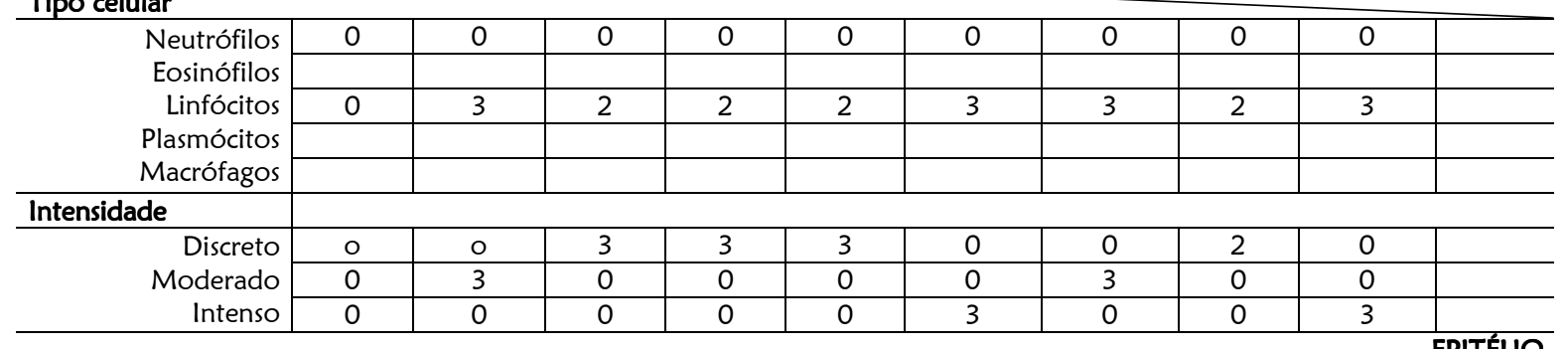

\begin{tabular}{l|l|l|l|l|l|l|l|l|l|l}
\hline Hiperplásico & 3 & 3 & 3 & 3 & 3 & 3 & 3 & 3 & 3 & \\
\hline Atrófico & 0 & 0 & 0 & 0 & 0 & 0 & 0 & 0 & 0 & \\
\hline Ulcerado & 0 & 0 & 0 & 0 & 0 & 0 & 0 & 0 & 2 & \\
\hline
\end{tabular}

Escores: 0 = ausente; 1 = escasso; 2 = moderado; 3 = freqüente. 


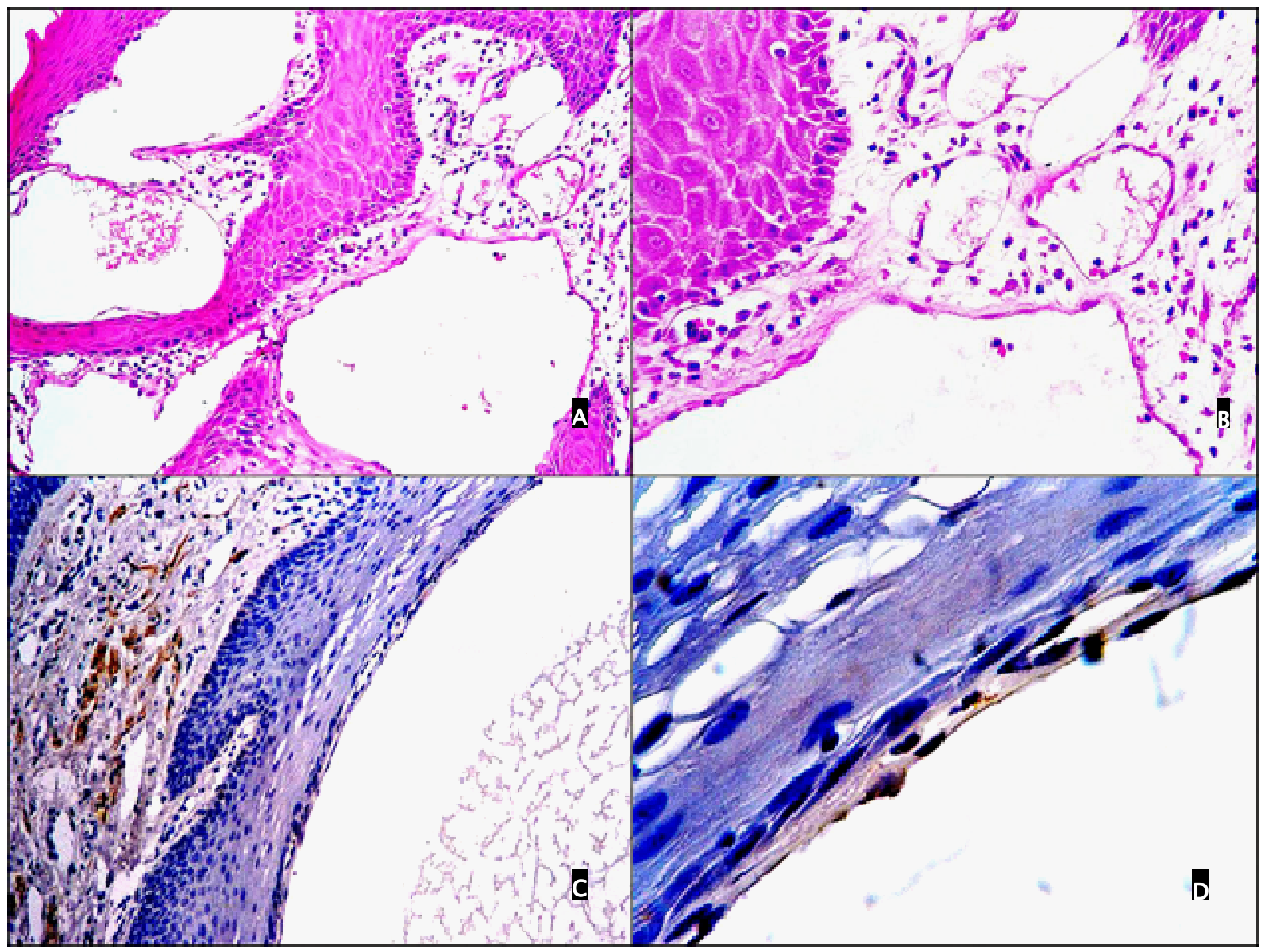

Figura 6 - Malformação linfática bucal. Em (A) e (B) notam-se espaços vasculares subepiteliais revestidos por camada simples de células endoteliais planas; nos lumes encontram-se raras hemácias, leucócitos e material fibrilar eosinofílico. O interstício apresenta edema e moderado infiltrado inflamatório predominantemente mononuclear. A imagem (C) demonstra a reatividade do anticorpo anti-p75 ${ }^{\mathrm{NTR}}$ ao redor de pequenos vasos sanguíneos da lâmina própria, não ocorrendo no endotélio da lesão. Em (D), observa-se positividade focal e discreta para FGFb nas células endoteliais linfáticas. [HE (A e B) e IHQ (C e D). Objetivas 20X (A e C), 40X (B) e $100 \times(D)]$ 
Tabela 10 - Avaliação imuno-histoquímica da expressão de p75 NTR e FGFb nos espécimes de malformação linfática cutânea quanto à intensidade e distribuição. Valores demonstrados em medianas dos escores

\begin{tabular}{|c|c|c|c|c|}
\hline \multicolumn{5}{|c|}{ Malformação Linfática Cutânea } \\
\hline Data de Registro & P75 ${ }^{\mathrm{NTR}}$ - intensidade & P75 NTR - distribuição & FGFb - intensidade & FGFb - distribuição \\
\hline 2001 & 0 & 0 & 0 & 0 \\
\hline 2000 & 0 & 0 & 0 & 0 \\
\hline 1998 & 1 & 1 & 0 & 0 \\
\hline 1998 & 1 & 1 & 2 & 1 \\
\hline 1992 & 0 & 0 & 0 & 0 \\
\hline
\end{tabular}


Tabela 11 - Medianas dos critérios morfológicos analisados nos espécimes de malformação linfática

\begin{tabular}{|c|c|c|c|c|c|c|c|c|c|c|}
\hline ESTRUTURA & \multicolumn{10}{|c|}{ MALFORMAÇÃO LINFÁTICA CUTÂNEA } \\
\hline $\mathrm{N}=10$ & $\mathbf{A}$ & B & $\mathrm{C}$ & $E$ & $\mathrm{~F}$ & $G$ & $\mathrm{H}$ & 1 & $\mathrm{~J}$ & $\mathrm{~K}$ \\
\hline \multicolumn{10}{|l|}{ Tipo } & VASOS \\
\hline \multirow{6}{*}{$\begin{array}{r}\text { Capilar } \\
\text { Vênula } \\
\text { Arteríola } \\
\text { Veia } \\
\text { Artéria } \\
\text { Linfático }\end{array}$} & 1 & 2 & 2 & 2 & 1 & 2 & 2 & 2 & 2 & 2 \\
\hline & 2 & 2 & 2 & 1 & 1 & 1 & 2 & 1 & 1 & 1 \\
\hline & 0 & 0 & 0 & 0 & 0 & 0 & 0 & 0 & 0 & 0 \\
\hline & 0 & 0 & 0 & 0 & 0 & 0 & 0 & 0 & 0 & 0 \\
\hline & 0 & 0 & 0 & 0 & 0 & 0 & 0 & 0 & 0 & 0 \\
\hline & 3 & 3 & 3 & 3 & 3 & 3 & 3 & 3 & 3 & 3 \\
\hline \multicolumn{11}{|l|}{ Arranjo } \\
\hline \multirow{4}{*}{$\begin{array}{r}\text { Lobular } \\
\text { Cordonal } \\
\text { Fasciculado } \\
\text { Aleatório }\end{array}$} & 3 & 2 & 0 & 3 & 3 & 3 & 3 & 3 & 2 & 3 \\
\hline & 0 & 0 & 0 & 0 & 0 & 0 & 0 & 0 & 0 & 0 \\
\hline & 0 & 0 & 0 & 0 & 0 & 0 & 0 & 0 & 0 & 0 \\
\hline & 0 & 2 & 3 & 0 & 0 & 0 & 0 & 0 & 0 & 0 \\
\hline \multicolumn{11}{|l|}{ Localização } \\
\hline \multirow{3}{*}{$\begin{array}{r}\text { Superficial } \\
\text { Média } \\
\text { Profunda }\end{array}$} & 3 & 3 & 3 & 3 & 3 & 3 & 3 & 3 & 3 & 3 \\
\hline & 0 & 2 & 0 & 0 & 0 & 0 & 0 & 0 & 0 & 0 \\
\hline & 0 & 0 & 0 & 0 & 0 & 0 & 0 & 0 & 0 & 0 \\
\hline \multicolumn{11}{|l|}{ Distribuição } \\
\hline \multirow{3}{*}{$\begin{array}{r}\text { Localizada } \\
\text { Multifocal } \\
\text { Disseminada }\end{array}$} & 3 & 0 & 3 & 3 & 3 & 0 & 0 & 3 & 3 & 3 \\
\hline & 0 & 3 & 0 & 0 & 0 & 3 & 3 & 0 & 0 & 0 \\
\hline & 0 & 0 & 0 & 0 & 0 & 0 & 0 & 0 & 0 & 0 \\
\hline \multicolumn{11}{|l|}{ Contornos } \\
\hline \multirow{2}{*}{$\begin{array}{r}\text { Regulares } \\
\text { Irregulares } \\
\end{array}$} & 3 & 2 & 0 & 0 & 0 & 0 & 2 & 2 & 0 & 0 \\
\hline & 0 & 3 & 3 & 3 & 3 & 3 & 2 & 2 & 3 & 3 \\
\hline Dilatação & 3 & 3 & 3 & 3 & 3 & 3 & 3 & 3 & 2 & 3 \\
\hline Congestão & 0 & 3 & 2 & 2 & 2 & 3 & 3 & 3 & 2 & 3 \\
\hline Trombose & 0 & 0 & 0 & 0 & 0 & 0 & 0 & 0 & 0 & 0 \\
\hline \multicolumn{11}{|l|}{ Morfologia celular } \\
\hline \multirow{4}{*}{$\begin{array}{r}\text { Epitelióide } \\
\text { Fusiforme } \\
\text { Poliédrico } \\
\text { Pleomórfico }\end{array}$} & 0 & 0 & 0 & 0 & 0 & 0 & 0 & 0 & 0 & 0 \\
\hline & 3 & 3 & 3 & 2 & 3 & 3 & 3 & 3 & 3 & 3 \\
\hline & 0 & 2 & 2 & 3 & 0 & 0 & 2 & 1 & 0 & 0 \\
\hline & 0 & 0 & 0 & 0 & 0 & 0 & 0 & 0 & 0 & 0 \\
\hline \multicolumn{11}{|l|}{ Camadas de células } \\
\hline \multirow{2}{*}{$\begin{array}{r}\text { Simples } \\
\text { Múltiplas }\end{array}$} & 3 & 3 & 3 & 3 & 3 & 3 & 3 & 3 & 3 & 3 \\
\hline & 0 & 0 & 0 & 0 & 0 & 0 & 0 & 0 & 0 & 0 \\
\hline \multicolumn{11}{|l|}{ Disposição } \\
\hline \multirow{3}{*}{$\begin{array}{r}\text { Aplainado } \\
\text { Proeminente } \\
\text { Papilar }\end{array}$} & 3 & 3 & 3 & 3 & 3 & 3 & 3 & 3 & 3 & 3 \\
\hline & 0 & 2 & 2 & 2 & 2 & 0 & 0 & 0 & 0 & 0 \\
\hline & 0 & 0 & 0 & 0 & 0 & 0 & 0 & 0 & 0 & 0 \\
\hline \multicolumn{11}{|l|}{ Mitoses } \\
\hline \multirow{2}{*}{$\begin{array}{r}\text { Típicas } \\
\text { Atípicas } \\
\end{array}$} & 0 & 0 & 0 & 0 & 0 & 0 & 0 & 0 & 0 & 0 \\
\hline & 0 & 0 & 0 & 0 & 0 & 0 & 0 & 0 & 0 & 0 \\
\hline $\begin{array}{l}\text { Lumes } \\
\text { intracitoplasmáticos }\end{array}$ & 0 & 0 & 0 & 0 & 0 & 0 & 0 & 0 & 0 & 0 \\
\hline
\end{tabular}

\begin{tabular}{ll}
\hline & TECIDO CONJUNTIVO
\end{tabular}

\begin{tabular}{l|l|l|l|l|l|l|l|l|l|l}
\hline Exsudação & 2 & 2 & 2 & 1 & 0 & 2 & 2 & 2 & 1 & 3 \\
\hline Hemossiderose & 0 & 3 & 2 & 0 & 0 & 2 & 2 & 0 & 0 & 0 \\
\hline
\end{tabular}

Tipo celular

\begin{tabular}{|c|c|c|c|c|c|c|c|c|c|c|}
\hline \multirow{5}{*}{$\begin{array}{r}\text { Neutrófilos } \\
\text { Eosinófilos } \\
\text { Linfócitos } \\
\text { Plasmócitos } \\
\text { Macrófagos }\end{array}$} & 0 & 0 & 0 & 0 & 0 & 0 & 0 & 0 & 0 & 0 \\
\hline & & & & & & & & & & \\
\hline & 2 & 2 & 2 & 1 & 0 & 3 & 3 & 3 & 3 & 3 \\
\hline & & & & & & & & & & \\
\hline & & & & & & & & & & \\
\hline \multicolumn{11}{|l|}{ Intensidade } \\
\hline \multirow{3}{*}{$\begin{array}{r}\text { Discreto } \\
\text { Moderado } \\
\text { Intenso }\end{array}$} & 3 & 0 & 3 & 3 & 0 & 0 & 0 & 0 & 3 & 0 \\
\hline & 0 & 3 & 0 & 0 & 0 & 0 & 0 & 0 & 0 & 0 \\
\hline & 0 & 0 & 0 & 0 & 0 & 3 & 3 & 3 & 0 & 3 \\
\hline
\end{tabular}

\begin{tabular}{l|l|l|l|l|l|l|l|l|l|l}
\hline Hiperplásico & 0 & 2 & 2 & 2 & 2 & 2 & 2 & 2 & 3 & 2 \\
\hline Atrófico & 2 & 0 & 0 & 2 & 2 & 0 & 0 & 0 & 0 & 2 \\
\hline Ulcerado & 0 & 0 & 0 & 0 & 0 & 0 & 0 & 0 & 0 & 0 \\
\hline
\end{tabular}

Escores: 0 = ausente; 1 = escasso; 2 = moderado; 3 = freqüente. 


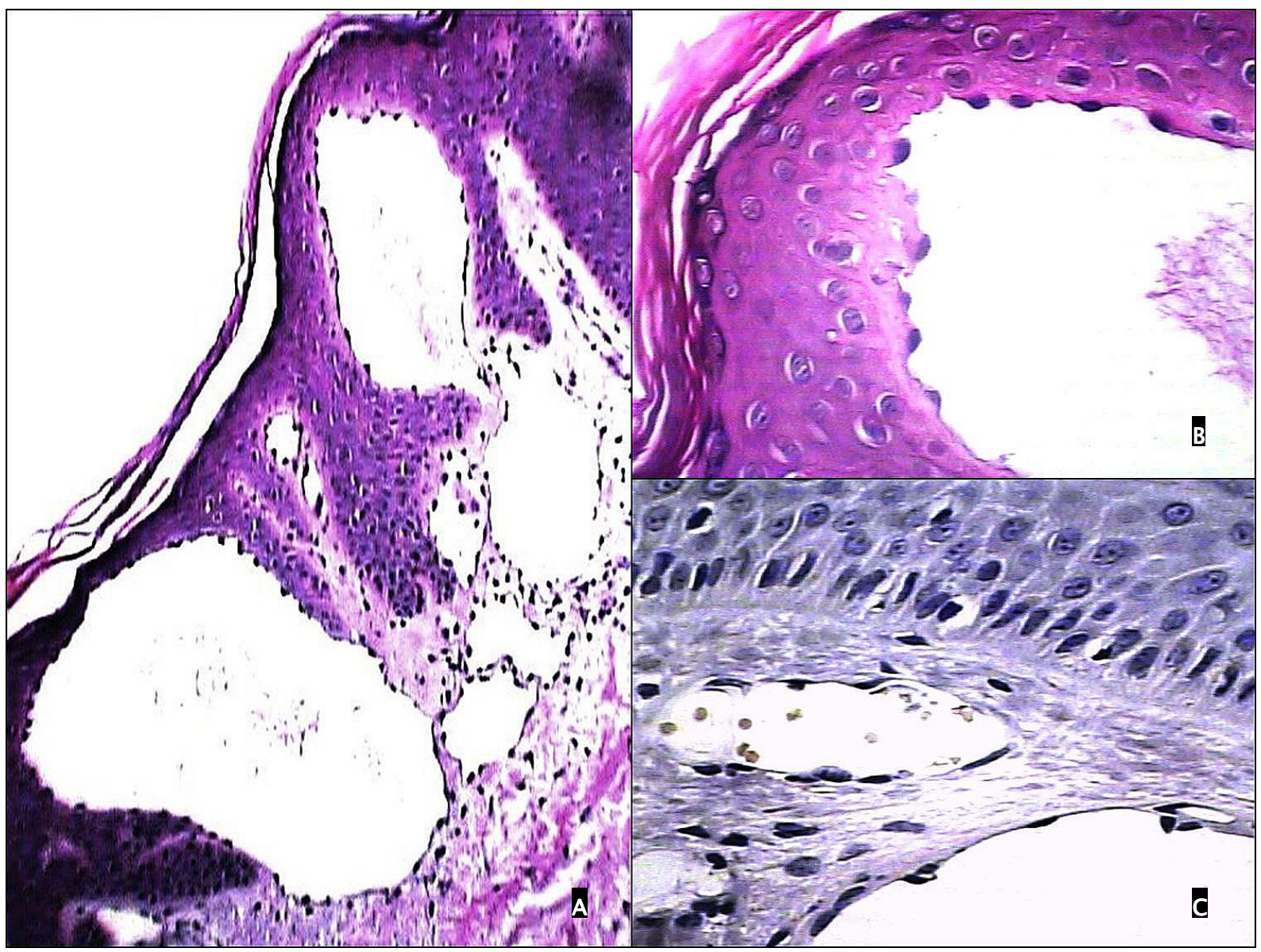

Figura 7 - Malformação linfática cutânea com apresentação justaepitelial. No aspecto microscópico representado em (A) observam-se espaços vasculares dilatados, de contornos irregulares, associados a um discreto infiltrado inflamatório mononuclear. Em (B) observa-se a íntima relação do endotélio linfático com o revestimento epitelial cutâneo. Notam-se, ainda, a relação descontínua das células endoteliais e a presença de material fibrilar no lume do vaso. O aspecto microscópico (C) demonstra sinal imuno-histoquímico negativo para FGFb. [HE (A e B) e IHQ (C). Objetivas 40X(A) e 100X (B e C)] 


\subsection{3 - GRANULOMA PIOGÊNICO}

Os granulomas piogênicos bucais estudados apresentaram-se como lesões nodulares com áreas ulceradas recobertas por exsudato fibrinoso. $O$ interstício subjacente demonstrou rica proliferação vascular, intenso infiltrado inflamatório misto, focos hemorrágicos e áreas de hemossiderose. Na submucosa predominaram pequenos vasos com lumes regulares, compostos por células epitelióides com citoplasma vacuolar e núcleo arredondado. Nos granulomas piogênicos cutâneos, as áreas proliferativas exibiram pequenos vasos dilatados com contornos irregulares, paredes eventualmente hialinizadas e células endoteliais arredondadas. As lesões cutâneas estudadas também apresentaram ulceração e intenso infiltrado inflamatório misto. A análise da expressão de FGFb e p75NTR nos granulomas piogênicos bucais resultou em marcação multifocal nuclear e citoplasmática para FGFb (Figuras 8 e 9) e citoplasmática focal para o receptor p75 NTR. O anticorpo anti-FGFb foi negativo e p75 ${ }^{\text {NTR }}$ focalmente positivo nas lesões cutâneas (Figura 10 e $11)$.

Tabela 12 - Avaliação imuno-histoquímica da expressão de p75NTR e FGFb nos espécimes de granuloma piogênico bucal quanto à intensidade e distribuição. Valores demonstrados em medianas dos escores

\begin{tabular}{|c|c|c|c|c|}
\hline \multicolumn{5}{|c|}{ Granuloma Piogênico Bucal } \\
\hline Data de Registro & P75 ${ }^{\text {NTR }}$ - intensidade & P75 NTR - distribuição & FGFb - intensidade & FGFb - distribuição \\
\hline 2002 & 0 & 0 & 2 & 2 \\
\hline 2002 & 1 & 1 & 1 & 1 \\
\hline 2002 & 1 & 1 & 2 & 1 \\
\hline 2002 & 0 & 0 & 1 & 2 \\
\hline 2002 & 2 & 1 & 1 & 1 \\
\hline 2002 & 1 & 1 & 2 & 2 \\
\hline 2002 & 1 & 2 & 2 & 3 \\
\hline 2002 & 1 & 1 & 1 & 1 \\
\hline 1999 & 0 & 0 & 1 & 1 \\
\hline
\end{tabular}


Tabela 13 - Medianas dos critérios morfológicos analisados nos espécimes de granuloma piogênico bucal

\begin{tabular}{|c|c|c|c|c|c|c|c|c|c|c|}
\hline ESTRUTURA & \multicolumn{10}{|c|}{ GRANULOMA PIOGÊNICO BUCAL } \\
\hline $\mathrm{N}=10$ & $\mathbf{A}$ & B & $\mathrm{C}$ & $E$ & $F$ & $G$ & $\bar{H}$ & 1 & $\mathrm{~J}$ & $\mathrm{~K}$ \\
\hline & & & & & & & & & & VASOS \\
\hline \multicolumn{11}{|l|}{ Tipo } \\
\hline \multirow{6}{*}{$\begin{array}{r}\text { Capilar } \\
\text { Vênula } \\
\text { Arteríola } \\
\text { Veia } \\
\text { Artéria } \\
\text { Linfático }\end{array}$} & 3 & 3 & 3 & 3 & 3 & 3 & 2 & 3 & 3 & 3 \\
\hline & 3 & 3 & 2 & 2 & 2 & 3 & 3 & 3 & 2 & 3 \\
\hline & 1 & 2 & 1 & 3 & 3 & 2 & 3 & 2 & 2 & 1 \\
\hline & 0 & 0 & 0 & 0 & 0 & 0 & 0 & 0 & 0 & 0 \\
\hline & 0 & 0 & 0 & 0 & 0 & 0 & 0 & 0 & 0 & 0 \\
\hline & 0 & 0 & 0 & 0 & 0 & 0 & 0 & 0 & 0 & 0 \\
\hline \multicolumn{11}{|l|}{ Arranjo } \\
\hline \multirow{4}{*}{$\begin{array}{r}\text { Lobular } \\
\text { Cordonal } \\
\text { Fasciculado } \\
\text { Aleatório }\end{array}$} & 2 & 2 & 2 & 2 & 0 & 3 & 2 & 2 & 1 & 0 \\
\hline & 2 & 0 & 0 & 0 & 3 & 0 & 3 & 0 & 2 & 2 \\
\hline & 0 & 0 & 2 & 0 & 0 & 0 & 0 & 0 & 0 & 1 \\
\hline & 3 & 3 & 3 & 0 & 2 & 2 & 2 & 3 & 3 & 3 \\
\hline \multicolumn{11}{|l|}{ Localização } \\
\hline \multirow{3}{*}{$\begin{array}{r}\text { Superficial } \\
\text { Média } \\
\text { Profunda }\end{array}$} & 3 & 3 & 3 & 2 & 3 & 3 & 3 & 3 & 3 & 3 \\
\hline & 3 & 3 & 2 & 3 & 2 & 3 & 2 & 3 & 3 & 2 \\
\hline & 0 & 0 & 0 & 0 & 0 & 0 & 0 & 0 & 0 & 0 \\
\hline \multicolumn{11}{|l|}{ Distribuição } \\
\hline \multirow{3}{*}{$\begin{array}{r}\text { Localizada } \\
\text { Multifocal } \\
\text { Disseminada } \\
\end{array}$} & 0 & 0 & 0 & 0 & 0 & 0 & 0 & 0 & 0 & 0 \\
\hline & 0 & 0 & 0 & 3 & 3 & 3 & 3 & 2 & 2 & 0 \\
\hline & 3 & 3 & 3 & 0 & 0 & 2 & 2 & 3 & 3 & 3 \\
\hline \multicolumn{11}{|l|}{ Contornos } \\
\hline \multirow{2}{*}{$\begin{array}{r}\text { Regulares } \\
\text { Irregulares }\end{array}$} & 3 & 3 & 2 & 3 & 3 & 2 & 3 & 2 & 2 & 0 \\
\hline & 2 & 2 & 3 & 2 & 2 & 3 & 2 & 3 & 3 & 3 \\
\hline Dilatação & 3 & 3 & 2 & 2 & 3 & 3 & 3 & 3 & 2 & 3 \\
\hline Congestão & 3 & 3 & 3 & 1 & 3 & 3 & 3 & 2 & 2 & 3 \\
\hline Trombose & 0 & 2 & 0 & 0 & 0 & 0 & 0 & 0 & 0 & 0 \\
\hline \multirow{2}{*}{\multicolumn{11}{|c|}{ Morfologia celular }} \\
\hline & & & & & & & & & & \\
\hline \multirow{4}{*}{$\begin{array}{r}\text { Epitelióide } \\
\text { Fusiforme } \\
\text { Poliédrico } \\
\text { Pleomórfico }\end{array}$} & 3 & 3 & 2 & 2 & 3 & 3 & 3 & 3 & 3 & 3 \\
\hline & 2 & 2 & 1 & 1 & 1 & 1 & 2 & 1 & 1 & 1 \\
\hline & 2 & 1 & 3 & 3 & 2 & 3 & 2 & 2 & 2 & 2 \\
\hline & 0 & 1 & 0 & 0 & 0 & 0 & 0 & 0 & 0 & 0 \\
\hline \multicolumn{11}{|l|}{ Camadas de células } \\
\hline \multirow{2}{*}{$\begin{array}{r}\text { Simples } \\
\text { Múltiplas }\end{array}$} & 3 & 3 & 2 & 3 & 3 & 3 & 3 & 3 & 3 & 2 \\
\hline & 0 & 1 & 2 & 0 & 0 & 0 & 1 & 0 & 0 & 3 \\
\hline \multicolumn{11}{|l|}{ Disposição } \\
\hline \multirow{3}{*}{$\begin{array}{r}\text { Aplainado } \\
\text { Proeminente } \\
\text { Papilar }\end{array}$} & 2 & 3 & 0 & 2 & 3 & 2 & 3 & 3 & 3 & 3 \\
\hline & 3 & 2 & 3 & 2 & 2 & 3 & 2 & 2 & 2 & 2 \\
\hline & 0 & 0 & 0 & 0 & 0 & 0 & 0 & 0 & 0 & 0 \\
\hline \multicolumn{11}{|l|}{ Mitoses } \\
\hline \multirow{2}{*}{$\begin{array}{l}\text { Típicas } \\
\text { Atípicas }\end{array}$} & 0 & 2 & 3 & 0 & 2 & 2 & 1 & 1 & 2 & 2 \\
\hline & 0 & 0 & 1 & 0 & 0 & 0 & 0 & 0 & 0 & 0 \\
\hline $\begin{array}{l}\text { Lumes } \\
\text { intracitoplasmáticos }\end{array}$ & 1 & 3 & 2 & 0 & 0 & 2 & 0 & 0 & 2 & 2 \\
\hline
\end{tabular}

\begin{tabular}{|c|c|c|c|c|c|c|c|c|c|c|}
\hline & & & & & & & & \multicolumn{3}{|c|}{ TECIDO CONJUNTIVO } \\
\hline Exsudação & 3 & 3 & 3 & 2 & 3 & 3 & 3 & 2 & 2 & 3 \\
\hline Hemossiderose & 0 & 1 & 1 & 0 & 1 & 2 & 0 & 0 & 1 & 2 \\
\hline & & & & & & & & \multicolumn{3}{|c|}{ INFILTRADO INFLAMATÓRIO } \\
\hline \multicolumn{11}{|l|}{ Tipo celular } \\
\hline \multirow{5}{*}{$\begin{array}{r}\text { Neutrófilos } \\
\text { Eosinófilos } \\
\text { Linfócitos } \\
\text { Plasmócitos } \\
\text { Macrófagos } \\
\end{array}$} & 3 & 3 & 3 & 2 & 3 & 2 & 3 & 3 & 2 & 2 \\
\hline & 1 & 1 & 1 & 1 & 1 & 2 & 1 & 1 & 2 & 2 \\
\hline & 3 & 2 & 2 & 2 & 2 & 2 & 2 & 2 & 3 & 2 \\
\hline & 1 & 3 & 1 & 3 & 1 & 2 & 2 & 2 & 1 & 2 \\
\hline & 2 & 2 & 2 & 2 & 2 & 2 & 2 & 2 & 2 & 2 \\
\hline \multicolumn{11}{|l|}{ Intensidade } \\
\hline Discreto & 0 & 0 & 0 & 0 & 0 & 0 & 0 & 0 & 0 & 0 \\
\hline Moderado & 0 & 0 & 0 & 3 & 3 & 3 & 2 & 3 & 2 & 0 \\
\hline Intenso & 3 & 3 & 3 & 0 & 2 & 2 & 3 & 2 & 0 & 3 \\
\hline
\end{tabular}

\begin{tabular}{l|l|l|l|l|l|l|l|l|l|l}
\multicolumn{1}{c}{} & \multicolumn{1}{c}{ EPITÉLIO } \\
\hline Hiperplásico & 3 & 3 & 2 & 3 & 1 & 3 & 3 & 0 & 3 & 2 \\
\hline Atrófico & 0 & 1 & 2 & 0 & 2 & 1 & 1 & 0 & 0 & 0 \\
\hline Ulcerado & 2 & 3 & 3 & 0 & 3 & 3 & 2 & 3 & 0 & 3 \\
\hline
\end{tabular}

Escores: 0 = ausente; 1 = escasso; 2 = moderado; 3 = freqüente. 


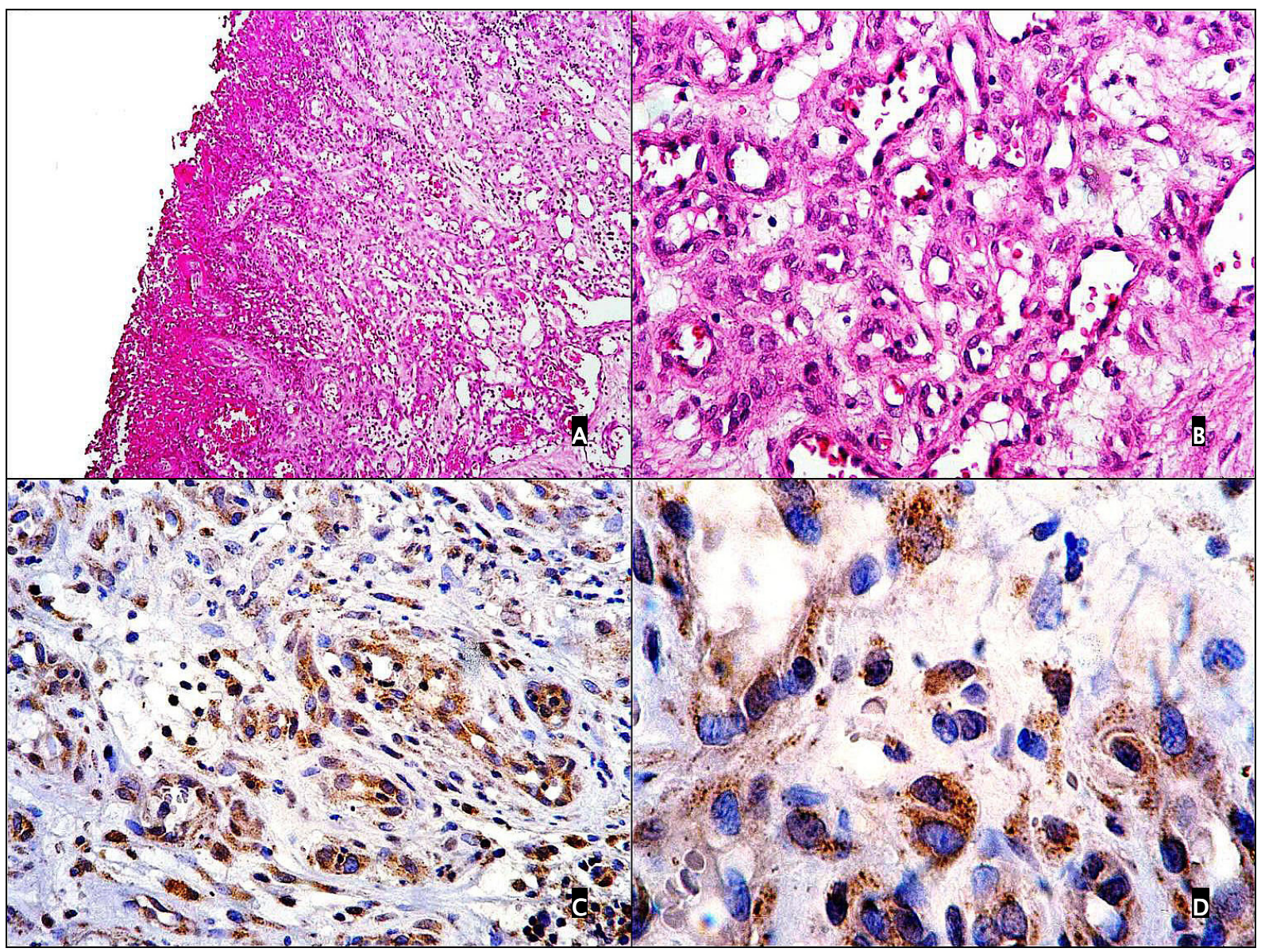

Figura 8 - As imagens (A) e (B) retratam cortes microscópicos de um espécime de granuloma piogênico bucal em aumentos progressivos. No menor aumento (A), destaca-se o típico padrão ulcerado dessa lesão em associação à deposição de fibrina e presença de infiltrado inflamatório. Na imagem (B), encontram-se pequenos vasos uniformes, de aspecto microvenular distribuídos difusamente no tecido conjuntivo subjacente. Em (C) observa-se intensa e difusa coloração imunohistoquímica para o mediador FGFb. A imagem (D) demonstra positividade citoplasmática para FGFb. [HE (A e B) e IHQ (C e D). Objetivas 10X (A), 20X (C), $40 \times(B), 100 \times(D)]$ 


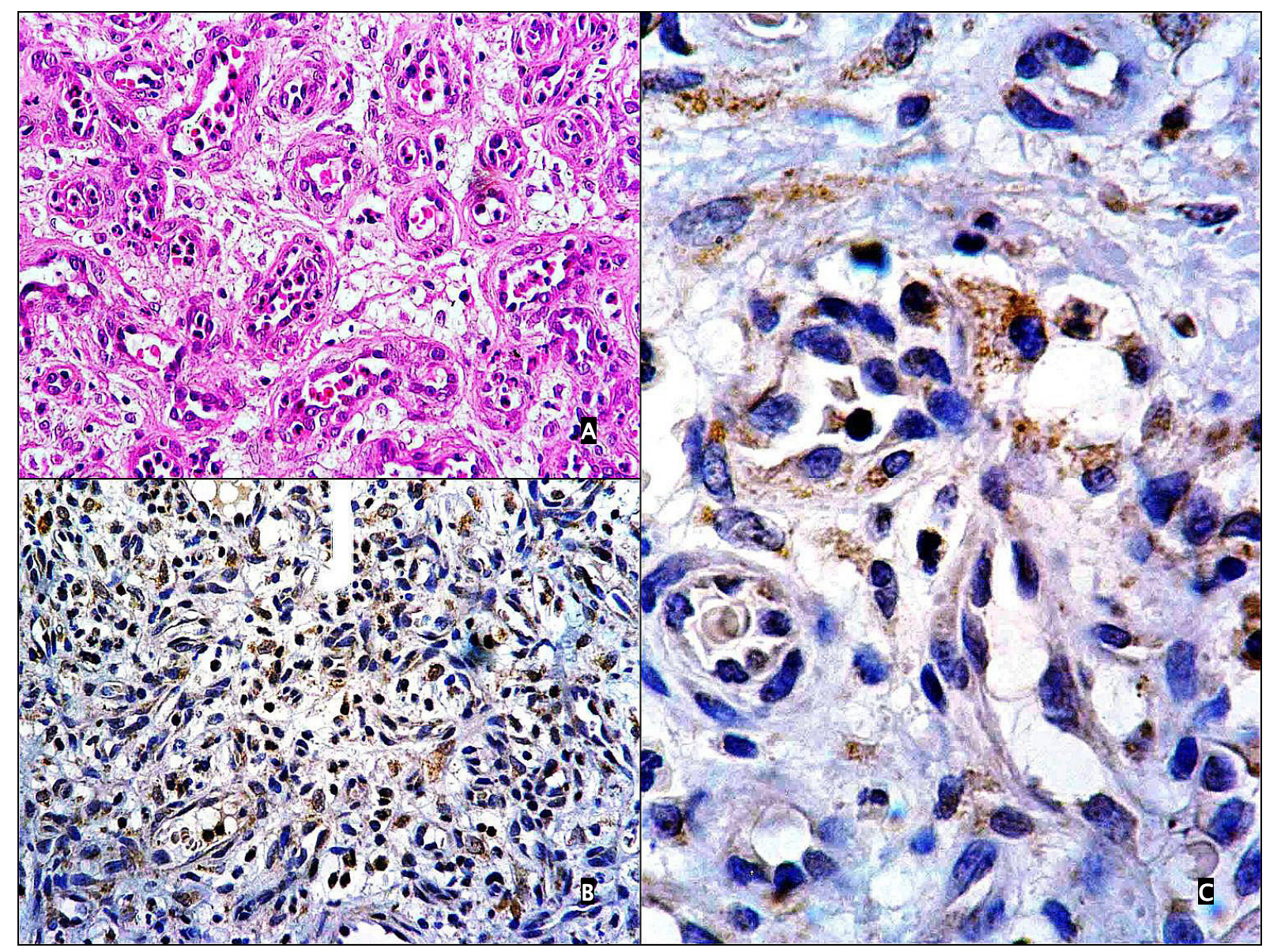

Figura 9 - Na Imagem (A) observa-se um corte microscópico de granuloma piogênico bucal apresentando inúmeras vênulas de contornos regulares distribuídas pelo interstício. Destacam-se, ainda, infiltrado inflamatório misto e hialinização subendotelial. A imagem (B) demonstra marcação imuno-histoquímica para FGFb com padrão difuso. A imagem (C) evidencia a presença do fator de crescimento no citoplasma das células endoteliais. [HE (A) e IHQ (B e C). Objetivas 20X (A e B) e $100 \times(C)]$ 
Tabela 14 - Avaliação imuno-histoquímica da expressão de p75 NTR e FGFb nos espécimes de granuloma piogênico cutâneo quanto à intensidade e distribuição. Valores demonstrados em medianas dos escores

\begin{tabular}{|c|c|c|c|c|}
\hline \multicolumn{5}{|c|}{ Granuloma Piogênico Cutâneo } \\
\hline Data de Registro & P75 ${ }^{\text {NTR }}$ - intensidade & P75 NTR - distribuição & FGFb - intensidade & FGFb - distribuição \\
\hline 2002 & 2 & 2 & 0 & 0 \\
\hline 2002 & 2 & 1 & 0 & 0 \\
\hline 2002 & 1 & 1 & 0 & 0 \\
\hline 2002 & 1 & 1 & 0 & 0 \\
\hline 2002 & 3 & 2 & 0 & 0 \\
\hline 2002 & 2 & 1 & 0 & 0 \\
\hline 2001 & 3 & 1 & 0 & 0 \\
\hline 2001 & 2 & 2 & 0 & 0 \\
\hline
\end{tabular}


Tabela 15 - Medianas dos critérios morfológicos analisados nos espécimes de granuloma piogênico cutâneo

\begin{tabular}{c|c|c|c|c|c|c|c|c|}
\hline ESTRUTURA & \multicolumn{1}{c|}{ GRANULOMA PIOCÊNICO CUTÂNEO } \\
\hline $\mathbf{N}=10$ & A & B & C & E & F & G & H \\
\hline
\end{tabular}

Tipo

\begin{tabular}{|c|c|c|c|c|c|c|c|c|c|c|}
\hline \multirow{6}{*}{$\begin{array}{r}\text { Capilar } \\
\text { Vênula } \\
\text { Arteríola } \\
\text { Veia } \\
\text { Artéria } \\
\text { Linfático }\end{array}$} & 3 & 3 & 3 & 3 & 3 & 3 & 3 & 2 & 3 & 3 \\
\hline & 2 & 2 & 2 & 2 & 3 & 2 & 2 & 3 & 2 & 2 \\
\hline & 2 & 2 & 2 & 2 & 2 & 1 & 2 & 2 & 1 & 2 \\
\hline & 0 & 1 & 0 & 1 & 0 & 0 & 0 & 0 & 0 & 0 \\
\hline & 0 & 1 & 0 & 1 & 0 & 0 & 0 & 0 & 0 & 0 \\
\hline & 2 & 1 & 1 & 0 & 0 & 1 & 0 & 0 & 0 & 0 \\
\hline \multicolumn{11}{|l|}{ Arranjo } \\
\hline \multirow{4}{*}{$\begin{array}{r}\text { Lobular } \\
\text { Cordonal } \\
\text { Fasciculado } \\
\text { Aleatório }\end{array}$} & 3 & 3 & 3 & 3 & 2 & 3 & 3 & 0 & 3 & 3 \\
\hline & 2 & 0 & 1 & 0 & 0 & 0 & 2 & 3 & 2 & 0 \\
\hline & 0 & 0 & 0 & 0 & 0 & 0 & 0 & 0 & 0 & 0 \\
\hline & 0 & 1 & 0 & 2 & 3 & 0 & 0 & 0 & 0 & 0 \\
\hline \multicolumn{11}{|l|}{ Localização } \\
\hline \multirow{3}{*}{$\begin{array}{r}\text { Superficial } \\
\text { Média } \\
\text { Profunda }\end{array}$} & 3 & 2 & 3 & 3 & 3 & 3 & 3 & 2 & 3 & 3 \\
\hline & 3 & 3 & 3 & 3 & 3 & 0 & 3 & 3 & 3 & 3 \\
\hline & 0 & 1 & 0 & 0 & 0 & 0 & 0 & 0 & 0 & 0 \\
\hline \multicolumn{11}{|l|}{ Distribuição } \\
\hline \multirow{3}{*}{$\begin{array}{r}\text { Localizada } \\
\text { Multifocal } \\
\text { Disseminada }\end{array}$} & 0 & 0 & 0 & 0 & 0 & 0 & 0 & 0 & 0 & 0 \\
\hline & 3 & 3 & 3 & 2 & 2 & 3 & 3 & 3 & 3 & 3 \\
\hline & 2 & 0 & 1 & 3 & 3 & 0 & 0 & 0 & 0 & 0 \\
\hline \multicolumn{11}{|l|}{ Contornos } \\
\hline \multirow{2}{*}{$\begin{array}{r}\text { Regulares } \\
\text { Irregulares } \\
\end{array}$} & 3 & 3 & 3 & 2 & 2 & 2 & 3 & 2 & 1 & 3 \\
\hline & 1 & 2 & 2 & 3 & 3 & 3 & 2 & 3 & 3 & 2 \\
\hline Dilatação & 3 & 2 & 3 & 2 & 3 & 2 & 3 & 3 & 3 & 2 \\
\hline Congestão & 3 & 2 & 3 & 2 & 2 & 2 & 3 & 3 & 2 & 3 \\
\hline Trombose & 0 & 0 & 0 & 0 & 2 & 0 & 0 & 0 & 0 & 1 \\
\hline
\end{tabular}

Morfologia celular

Epitelióide

Poliédrico

Pleomórfico

Camadas de células

\begin{tabular}{|c|c|c|c|c|c|c|c|c|c|c|}
\hline \multicolumn{11}{|l|}{ Camadas de células } \\
\hline Simples & 3 & 3 & 3 & 3 & 3 & 3 & 3 & 3 & 3 & 3 \\
\hline Múltiplas & 2 & 0 & 1 & 2 & 2 & 1 & 0 & 1 & 0 & 2 \\
\hline \multicolumn{11}{|l|}{ Disposição } \\
\hline \multirow{3}{*}{$\begin{array}{r}\text { Aplainado } \\
\text { Proeminente } \\
\text { Papilar }\end{array}$} & 3 & 3 & 1 & 1 & 3 & 3 & 3 & 3 & 3 & 3 \\
\hline & 2 & 2 & 3 & 3 & 1 & 1 & 1 & 0 & 0 & 2 \\
\hline & 0 & 0 & 0 & 0 & 0 & 0 & 0 & 0 & 0 & 0 \\
\hline \multicolumn{11}{|l|}{ Mitoses } \\
\hline \multirow{2}{*}{$\begin{array}{r}\text { Típicas } \\
\text { Atípicas } \\
\end{array}$} & 2 & 1 & 2 & 1 & 0 & 0 & 0 & 0 & 0 & 2 \\
\hline & 0 & 0 & 0 & 0 & 0 & 0 & 0 & 0 & 0 & 0 \\
\hline $\begin{array}{l}\text { Lumes } \\
\text { intracitoplasmáticos }\end{array}$ & & & & & & & & & & \\
\hline
\end{tabular}

intracitoplasmáticos

TECIDO CONJUNTIVO

\begin{tabular}{l|l|l|l|l|l|l|l|l|l|l}
\hline Exsudação & 2 & 1 & 1 & 3 & 3 & 2 & 3 & 2 & 3 & 3 \\
\hline Hemossiderose & 1 & 1 & 1 & 1 & 1 & 0 & 0 & 1 & 0 & 0 \\
\hline
\end{tabular}

Tipo celular

\begin{tabular}{|c|c|c|c|c|c|c|c|c|c|c|}
\hline \multirow{2}{*}{$\begin{array}{r}\text { Neutrófilos } \\
\text { Eosinófilos }\end{array}$} & 3 & 0 & 1 & 2 & 3 & 2 & 1 & 1 & 3 & 3 \\
\hline & & & & & & & & & & \\
\hline \multirow{3}{*}{$\begin{array}{r}\text { Linfócitos } \\
\text { Plasmócitos } \\
\text { Macrófagos }\end{array}$} & 2 & 2 & 2 & 1 & 2 & 2 & 2 & 3 & 2 & 2 \\
\hline & & & & & & & & & & \\
\hline & & & & & & & & & & \\
\hline \multicolumn{11}{|l|}{ Intensidade } \\
\hline \multirow{3}{*}{$\begin{array}{r}\text { Discreto } \\
\text { Moderado } \\
\text { Intenso }\end{array}$} & 0 & 3 & 3 & 3 & 0 & 0 & 0 & 0 & 0 & 0 \\
\hline & 0 & 0 & 0 & 0 & 0 & 3 & 3 & 3 & 3 & 3 \\
\hline & 3 & 0 & 0 & 0 & 3 & 0 & 0 & 0 & 0 & 2 \\
\hline
\end{tabular}

\begin{tabular}{l|l|l|l|l|l|l|l|l|l|l}
\hline Hiperplásico & 0 & 3 & 3 & 2 & 2 & 2 & 2 & 3 & 1 & 0 \\
\hline Atrófico & 1 & 0 & 0 & 0 & 0 & 0 & 2 & 0 & 0 & 0 \\
\hline Ulcerado & 3 & 0 & 2 & 2 & 2 & 0 & 0 & 1 & 3 & 3 \\
\hline
\end{tabular}

Escores: 0 = ausente; 1 = escasso; 2 = moderado; 3 = freqüente. 


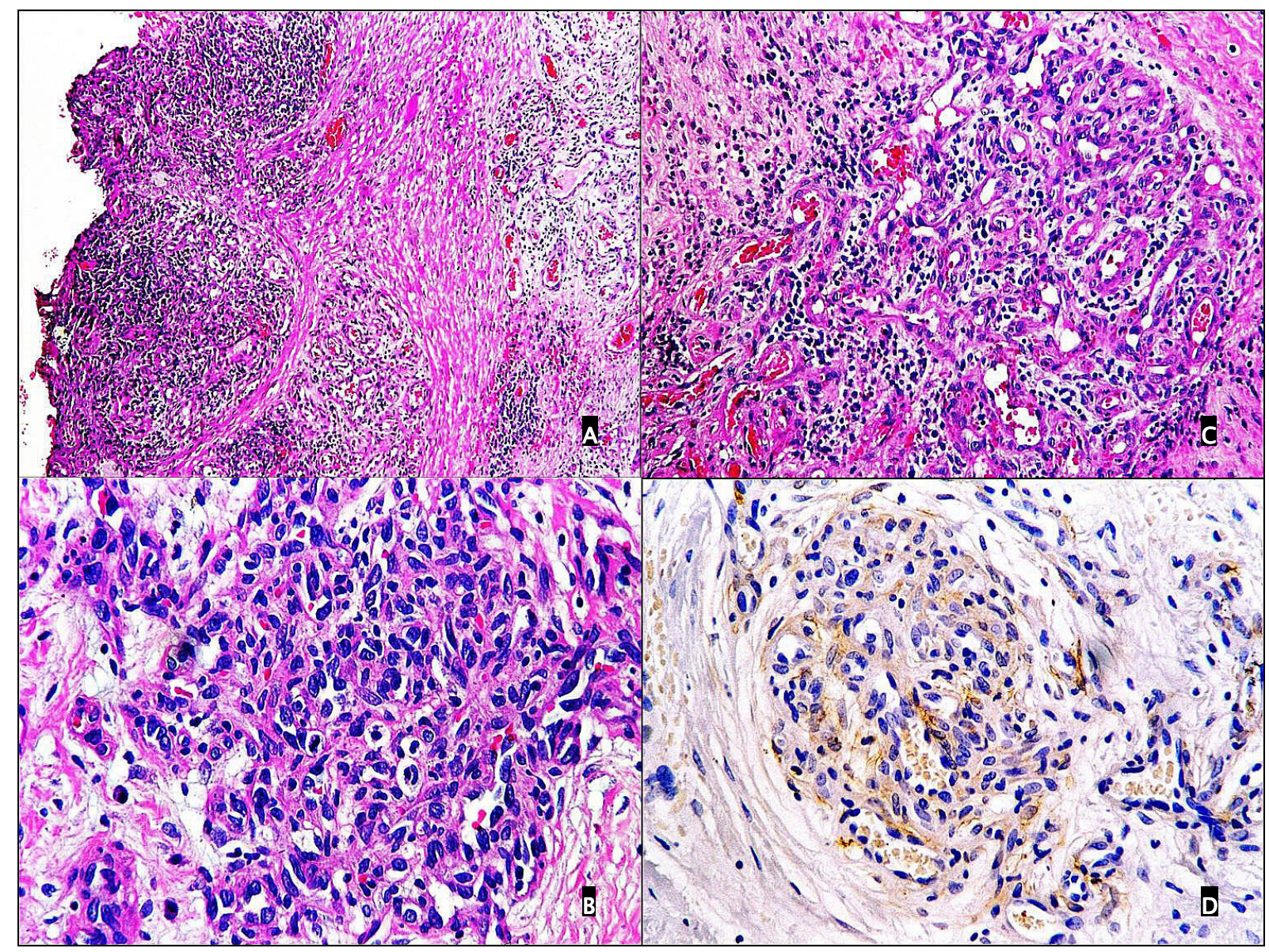

Figura 10 - Granuloma piogênico cutâneo. O aumento panorâmico (A) demonstra superfície ulcerada com proliferação capilar subjacente acompanhada por intenso infiltrado inflamatório, bem como densos feixes colagênicos na derme reticular sobrepondo área de proliferação vascular lobular. Logo abaixo à área ulcerada, a imagem (B) ilustra pequenos vasos com lumes discretos e contornos irregulares que se confundem por entre as células inflamatórias. A imagem (C) representa um segmento da derme reticular no qual nota-se certa uniformidade nos contornos externos dos elementos vasculares envolvidos na lesão, apresentando áreas de congestão e espessamento nas paredes endoteliais por entre intenso infiltrado inflamatório mononuclear. A imagem (D) apresenta um lóbulo vascular evidenciando o receptor p75 em localização predominantemente subendotelial. [HE (A, B e C) e IHQ (D). Objetivas 10X (A), 20X (C e D) e 40X (B)] 


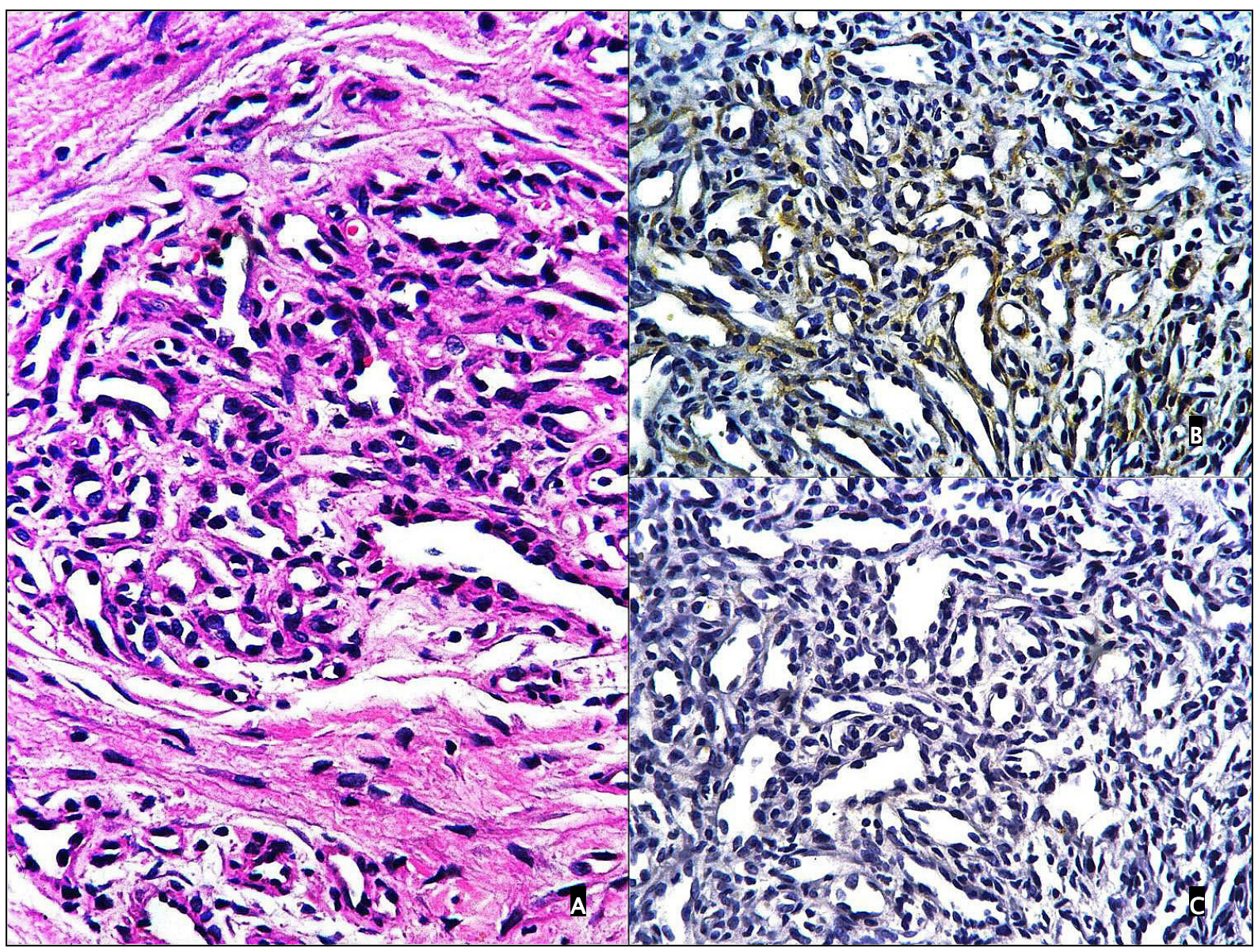

Figura 11 - Granuloma piogênico cutâneo. As fotomicrografias acima ilustram uma área vascular lobular corada por $\mathrm{HE}$, na imagem (A) e o endotélio do mesmo espécime marcado pelo anticorpo anti-p75 ${ }^{\mathrm{NTR}}$, em (B). A imagem (C) apresenta um corte microscópico subseqüente negativo para o anticorpo anti-FGFb. [HE (A) e IHQ (B e C). Objetivas 20X (B e C) e 40X (A)] 


\subsection{4 - HEMANGIOMA CAPILAR}

Os espécimes de hemangiomas capilares bucais apresentaram-se com células endoteliais hiperplásicas formando capilares e vênulas dispostas difusamente pelo interstício, com discreto infiltrado inflamatório mononuclear. A maioria dos hemangiomas capilares cutâneos, demonstrou padrão simétrico e arranjo lobular, com vasos regulares e septos de tecido conjuntivo entrepostos. $\mathrm{Na}$ análise imunohistoquímica dos hemangiomas capilares, houve expressão focal de FGFb e p75 NTR nas lesões bucais (Figura 12 e 13). As lesões cutâneas foram positivas somente para p75 NTR (Figura 14 e 15), onde a distribuição do sinal imuno-histoquímico foi multifocal.

Tabela 16 - Avaliação imuno-histoquímica da expressão de p75 NTR e FGFb nos espécimes de hemangioma capilar bucal quanto à intensidade e distribuição. Valores demonstrados em medianas dos escores

\begin{tabular}{l|l|l|l|l}
\hline \multicolumn{5}{c}{ Hemangioma Capilar Bucal } \\
\hline Data de Registro & P75 NTR - intensidade & P75 NTR - distribuição & FGFb - intensidade & FGFb - distribuição \\
\hline 2001 & 2 & 3 & 0 & 0 \\
\hline 2001 & 0 & 0 & 2 & 3 \\
\hline 2000 & 0 & 0 & 0 & 0 \\
\hline 1999 & 2 & 2 & 1 & 2 \\
\hline 1999 & 0 & 0 & 0 & 0 \\
\hline 1999 & 0 & 0 & 1 & 1 \\
\hline 1993 & 0 & 0 & 3 & 2 \\
\hline
\end{tabular}


Tabela 17 - Medianas dos critérios morfológicos analisados nos espécimes de hemangioma capilar bucal

\begin{tabular}{|c|c|c|c|c|c|c|c|c|c|c|}
\hline ESTRUTURA & \multicolumn{10}{|c|}{ HEMANGIOMA CAPILAR BUCAL } \\
\hline $\mathrm{N}=10$ & A & B & $C$ & $\mathrm{E}$ & $\mathbf{F}$ & $G$ & $\mathrm{H}$ & 1 & $\mathrm{~J}$ & $\mathrm{~K}$ \\
\hline \multirow{2}{*}{\multicolumn{11}{|c|}{ Tipo }} \\
\hline & & & & & & & & & & \\
\hline \multirow{6}{*}{$\begin{array}{r}\text { Capilar } \\
\text { Vênula } \\
\text { Arteríola } \\
\text { Veia } \\
\text { Artéria } \\
\text { Linfático }\end{array}$} & 3 & 3 & 3 & 3 & 3 & 1 & 1 & 3 & 3 & 1 \\
\hline & 2 & 2 & 2 & 3 & 1 & 3 & 3 & 2 & 2 & 3 \\
\hline & 0 & 1 & 1 & 1 & 2 & 3 & 3 & 0 & 0 & 3 \\
\hline & 0 & 0 & 0 & 0 & 0 & 2 & 0 & 0 & 0 & 0 \\
\hline & 0 & 0 & 0 & 0 & 0 & 0 & 0 & 0 & 0 & 0 \\
\hline & 0 & 0 & 0 & 0 & 0 & 0 & 0 & 2 & 0 & 0 \\
\hline \multicolumn{11}{|l|}{ Arranjo } \\
\hline \multirow{4}{*}{$\begin{array}{r}\text { Lobular } \\
\text { Cordonal } \\
\text { Fasciculado } \\
\text { Aleatório }\end{array}$} & 3 & 2 & 3 & 3 & 3 & 0 & 0 & 3 & 3 & 0 \\
\hline & 0 & 0 & 0 & 0 & 0 & 3 & 0 & 0 & 0 & 3 \\
\hline & 0 & 0 & 0 & 0 & 0 & 0 & 0 & 0 & 0 & 0 \\
\hline & 0 & 3 & 0 & 0 & 0 & 0 & 3 & 0 & 0 & 0 \\
\hline \multicolumn{11}{|l|}{ Localização } \\
\hline \multirow{3}{*}{$\begin{array}{r}\text { Superficial } \\
\text { Média } \\
\text { Profunda }\end{array}$} & 3 & 3 & 3 & 3 & 0 & 3 & 0 & 3 & 3 & 3 \\
\hline & 3 & 3 & 3 & 3 & 3 & 3 & 3 & 0 & 3 & 0 \\
\hline & 2 & 2 & 2 & 0 & 0 & 0 & 0 & 0 & 0 & 0 \\
\hline \multicolumn{11}{|l|}{ Distribuição } \\
\hline & 3 & 0 & 0 & 0 & 3 & 0 & 0 & 3 & 0 & 3 \\
\hline \multirow{2}{*}{$\begin{array}{r}\text { Multifocal } \\
\text { Disseminada }\end{array}$} & 0 & 3 & 3 & 3 & 0 & 3 & 3 & 0 & 3 & 0 \\
\hline & 0 & 0 & 0 & 0 & 0 & 0 & 0 & 0 & 0 & 0 \\
\hline \multicolumn{11}{|l|}{ Contornos } \\
\hline \multirow{2}{*}{$\begin{array}{r}\text { Regulares } \\
\text { Irregulares }\end{array}$} & 2 & 1 & 1 & 1 & 1 & 2 & 2 & 2 & 0 & 0 \\
\hline & 3 & 3 & 3 & 3 & 3 & 3 & 3 & 3 & 3 & 3 \\
\hline Dilatação & 2 & 2 & 3 & 3 & 2 & 3 & 3 & 2 & 2 & 3 \\
\hline Congestão & 2 & 2 & 2 & 2 & 1 & 3 & 1 & 2 & 1 & 0 \\
\hline Trombose & 0 & 0 & 0 & 0 & 0 & 3 & 0 & 0 & 0 & 0 \\
\hline \multirow{2}{*}{\multicolumn{11}{|c|}{ Morfologia celular }} \\
\hline & & & & & & & & & & \\
\hline \multirow{4}{*}{$\begin{array}{r}\text { Epitelióide } \\
\text { Fusiforme } \\
\text { Poliédrico } \\
\text { Pleomórfico } \\
\end{array}$} & 3 & 3 & 3 & 3 & 3 & 3 & 0 & 3 & 3 & 0 \\
\hline & 1 & 0 & 2 & 1 & 2 & 3 & 3 & 2 & 0 & 3 \\
\hline & 2 & 2 & 1 & 2 & 0 & 0 & 0 & 2 & 2 & 0 \\
\hline & 1 & 1 & 1 & 1 & 2 & 0 & 0 & 0 & 1 & 0 \\
\hline \multicolumn{11}{|l|}{ Camadas de células } \\
\hline \multirow{2}{*}{$\begin{array}{r}\text { Simples } \\
\text { Múltiplas }\end{array}$} & 3 & 3 & 3 & 3 & 3 & 3 & 3 & 3 & 3 & 3 \\
\hline & 1 & 0 & 0 & 0 & 0 & 2 & 0 & 0 & 1 & 0 \\
\hline \multicolumn{11}{|l|}{ Disposição } \\
\hline \multirow{3}{*}{$\begin{array}{r}\text { Aplainado } \\
\text { Proeminente } \\
\text { Papilar }\end{array}$} & 3 & 3 & 3 & 2 & 1 & 3 & 3 & 3 & 3 & 3 \\
\hline & 2 & 1 & 2 & 3 & 3 & 0 & 0 & 2 & 0 & 0 \\
\hline & 0 & 0 & 0 & 1 & 0 & 0 & 0 & 0 & 0 & 0 \\
\hline \multicolumn{11}{|l|}{ Mitoses } \\
\hline Típicas & 0 & 2 & 1 & 2 & 1 & 0 & 0 & 0 & 3 & 0 \\
\hline Atípicas & 0 & 0 & 0 & 0 & 0 & 0 & 0 & 0 & 0 & 0 \\
\hline $\begin{array}{l}\text { Lumes } \\
\text { intracitoplasmáticos }\end{array}$ & 0 & 2 & 0 & 2 & 2 & 0 & 0 & 1 & 2 & 0 \\
\hline
\end{tabular}

\begin{tabular}{ll|l|l} 
& TECIDO CONJUNTIVO \\
\hline
\end{tabular}

\begin{tabular}{l|l|l|l|l|l|l|l|l|l|c}
\hline Exsudação & 0 & 2 & 0 & 0 & 0 & 0 & 0 & 0 & 1 & 0 \\
\hline Hemossiderose & 0 & 1 & 2 & 1 & 0 & 2 & 0 & 0 & 1 & 0 \\
\hline
\end{tabular}

Tipo celular

\begin{tabular}{|c|c|c|c|c|c|c|c|c|c|c|}
\hline Neutrófilos & 0 & 0 & 0 & 1 & 0 & 0 & 0 & 0 & 0 & 0 \\
\hline & & & & & & & & & & \\
\hline \multirow{2}{*}{\multicolumn{11}{|c|}{$\begin{array}{r}\text { Linfócitos } \\
\text { Plasmócitos }\end{array}$}} \\
\hline & & & & & & & & & & \\
\hline Macrófagos & & & & & & & & & & \\
\hline \multicolumn{11}{|l|}{ Intensidade } \\
\hline \multirow{3}{*}{$\begin{array}{r}\text { Discreto } \\
\text { Moderado } \\
\text { Intenso }\end{array}$} & 3 & 3 & 0 & 3 & 0 & 0 & 0 & 3 & 0 & 0 \\
\hline & 0 & 0 & 0 & 0 & 3 & 0 & 0 & 0 & 0 & 0 \\
\hline & 0 & 0 & 0 & 0 & 0 & 0 & 0 & 0 & 0 & 0 \\
\hline
\end{tabular}

\begin{tabular}{l|l|l|l|l|l|l|l|l|l|l|l}
\hline \multicolumn{1}{c|}{ EPITÉLIO } \\
\hline Hiperplásico & 2 & 3 & 0 & 3 & 3 & 3 & 3 & 3 & 3 & 3 \\
\hline Atrófico & 2 & 2 & 0 & 2 & 0 & 0 & 0 & 0 & 2 & 0 \\
\hline Ulcerado & 0 & 1 & 0 & 0 & 0 & 0 & 0 & 0 & 1 & 0 \\
\hline
\end{tabular}

Escores: 0 = ausente; 1 = escasso; 2 = moderado; 3 = freqüente. 


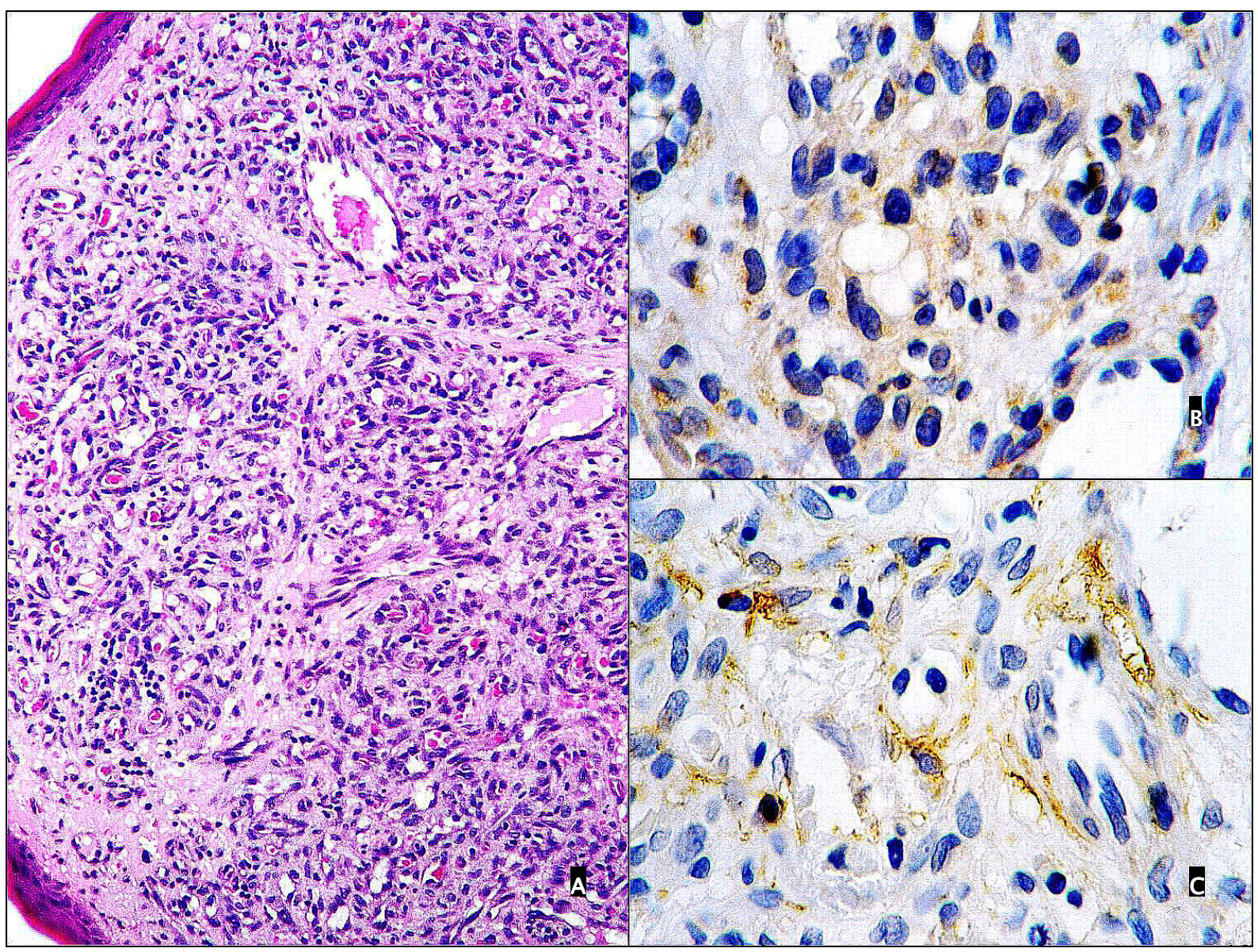

Figura 12 - O hemangioma capilar bucal ilustrado em HE na imagem (A) está caracterizado pela proliferação difusa de células endoteliais com núcleos arredondados e lumes inconspícuos, bem como pequenos vasos congestos permeando a lâmina própria e a submucosa. Em (B) e (C), os marcadores imunohistoquímicos para FGFb e p75, respectivamente, evidenciam o endotélio de capilares e vênulas. [HE (A) e IHQ (B e C). Objetivas 20X (A) e 100X (B e C)] 


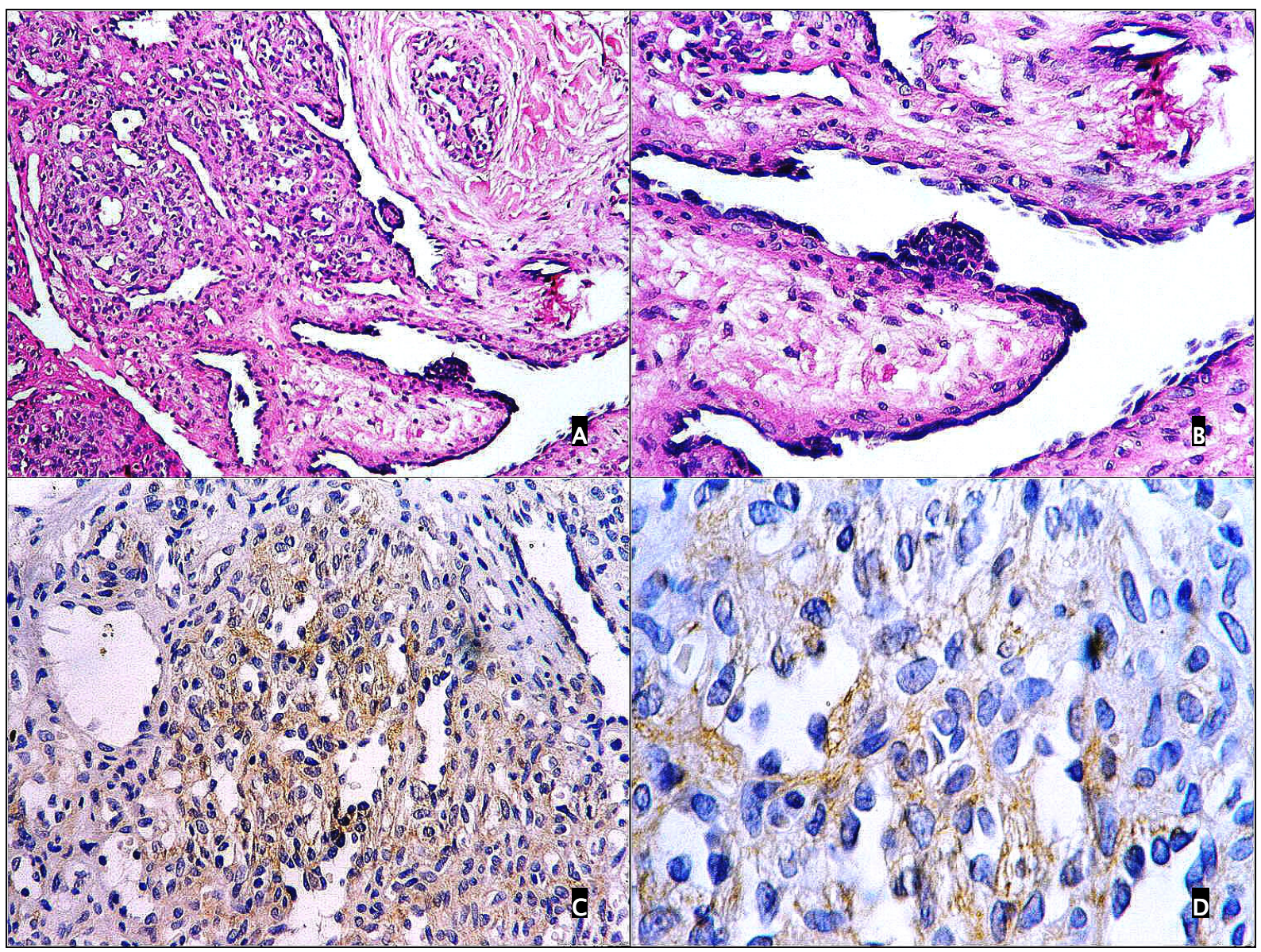

Figura 13 - Hemangioma capilar bucal. Os cortes microscópicos ressaltam, em (A), proliferação de células endoteliais sobre estroma hialinizado, em meio a espaços vasculares maiores. Em (B) notam-se vasos de contornos irregulares, um dos quais demonstrando projeção intraluminal papilífera e pericitos ao redor. As imagens (C) e (D) apresentam expressão focal do mediador p75 ${ }^{\mathrm{NTR}}$. [HE (A e B) e IHQ (C e D). Objetivas 20X (A e C), 40X (B) e 100X (D)] 
Tabela 18 - Avaliação imuno-histoquímica da expressão de p75 NTR e FGFb nos espécimes de hemangioma capilar cutâneo quanto à intensidade e distribuição. Valores demonstrados em medianas dos escores

Hemangioma Capilar Cutâneo

\begin{tabular}{|c|c|c|c|c|}
\hline Data de Registro & P75 NTR - intensidade & P75 NTR - distribuição & FGFb - introdução & FGFb - distribuição \\
\hline 2002 & 1 & 1 & 0 & 0 \\
\hline 2002 & 0 & 0 & 0 & 0 \\
\hline 2002 & 1 & 2 & 0 & 0 \\
\hline 2001 & 1 & 1 & 0 & 0 \\
\hline 2001 & 2 & 1 & 0 & 0 \\
\hline 2001 & 0 & 0 & 0 & 0 \\
\hline 2001 & 2 & 2 & 0 & 0 \\
\hline 2001 & 1 & 1 & 0 & 0 \\
\hline 2000 & 0 & 0 & 0 & 0 \\
\hline
\end{tabular}


Tabela 19 - Medianas dos critérios morfológicos analisados nos espécimes de hemangioma capilar cutâneo

\begin{tabular}{|c|c|c|c|c|c|c|c|c|c|c|}
\hline ESTRUTURA & \multicolumn{10}{|c|}{ HEMANGIOMA CAPILAR CUTÃNEO } \\
\hline $\mathrm{N}=10$ & A & B & $\mathrm{C}$ & $\mathrm{E}$ & $F$ & G & $\mathrm{H}$ & 1 & $\mathrm{~J}$ & $\mathrm{~K}$ \\
\hline \multicolumn{10}{|l|}{ Tipo } & VASOS \\
\hline \multirow{6}{*}{$\begin{array}{r}\text { Capilar } \\
\text { Vênula } \\
\text { Arteríola } \\
\text { Veia } \\
\text { Artéria } \\
\text { Linfático }\end{array}$} & 2 & 2 & 2 & 1 & 1 & 2 & 3 & 3 & 1 & 3 \\
\hline & 3 & 3 & 3 & 3 & 3 & 3 & 2 & 2 & 3 & 2 \\
\hline & 1 & 2 & 2 & 2 & 1 & 1 & 1 & 1 & 1 & 0 \\
\hline & 0 & 0 & 0 & 0 & 0 & 0 & 0 & 0 & 0 & 0 \\
\hline & 0 & 0 & 0 & 0 & 0 & 0 & 0 & 0 & 0 & 0 \\
\hline & 0 & 0 & 0 & 0 & 0 & 0 & 0 & 0 & 0 & 0 \\
\hline \multicolumn{11}{|l|}{ Arranjo } \\
\hline \multirow{4}{*}{$\begin{array}{r}\text { Lobular } \\
\text { Cordonal } \\
\text { Fasciculado } \\
\text { Aleatório }\end{array}$} & 3 & 3 & 0 & 3 & 3 & 2 & 3 & 2 & 0 & 0 \\
\hline & 0 & 0 & 0 & 0 & 0 & 2 & 0 & 2 & 0 & 0 \\
\hline & 0 & 0 & 0 & 0 & 0 & 0 & 0 & 0 & 0 & 0 \\
\hline & 0 & 0 & 3 & 0 & 0 & 0 & 0 & 0 & 3 & 3 \\
\hline \multicolumn{11}{|l|}{ Localização } \\
\hline \multirow{3}{*}{$\begin{array}{r}\text { Superficial } \\
\text { Média } \\
\text { Profunda } \\
\end{array}$} & 3 & 3 & 3 & 3 & 3 & 3 & 3 & 3 & 3 & 3 \\
\hline & 3 & 0 & 2 & 0 & 2 & 0 & 0 & 0 & 0 & 3 \\
\hline & 0 & 0 & 0 & 0 & 0 & 0 & 0 & 0 & 0 & 0 \\
\hline \multicolumn{11}{|l|}{ Distribuição } \\
\hline \multirow{3}{*}{$\begin{array}{r}\text { Localizada } \\
\text { Multifocal } \\
\text { Disseminada } \\
\end{array}$} & 0 & 3 & 3 & 0 & 3 & 0 & 3 & 0 & 3 & 0 \\
\hline & 3 & 0 & 0 & 3 & 0 & 3 & 0 & 3 & 0 & 0 \\
\hline & 0 & 0 & 0 & 0 & 0 & 0 & 0 & 0 & 0 & 3 \\
\hline \multicolumn{11}{|l|}{ Contornos } \\
\hline \multirow{2}{*}{$\begin{array}{r}\text { Regulares } \\
\text { Irregulares } \\
\end{array}$} & 3 & 3 & 2 & 2 & 0 & 2 & 2 & 2 & 1 & 3 \\
\hline & 2 & 2 & 3 & 3 & 3 & 3 & 2 & 2 & 3 & 1 \\
\hline Dilatação & 3 & 3 & 3 & 3 & 3 & 3 & 3 & 3 & 3 & 2 \\
\hline Congestão & 3 & 3 & 3 & 2 & 1 & 1 & 3 & 3 & 3 & 0 \\
\hline Trombose & 0 & 0 & 0 & 0 & 0 & 0 & 0 & 0 & 1 & 0 \\
\hline \multicolumn{11}{|l|}{ Morfologia celular } \\
\hline \multirow{4}{*}{$\begin{array}{r}\text { Epitelióide } \\
\text { Fusiforme } \\
\text { Poliédrico } \\
\text { Pleomórfico }\end{array}$} & 1 & 2 & 0 & 0 & 0 & 0 & 1 & 1 & 0 & 3 \\
\hline & 3 & 3 & 3 & 3 & 3 & 3 & 3 & 2 & 3 & 1 \\
\hline & 2 & 1 & 2 & 2 & 1 & 1 & 2 & 2 & 3 & 2 \\
\hline & 0 & 0 & 0 & 0 & 0 & 0 & 0 & 0 & 0 & 2 \\
\hline \multicolumn{11}{|l|}{ Camadas de células } \\
\hline \multirow{2}{*}{$\begin{array}{r}\text { Simples } \\
\text { Múltiplas }\end{array}$} & 3 & 3 & 3 & 3 & 3 & 3 & 3 & 3 & 3 & 3 \\
\hline & 0 & 0 & 0 & 0 & 0 & 0 & 0 & 0 & 0 & 0 \\
\hline \multicolumn{11}{|l|}{ Disposição } \\
\hline \multirow{3}{*}{$\begin{array}{r}\text { Aplainado } \\
\text { Proeminente } \\
\text { Papilar }\end{array}$} & 3 & 3 & 3 & 3 & 3 & 3 & 3 & 3 & 3 & 3 \\
\hline & 1 & 1 & 0 & 0 & 0 & 0 & 0 & 0 & 0 & 3 \\
\hline & 0 & 0 & 0 & 0 & 0 & 0 & 0 & 0 & 0 & 0 \\
\hline \multicolumn{11}{|l|}{ Mitoses } \\
\hline \multirow{2}{*}{$\begin{array}{r}\text { Típicas } \\
\text { Atípicas } \\
\end{array}$} & 0 & 0 & 0 & 0 & 0 & 0 & 0 & 0 & 0 & 1 \\
\hline & 0 & 0 & 0 & 0 & 0 & 0 & 0 & 0 & 0 & 0 \\
\hline $\begin{array}{l}\text { Lumes } \\
\text { intracitoplasmáticos }\end{array}$ & 0 & 0 & 0 & 0 & 0 & 0 & 0 & 0 & 0 & 0 \\
\hline
\end{tabular}

TECIDO CONJUNTIVO

\begin{tabular}{l|l|l|l|l|l|l|l|l|l|l}
\hline Exsudação & 1 & 1 & 1 & 1 & 0 & 0 & 0 & 0 & 1 & 0 \\
\hline Hemossiderose & 0 & 0 & 0 & 0 & 0 & 0 & 0 & 0 & 0 & 0 \\
\hline
\end{tabular}

Tipo celular

\begin{tabular}{|c|c|c|c|c|c|c|c|c|c|c|}
\hline \multirow{2}{*}{$\begin{array}{l}\text { Neutrófilos } \\
\text { Eosinófilos }\end{array}$} & 0 & 0 & 0 & 0 & 0 & 0 & 0 & 0 & 0 & 0 \\
\hline & & & & & & & & & & \\
\hline & 0 & 0 & 3 & 3 & 3 & 0 & 0 & 0 & 0 & 0 \\
\hline \multirow{2}{*}{$\begin{array}{l}\text { Plasmócitos } \\
\text { Macrófagos }\end{array}$} & & & & & & & & & 3 & \\
\hline & & & & & & & & & & \\
\hline \multicolumn{11}{|l|}{ Intensidade } \\
\hline \multirow{3}{*}{$\begin{array}{r}\text { Discreto } \\
\text { Moderado } \\
\text { Intenso }\end{array}$} & 0 & 0 & 3 & 3 & 3 & 0 & 0 & 0 & 3 & 0 \\
\hline & 0 & 0 & 0 & 0 & 0 & 0 & 0 & 0 & 0 & 0 \\
\hline & 0 & 0 & 0 & 0 & 0 & 0 & 0 & 0 & 0 & 0 \\
\hline
\end{tabular}

\begin{tabular}{l|l|l|l|l|l|l|l|l|l|c|c}
\hline Hiperplásico & 0 & 2 & 0 & 2 & 0 & 0 & 0 & 0 & 0 & 1 \\
\hline Atrófico & 0 & 0 & 0 & 0 & 0 & 0 & 0 & 0 & 2 & 0 \\
\hline Ulcerado & 0 & 0 & 0 & 0 & 0 & 0 & 0 & 0 & 0 & 0 \\
\hline
\end{tabular}

Escores: 0 = ausente; 1 = escasso; 2 = moderado; 3 = freqüente. 


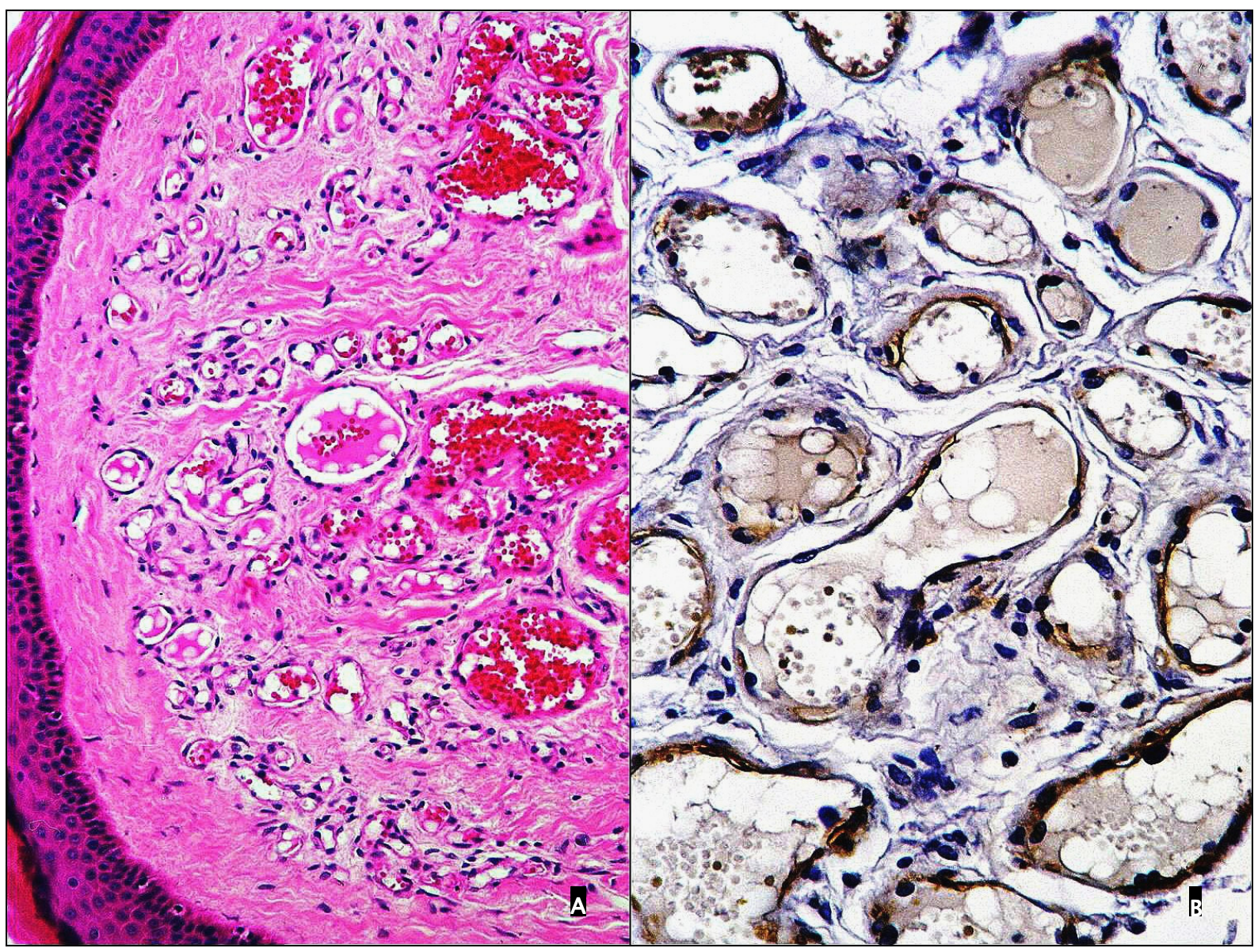

Figura 14 - Hemangioma capilar cutâneo. A fotomicrografia (A) revela inúmeras vênulas e capilares revestidos por células endoteliais arredondadas. Destacam-se, congestão vascular, densa colagenização entremeando os vasos e o cório cutâneo livre da lesão. A análise imuno-histoquímica para o receptor $\mathrm{p} 75^{\mathrm{NTR}}$ evidencia áreas positivas ao longo do endotélio de praticamente todos os vasos do corte microscópico, observado na imagem (B). [HE (A) e IHQ (B). Objetivas 20X (A) e $40 X(B)]$ 


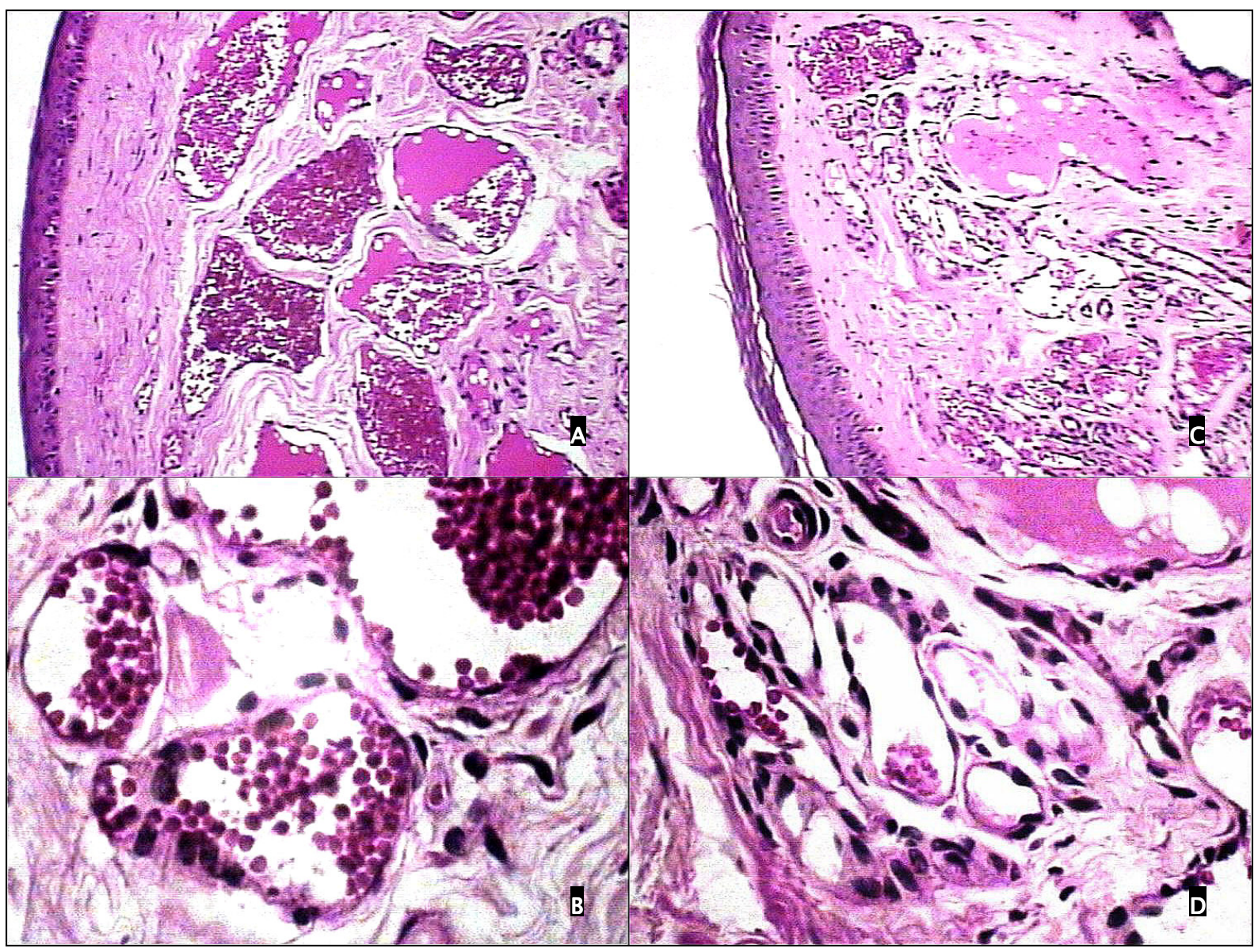

Figura 15 - Hemangioma capilar cutâneo com aspecto regressivo. Os cortes microscópicos corados por HE demonstram dois espécimes semelhantes, ambos com vasos dilatados e congestos em meio a um estroma parcialmente hialinizado. Os aspectos descritos assemelham-se, em algumas instâncias, àqueles observados nas malformações venosas. [HE (A, B, C e D). Objetivas 20X (A e C) e 100X (B e D)] 


\subsection{5 - HEMANGIOMA ARTERIOVENOSO}

Os hemangiomas arteriovenosos da amostra apresentaram-se como lesões não ulceradas sem caráter infiltrativo, dispostas aleatoriamente na submucosa ou na derme reticular. Os elementos vasculares incluíram capilares, vênulas e arteríolas com camadas simples de células endoteliais. $O$ espessamento da parede vascular foi uma característica comum a todos os hemangiomas arteriovenosos estudados, embora houvesse alguns vasos com paredes delgadas entremeando os mais calibrosos. Nos planos profundos de alguns cortes microscópicos foi possível notar grandes segmentos vasculonervosos. Na avaliação imuno-histoquímica, as lesões bucais exibiram marcação nuclear e focal para FGFb, não havendo positividade para p75NTR (Figura 16). As lesões cutâneas apresentaram reatividade focal para p75 NTR na superfície de alguns vasos diminutos na periferia de vênulas maiores (Figura 17). Os espécimes cutâneos da amostra não expressaram FGFb.

Tabela 20 - Avaliação imuno-histoquímica da expressão de p75NTR e FGFb nos espécimes de hemangioma arteriovenoso bucal quanto à intensidade e distribuição. Valores demonstrados em medianas dos escores

\begin{tabular}{l|l|l|l|l}
\hline \multicolumn{5}{c}{ Hemangioma Arteriovenoso Bucal } \\
\hline Data de Registro & P75 NTR - intensidade & P75 NTR - distribuição & FGFb - intensidade & FGFb - distribuição \\
\hline 2002 & 0 & 0 & 1 & 2 \\
\hline 2001 & 2 & 1 & 1 & 1 \\
\hline 2001 & 0 & 0 & 1 & 1 \\
\hline 2000 & 0 & 0 & 1 & 1 \\
\hline 2000 & 0 & 0 & 1 & 2 \\
\hline 2000 & 0 & 0 & 0 & 0 \\
\hline 1998 & 0 & 0 & 0 & 0 \\
\hline 1997 & 0 & 0 & 3 & 1 \\
\hline
\end{tabular}


Tabela 21 - Medianas dos critérios morfológicos analisados nos espécimes de hemangioma arteriovenoso bucal

\begin{tabular}{|c|c|c|c|c|c|c|c|c|c|c|}
\hline \multirow{2}{*}{$\begin{array}{c}\text { ESTRUTURA } \\
\mathrm{N}=10 \\
\end{array}$} & \multicolumn{10}{|c|}{ HEMANGIOMA ARTERIOVENOSO BUCAL } \\
\hline & A & B & $\mathrm{C}$ & $E$ & $\mathrm{~F}$ & $\mathrm{G}$ & $\mathrm{H}$ & $\mathrm{I}$ & $\mathrm{J}$ & $\mathrm{K}$ \\
\hline \multicolumn{11}{|l|}{ Tipo } \\
\hline \multirow{6}{*}{$\begin{array}{r}\text { Capilar } \\
\text { Vênula } \\
\text { Arteríola } \\
\text { Veia } \\
\text { Artéria } \\
\text { Linfático }\end{array}$} & 2 & 3 & 2 & 3 & 2 & 2 & 3 & 1 & 1 & 2 \\
\hline & 3 & 3 & 3 & 3 & 3 & 3 & 3 & 3 & 2 & 3 \\
\hline & 0 & 2 & 1 & 2 & 3 & 3 & 0 & 2 & 1 & 3 \\
\hline & 0 & 0 & 0 & 0 & 0 & 0 & 0 & 0 & 0 & 2 \\
\hline & 0 & 0 & 0 & 0 & 0 & 0 & 0 & 0 & 0 & 0 \\
\hline & 0 & 0 & 0 & 0 & 0 & 0 & 0 & 0 & 2 & 0 \\
\hline \multicolumn{11}{|l|}{ Arranjo } \\
\hline \multirow{4}{*}{$\begin{array}{r}\text { Lobular } \\
\text { Cordonal } \\
\text { Fasciculado } \\
\text { Aleatório }\end{array}$} & 0 & 0 & 0 & 0 & 0 & 0 & 3 & 0 & 0 & 0 \\
\hline & 0 & 0 & 3 & 0 & 3 & 0 & 0 & 0 & 0 & 0 \\
\hline & 0 & 0 & 0 & 0 & 0 & 0 & 0 & 0 & 0 & 0 \\
\hline & 3 & 3 & 0 & 3 & 0 & 3 & 0 & 3 & 3 & 3 \\
\hline \multicolumn{11}{|l|}{ Localização } \\
\hline \multirow{3}{*}{$\begin{array}{r}\text { Superficial } \\
\text { Média } \\
\text { Profunda }\end{array}$} & 3 & 2 & 0 & 3 & 3 & 3 & 1 & 0 & 3 & 0 \\
\hline & 0 & 3 & 3 & 3 & 3 & 0 & 3 & 3 & 0 & 3 \\
\hline & 0 & 0 & 0 & 0 & 0 & 3 & 2 & 0 & 0 & 2 \\
\hline \multicolumn{11}{|l|}{ Distribuição } \\
\hline \multirow{3}{*}{$\begin{array}{r}\text { Localizada } \\
\text { Multifocal } \\
\text { Disseminada }\end{array}$} & 0 & 3 & 3 & 0 & 0 & 0 & 0 & 0 & 3 & 0 \\
\hline & 3 & 0 & 0 & 3 & 3 & 3 & 3 & 3 & 0 & 3 \\
\hline & 0 & 0 & 0 & 0 & 0 & 0 & 0 & 0 & 0 & 0 \\
\hline \multicolumn{11}{|l|}{ Contornos } \\
\hline \multirow{2}{*}{$\begin{array}{r}\text { Regulares } \\
\text { Irregulares }\end{array}$} & 0 & 2 & 0 & 0 & 2 & 2 & 1 & 0 & 0 & 2 \\
\hline & 3 & 2 & 3 & 3 & 3 & 2 & 3 & 3 & 3 & 2 \\
\hline Dilatação & 2 & 2 & 2 & 3 & 2 & 3 & 3 & 2 & 3 & 2 \\
\hline Congestão & 2 & 2 & 2 & 2 & 2 & 3 & 3 & 2 & 3 & 0 \\
\hline Trombose & 0 & 3 & 0 & 0 & 0 & 0 & 0 & 0 & 0 & 0 \\
\hline \multicolumn{11}{|l|}{ Morfologia celular } \\
\hline \multirow{4}{*}{$\begin{array}{r}\text { Epitelióide } \\
\text { Fusiforme } \\
\text { Poliédrico } \\
\text { Pleomórfico }\end{array}$} & 0 & 3 & 2 & 0 & 0 & 2 & 2 & 0 & 1 & 0 \\
\hline & 3 & 2 & 2 & 3 & 2 & 3 & 1 & 3 & 3 & 0 \\
\hline & 2 & 2 & 1 & 0 & 2 & 2 & 3 & 1 & 0 & 3 \\
\hline & 0 & 0 & 0 & 0 & 0 & 0 & 0 & 0 & 0 & 0 \\
\hline \multicolumn{11}{|l|}{ Camadas de células } \\
\hline \multirow{2}{*}{$\begin{array}{r}\text { Simples } \\
\text { Múltiplas }\end{array}$} & 3 & 3 & 3 & 3 & 2 & 3 & 1 & 3 & 3 & 2 \\
\hline & 0 & 2 & 0 & 0 & 2 & 2 & 3 & 0 & 0 & 2 \\
\hline \multicolumn{11}{|l|}{ Disposição } \\
\hline \multirow{3}{*}{$\begin{array}{r}\text { Aplainado } \\
\text { Proeminente } \\
\text { Papilar }\end{array}$} & 3 & 3 & 3 & 3 & 3 & 3 & 1 & 3 & 3 & 3 \\
\hline & 0 & 3 & 0 & 0 & 0 & 0 & 3 & 0 & 1 & 0 \\
\hline & 0 & 2 & 0 & 0 & 0 & 0 & 3 & 0 & 0 & 0 \\
\hline \multicolumn{11}{|l|}{ Mitoses } \\
\hline \multirow{2}{*}{$\begin{array}{r}\text { Típicas } \\
\text { Atípicas }\end{array}$} & 0 & 0 & 2 & 0 & 0 & 0 & 1 & 0 & 0 & 0 \\
\hline & 0 & 0 & 0 & 0 & 0 & 0 & 0 & 0 & 0 & 0 \\
\hline $\begin{array}{l}\text { Lumes } \\
\text { intracitoplasmáticos }\end{array}$ & 0 & 2 & 0 & 0 & 0 & 2 & 1 & 0 & 0 & 0 \\
\hline
\end{tabular}

\begin{tabular}{ll}
\hline & TECIDO CONJUNTIVO \\
\hline
\end{tabular}

\begin{tabular}{l|l|l|l|l|l|l|l|l|l|c}
\hline Exsudação & 0 & 2 & 0 & 0 & 1 & 1 & 0 & 0 & 2 & 0 \\
\hline Hemossiderose & 0 & 1 & 2 & 1 & 1 & 0 & 0 & 3 & 2 & 2 \\
\hline
\end{tabular}

Tipo celular

\begin{tabular}{r|c|c|c|c|c|c|c|c|c|c|c}
\hline $\begin{array}{l}\text { Neutrófilos } \\
\text { Linfócitos }\end{array}$ & 0 & 2 & 0 & 0 & 0 & 0 & 0 & 0 & 2 & 0 \\
\cline { 2 - 11 } & 0 & 2 & 0 & 2 & 0 & 0 & 0 & 0 & 2 & 0 \\
\hline Intensidade & 0 & 0 & 0 & 3 & 0 & 0 & 0 & 0 & 3 & 0 \\
\hline $\begin{array}{r}\text { Discreto } \\
\text { Moderado } \\
\text { Intenso }\end{array}$ & 0 & 3 & 0 & 0 & 0 & 0 & 0 & 0 & 0 & 0 \\
\cline { 2 - 11 } & 0 & 0 & 0 & 0 & 0 & 0 & 0 & 0 & 0 & 0 \\
\hline
\end{tabular}

\begin{tabular}{l|l|l|l|l|l|l|l|l|l|l|l}
\hline Hiperplásico & 3 & 2 & 0 & 3 & 3 & 0 & 0 & 3 & 3 & 2 \\
\hline Atrófico & 0 & 0 & 0 & 0 & 0 & 0 & 0 & 0 & 0 & 0 \\
\hline Ulcerado & 0 & 2 & 0 & 0 & 1 & 0 & 0 & 0 & 2 & 0 \\
\hline
\end{tabular}

Escores: 0 = ausente; 1 = escasso; 2 = moderado; 3 = freqüente. 


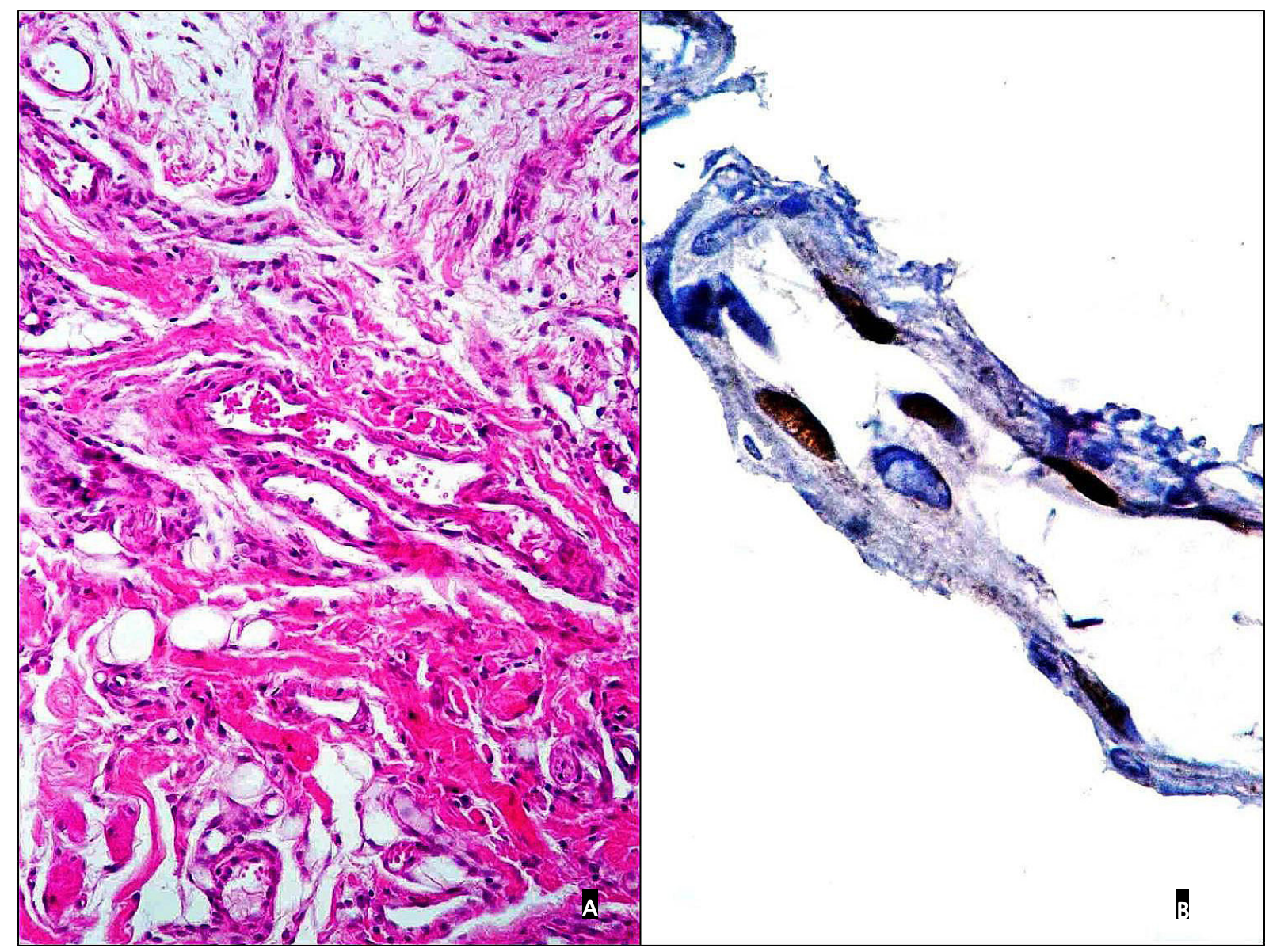

Figura 16 - Hemangioma arteriovenoso bucal. Em (A) observa-se lesão vascular com arranjo aleatório, apresentando vasos de contornos irregulares e hialinização da camada íntima. $O$ endotélio demonstra células predominantemente planas. $O$ anticorpo para FGFb encontra-se intensamente evidenciado no núcleo de células endoteliais da vênula destacada em (B). [HE (A) e IHQ (B). Objetivas 20X (A) e $100 \times(B)]$ 
Tabela 22 - Avaliação imuno-histoquímica da expressão de p75NTR e FGFb nos espécimes de hemangioma arteriovenoso cutâneo quanto à intensidade $e$ distribuição. Valores demonstrados em medianas dos escores

Hemangioma Arteriovenoso Cutâneo

\begin{tabular}{|c|c|c|c|c|}
\hline Data de Registro & P75 NTR - intensidade & P75 NTR - distribuição & FGFb - intensidade & FGFb - distribuição \\
\hline 2002 & 2 & 2 & 0 & 0 \\
\hline 2002 & 2 & 2 & 0 & 0 \\
\hline 2002 & 0 & 0 & 0 & 0 \\
\hline 2002 & 2 & 2 & 0 & 0 \\
\hline 2002 & 2 & 1 & 0 & 0 \\
\hline 2001 & 0 & 0 & 0 & 0 \\
\hline 2001 & 2 & 1 & 0 & 0 \\
\hline 2001 & 2 & 1 & 0 & 0 \\
\hline 2001 & 2 & 1 & 0 & 0 \\
\hline 2001 & 2 & 1 & 0 & 0 \\
\hline
\end{tabular}


Tabela 23 - Medianas dos critérios morfológicos analisados nos espécimes de hemangioma arteriovenoso cutâneo

\begin{tabular}{|c|c|c|c|c|c|c|c|c|c|c|}
\hline ESTRUTURA & \multicolumn{10}{|c|}{ HEMANGIOMA ARTERIOVENOSO CUTÂNEO } \\
\hline $\mathrm{N}=10$ & A & $\mathrm{B}$ & $\mathrm{C}$ & $\mathrm{E}$ & $\mathrm{F}$ & $G$ & $\mathrm{H}$ & $\mathrm{I}$ & $\mathrm{J}$ & $\mathrm{K}$ \\
\hline & & & & & & & & & & VASOS \\
\hline \multicolumn{11}{|l|}{ Tipo } \\
\hline \multirow{6}{*}{$\begin{array}{r}\text { Capilar } \\
\text { Vênula } \\
\text { Arteríola } \\
\text { Veia } \\
\text { Artéria } \\
\text { Linfático }\end{array}$} & 1 & 1 & 3 & 2 & 1 & 1 & 2 & 3 & 2 & 1 \\
\hline & 2 & 3 & 3 & 3 & 3 & 3 & 2 & 2 & 2 & 2 \\
\hline & 2 & 2 & 2 & 3 & 3 & 3 & 3 & 2 & 3 & 2 \\
\hline & 0 & 0 & 0 & 0 & 0 & 0 & 0 & 0 & 0 & 0 \\
\hline & 0 & 0 & 0 & 0 & 0 & 0 & 0 & 0 & 0 & 0 \\
\hline & 0 & 0 & 0 & 0 & 0 & 0 & 0 & 0 & 0 & 0 \\
\hline \multicolumn{11}{|l|}{ Arranjo } \\
\hline \multirow{4}{*}{$\begin{array}{r}\text { Lobular } \\
\text { Cordonal } \\
\text { Fasciculado } \\
\text { Aleatório }\end{array}$} & 0 & 3 & 0 & 0 & 3 & 3 & 0 & 0 & 2 & 0 \\
\hline & 0 & 0 & 0 & 0 & 0 & 0 & 0 & 0 & 0 & 0 \\
\hline & 0 & 0 & 0 & 0 & 0 & 0 & 0 & 0 & 0 & 0 \\
\hline & 3 & 0 & 3 & 3 & 0 & 0 & 3 & 3 & 3 & 3 \\
\hline \multicolumn{11}{|l|}{ Localização } \\
\hline \multirow{3}{*}{$\begin{array}{r}\text { Superficial } \\
\text { Média } \\
\text { Profunda }\end{array}$} & 3 & 3 & 3 & 2 & 2 & 3 & 3 & 3 & 3 & 0 \\
\hline & 2 & 0 & 3 & 3 & 3 & 0 & 3 & 0 & 3 & 3 \\
\hline & 0 & 0 & 0 & 0 & 0 & 0 & 0 & 0 & 0 & 0 \\
\hline \multicolumn{11}{|l|}{ Distribuição } \\
\hline \multirow{3}{*}{$\begin{array}{r}\text { Localizada } \\
\text { Multifocal } \\
\text { Disseminada }\end{array}$} & 0 & 3 & 0 & 0 & 3 & 3 & 0 & 3 & 0 & 3 \\
\hline & 3 & 0 & 3 & 3 & 0 & 0 & 3 & 0 & 3 & 0 \\
\hline & 0 & 0 & 0 & 0 & 0 & 0 & 0 & 0 & 0 & 0 \\
\hline \multicolumn{11}{|l|}{ Contornos } \\
\hline \multirow{2}{*}{$\begin{array}{r}\text { Regulares } \\
\text { Irregulares }\end{array}$} & 2 & 2 & 2 & 2 & 3 & 2 & 3 & 0 & 2 & 2 \\
\hline & 2 & 2 & 2 & 2 & 2 & 2 & 2 & 3 & 3 & 2 \\
\hline Dilatação & 3 & 3 & 3 & 2 & 2 & 3 & 2 & 3 & 3 & 2 \\
\hline Congestão & 2 & 3 & 3 & 1 & 3 & 2 & 3 & 2 & 3 & 2 \\
\hline Trombose & 0 & 0 & 0 & 0 & 0 & 0 & 0 & 0 & 0 & 0 \\
\hline \multirow{2}{*}{\multicolumn{11}{|c|}{ Morfologia celular }} \\
\hline & & & & & & & & & & \\
\hline \multirow{4}{*}{$\begin{array}{r}\text { Epitelióide } \\
\text { Fusiforme } \\
\text { Poliédrico } \\
\text { Pleomórfico }\end{array}$} & 0 & 0 & 3 & 0 & 1 & 1 & 0 & 0 & 0 & 0 \\
\hline & 2 & 2 & 1 & 2 & 3 & 2 & 3 & 3 & 3 & 2 \\
\hline & 2 & 2 & 3 & 2 & 2 & 3 & 2 & 0 & 2 & 2 \\
\hline & 0 & 0 & 0 & 0 & 0 & 0 & 0 & 0 & 0 & 0 \\
\hline \multicolumn{11}{|l|}{ Camadas de células } \\
\hline \multirow{2}{*}{$\begin{array}{r}\text { Simples } \\
\text { Múltiplas }\end{array}$} & 2 & 3 & 2 & 2 & 2 & 2 & 2 & 3 & 2 & 2 \\
\hline & 2 & 0 & 2 & 2 & 3 & 2 & 2 & 0 & 2 & 2 \\
\hline \multicolumn{11}{|l|}{ Disposição } \\
\hline \multirow{3}{*}{$\begin{array}{r}\text { Aplainado } \\
\text { Proeminente } \\
\text { Papilar }\end{array}$} & 3 & 2 & 2 & 2 & 3 & 3 & 3 & 3 & 3 & 3 \\
\hline & 0 & 2 & 3 & 2 & 0 & 2 & 2 & 0 & 2 & 0 \\
\hline & 0 & 0 & 0 & 0 & 0 & 0 & 0 & 0 & 0 & 0 \\
\hline \multicolumn{11}{|l|}{ Mitoses } \\
\hline \multirow{2}{*}{$\begin{array}{r}\text { Típicas } \\
\text { Atípicas }\end{array}$} & 0 & 0 & 2 & 0 & 0 & 0 & 0 & 0 & 0 & 0 \\
\hline & 0 & 0 & 0 & 0 & 0 & 0 & 0 & 0 & 0 & 0 \\
\hline $\begin{array}{l}\text { Lumes } \\
\text { intracitoplasmáticos }\end{array}$ & 0 & 0 & 1 & 0 & 0 & 0 & 0 & 0 & 0 & 0 \\
\hline
\end{tabular}

\begin{tabular}{ll} 
TECIDO CONJUNTIVO \\
\hline
\end{tabular}

\begin{tabular}{l|l|l|l|l|l|l|l|l|l|l}
\hline Exsudação & 2 & 0 & 1 & 0 & 0 & 0 & 0 & 2 & 2 & 0 \\
\hline Hemossiderose & 2 & 0 & 2 & 0 & 0 & 0 & 0 & 0 & 0 & 0 \\
\hline
\end{tabular}

Tipo celular

\begin{tabular}{|c|c|c|c|c|c|c|c|c|c|c|}
\hline \multirow{2}{*}{$\begin{array}{l}\text { Neutrófilos } \\
\text { Linfócitos }\end{array}$} & 0 & 0 & 0 & 0 & 0 & 0 & 0 & 0 & 0 & 0 \\
\hline & 2 & 0 & 3 & 0 & 0 & 0 & 0 & 3 & 3 & 0 \\
\hline \multicolumn{11}{|l|}{ Intensidade } \\
\hline \multirow{3}{*}{$\begin{array}{r}\text { Discreto } \\
\text { Moderado } \\
\text { Intenso }\end{array}$} & 0 & 0 & 0 & 0 & 0 & 0 & 0 & 0 & 3 & 0 \\
\hline & 3 & 0 & 0 & 0 & 0 & 0 & 0 & 3 & 0 & 0 \\
\hline & 0 & 0 & 3 & 0 & 0 & 0 & 0 & 0 & 0 & 0 \\
\hline
\end{tabular}

\begin{tabular}{l|l|l|l|l|l|l|l|l|l|l|l}
\hline Hiperplásico & 2 & 0 & 0 & 2 & 0 & 3 & 0 & 0 & 0 & 2 \\
\hline Atrófico & 0 & 0 & 2 & 0 & 0 & 0 & 0 & 0 & 0 & 0 \\
\hline Ulcerado & 0 & 0 & 0 & 0 & 0 & 0 & 0 & 0 & 0 & 0 \\
\hline
\end{tabular}

Escores: 0 = ausente; 1 = escasso; 2 = moderado; 3 = freqüente. 


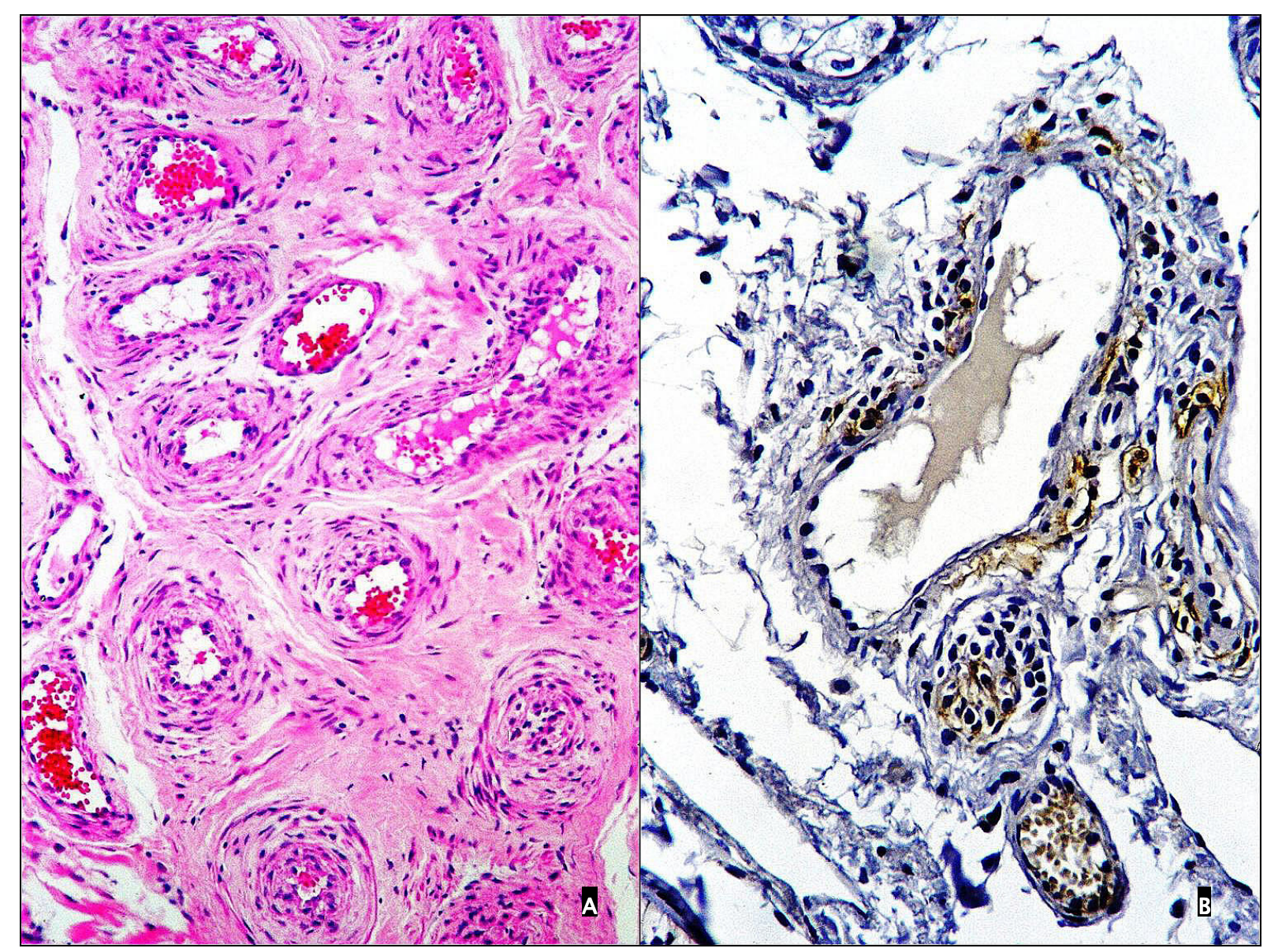

Figura 17 - O hemangioma arteriovenoso cutâneo representado na fotomicrografia (A) caracteriza-se por uma composição de vênulas e arteríolas revestidas por células arredondadas, algumas proeminentes para o lume, com paredes espessas de musculatura lisa. A análise imuno-histoquímica, representada em (B), apresenta em positividade focal para $\mathrm{p} 75^{\mathrm{NTR}}$ na membrana citoplasmática de células endoteliais dos vasos menores e em alguns pericitos do vaso mais calibroso. [HE (A) e IHQ (B). Objetivas 20X (A) e 40X (B)] 


\subsection{6 - SARCOMA DE KAPOSI}

Nos sarcomas de Kaposi da mucosa bucal, observou-se intensa proliferação de células epitelióides e fusiformes pelo interstício, dispostas aleatoriamente ou em padrão fasciculado, bem como focos de hemossiderose, corpúsculos hialinos eosinofílicos intracitoplasmáticos e mitoses atípicas. As estruturas habituais do tecido conjuntivo, como feixes musculares estriados e vasculonervosos, estavam infiltradas pela proliferação neoplásica e permeadas por moderado infiltrado inflamatório mononuclear. Os sarcomas de Kaposi cutâneos demonstraram arranjo predominantemente fasciculado. Nas células neoplásicas das lesões cutâneas notaram-se características similares àquelas das lesões bucais, apesar de uma discreta predominância de células neoplásicas arredondadas. Nas lesões bucais não houve expressão de p75 NTR e o anticorpo anti-FGFb evidenciou intensamente o fator de crescimento nos núcleos de grande parte das células neoplásicas (Figura 18). Nos sarcomas de Kaposi cutâneos destacaram-se áreas perivasculares evidenciadas focalmente pelo anticorpo anti-p75 NTR (Figura 19).

Tabela 24 - Avaliação imuno-histoquímica da expressão de p75NTR e FGFb nos espécimes de sarcoma de Kaposi bucal quanto à intensidade e distribuição. Valores demonstrados em medianas dos escores

\begin{tabular}{l|l|l|l|l}
\hline \multicolumn{5}{c}{ Sarcoma de Kaposi } \\
\hline Data de Registro & P75 NTR - I & P75 NTR - D & FGFb - I & FGFb - D \\
\hline 2000 & 1 & 1 & 3 & 3 \\
\hline 2002 & 0 & 0 & 3 & 1 \\
\hline
\end{tabular}


Tabela 25 - Medianas dos critérios morfológicos analisados nos espécimes de sarcoma de Kaposi bucal

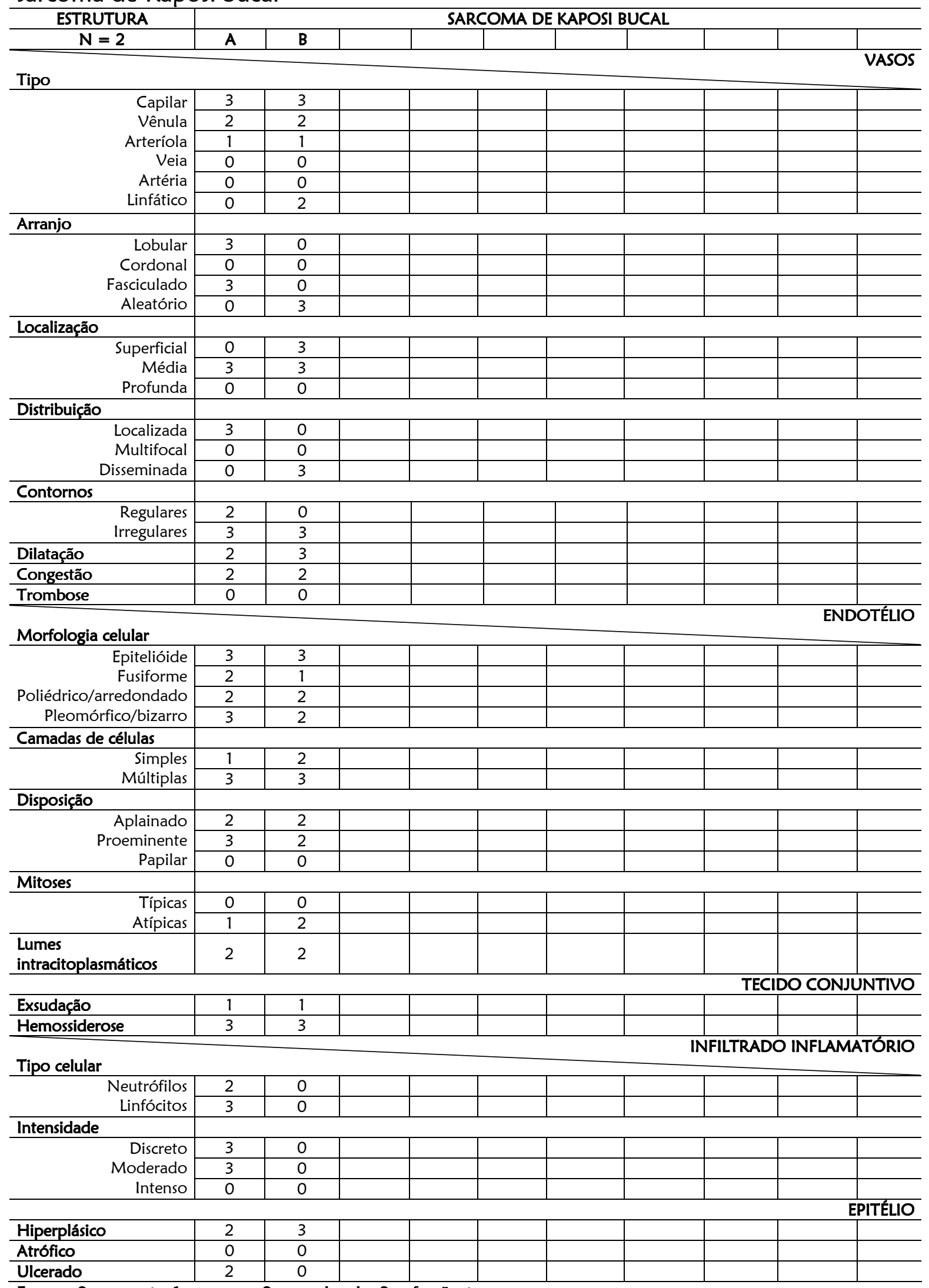

Escores: 0 = ausente; 1 = escasso; 2 = moderado; 3 = freqüente. 


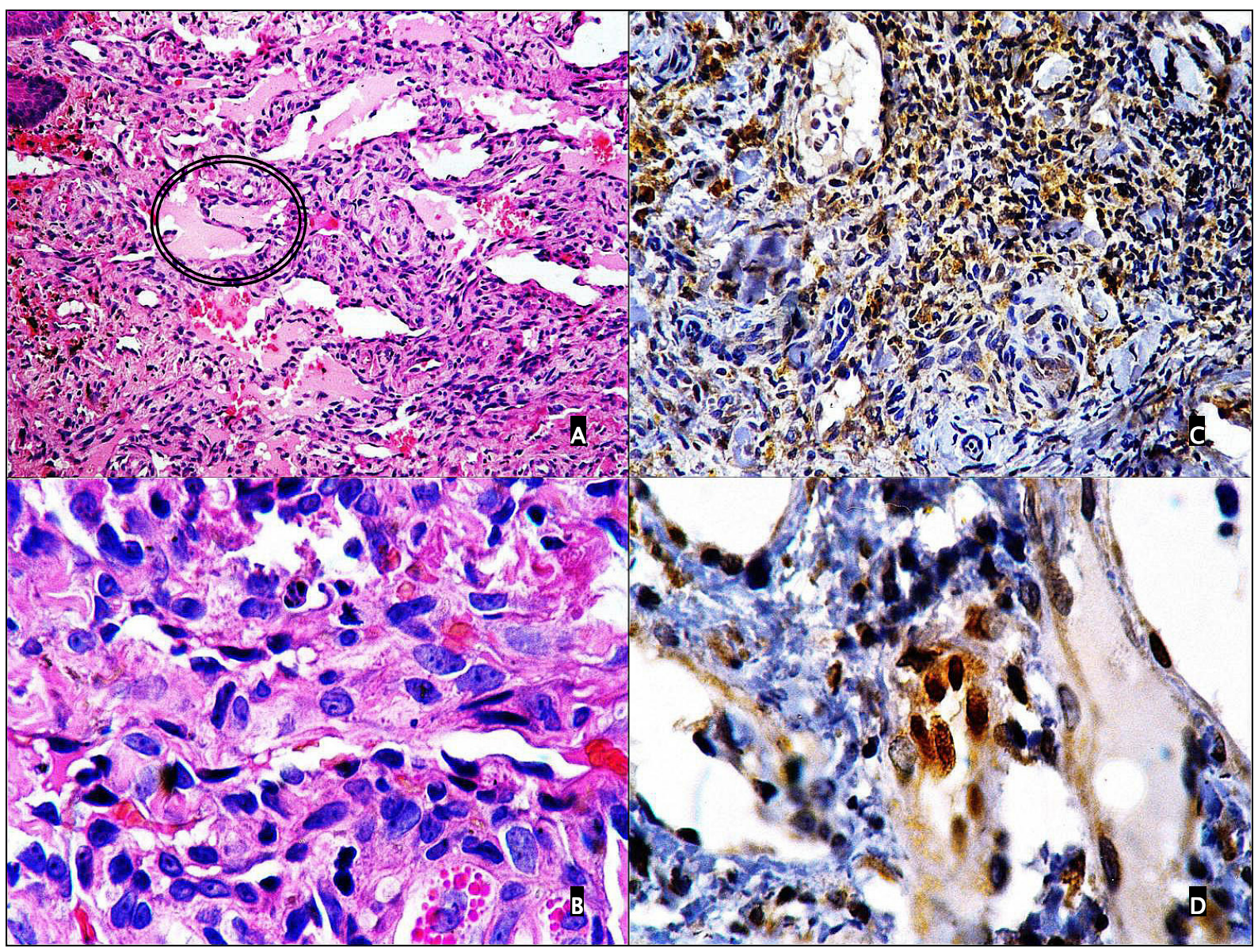

Figura 18 - Sarcoma de Kaposi bucal. Em menor aumento, (A), observa-se infiltração neoplásica difusa superficial e profunda, fendas preenchidas por material hialino eosinofílico, bem como depósitos intersticiais de hemossiderina e eritrócitos dispersos pelo estroma. Destaca-se, ainda, uma projeção endotelial em direção a uma das fendas, caracterizando o sinal de promontório (círculo). O maior aumento (B) exibe células vacuolizadas com núcleos hipercromáticos, apresentando corpúsculos hialinos intracitoplasmáticos. Nos cortes microscópicos (C) e (D) observam-se, citoplasmas e núcleos endoteliais evidenciados pelo anticorpo antiFGFb. [HE (A e B) e IHQ (C e D). Objetivas 20X (A e C) e 100X (B e D)] 
Tabela 26 - Avaliação imuno-histoquímica da expressão de p75NTR e FGFb nos espécimes de sarcoma de Kaposi cutâneo quanto à intensidade e distribuição. Valores demonstrados em medianas dos escores

Sarcoma de Kaposi Cutâneo

\begin{tabular}{|c|c|c|c|c|}
\hline Data de Registro & P75 ${ }^{\text {NTR }}$ - introdução & P75 ${ }^{\mathrm{NTR}}$ - distribuição & FGFb - introdução & FGFb - distribuição \\
\hline 2002 & 3 & 3 & 0 & 0 \\
\hline 2002 & 1 & 1 & 0 & 0 \\
\hline 2002 & 3 & 1 & 0 & 0 \\
\hline 1995 & 0 & 0 & 0 & 0 \\
\hline
\end{tabular}


Tabela 27 - Medianas dos critérios morfológicos analisados nos espécimes de sarcoma de Kaposi cutâneo

\begin{tabular}{|c|c|c|c|c|c|c|c|c|c|}
\hline \multirow{2}{*}{$\begin{array}{c}\text { ESTRUTURA } \\
\mathrm{N}=8 \\
\end{array}$} & \multicolumn{9}{|c|}{ SARCOMA DE KAPOSI CUTÂNEO } \\
\hline & A & B & C & $\mathrm{E}$ & $\mathrm{F}$ & G & $\mathrm{H}$ & $\mathrm{I}$ & \\
\hline & & & & & & & & & VASOS \\
\hline \multicolumn{10}{|l|}{ Tipo } \\
\hline \multirow{6}{*}{$\begin{array}{r}\text { Capilar } \\
\text { Vênula } \\
\text { Arteríola } \\
\text { Veia } \\
\text { Artéria } \\
\text { Linfático } \\
\end{array}$} & 3 & 3 & 3 & 3 & 3 & 3 & 3 & 3 & \\
\hline & 2 & 1 & 2 & 2 & 1 & 2 & 2 & 0 & \\
\hline & 1 & 1 & 1 & 1 & 1 & 2 & 1 & 0 & \\
\hline & 0 & 0 & 0 & 0 & 0 & 0 & 0 & 0 & \\
\hline & 0 & 0 & 0 & 0 & 0 & 0 & 0 & 0 & \\
\hline & 0 & 0 & 0 & 0 & 0 & 0 & 0 & 0 & \\
\hline \multicolumn{10}{|l|}{ Arranjo } \\
\hline \multirow{4}{*}{$\begin{array}{r}\text { Lobular } \\
\text { Cordonal } \\
\text { Fasciculado } \\
\text { Aleatório }\end{array}$} & 0 & 3 & 2 & 0 & 0 & 3 & 3 & 0 & \\
\hline & 3 & 1 & 0 & 0 & 0 & 0 & 0 & 0 & \\
\hline & 0 & 0 & 2 & 3 & 3 & 0 & 3 & 0 & \\
\hline & 2 & 2 & 0 & 2 & 0 & 0 & 0 & 3 & \\
\hline \multicolumn{10}{|l|}{ Localização } \\
\hline \multirow{3}{*}{$\begin{array}{r}\text { Superficial } \\
\text { Média } \\
\text { Profunda }\end{array}$} & 2 & 1 & 3 & 3 & 3 & 3 & 0 & 3 & \\
\hline & 3 & 3 & 3 & 3 & 3 & 3 & 3 & 0 & \\
\hline & 1 & 2 & 2 & 2 & 3 & 2 & 0 & 0 & \\
\hline \multicolumn{10}{|l|}{ Distribuição } \\
\hline \multirow{3}{*}{$\begin{array}{r}\text { Localizada } \\
\text { Multifocal } \\
\text { Disseminada }\end{array}$} & 0 & 0 & 0 & 0 & 0 & 0 & 3 & 0 & \\
\hline & 3 & 0 & 3 & 0 & 0 & 3 & 0 & 0 & \\
\hline & 0 & 3 & 3 & 3 & 3 & 0 & 0 & 3 & \\
\hline \multicolumn{10}{|l|}{ Contornos } \\
\hline \multirow{2}{*}{$\begin{array}{r}\text { Regulares } \\
\text { Irregulares }\end{array}$} & 0 & 1 & 0 & 0 & 0 & 2 & 1 & 0 & \\
\hline & 3 & 3 & 3 & 3 & 3 & 2 & 3 & 3 & \\
\hline Dilatação & 1 & 2 & 3 & 3 & 3 & 3 & 3 & 1 & \\
\hline Congestão & 1 & 2 & 3 & 3 & 3 & 2 & 3 & 2 & \\
\hline Trombose & 0 & 0 & 0 & 0 & 0 & 0 & 0 & 0 & \\
\hline
\end{tabular}

Morfologia celular

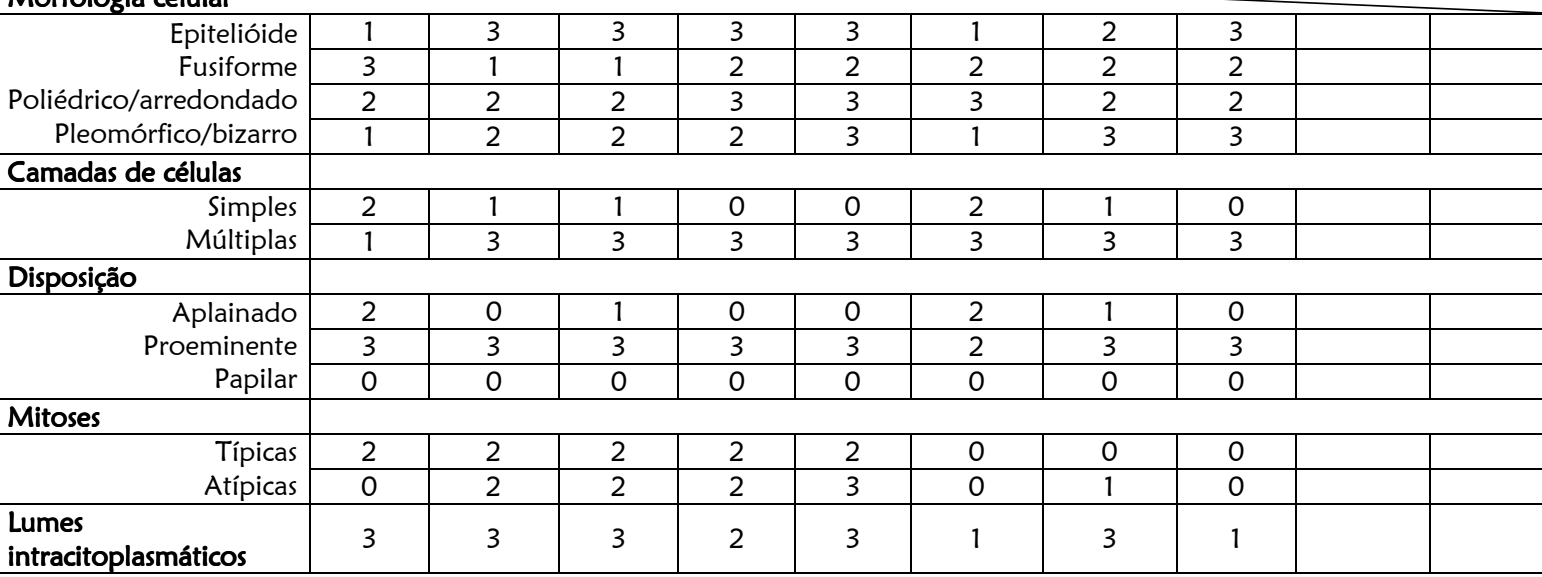

\begin{tabular}{ll|r}
\hline & TECIDO CONJUNTIVO \\
\hline
\end{tabular}

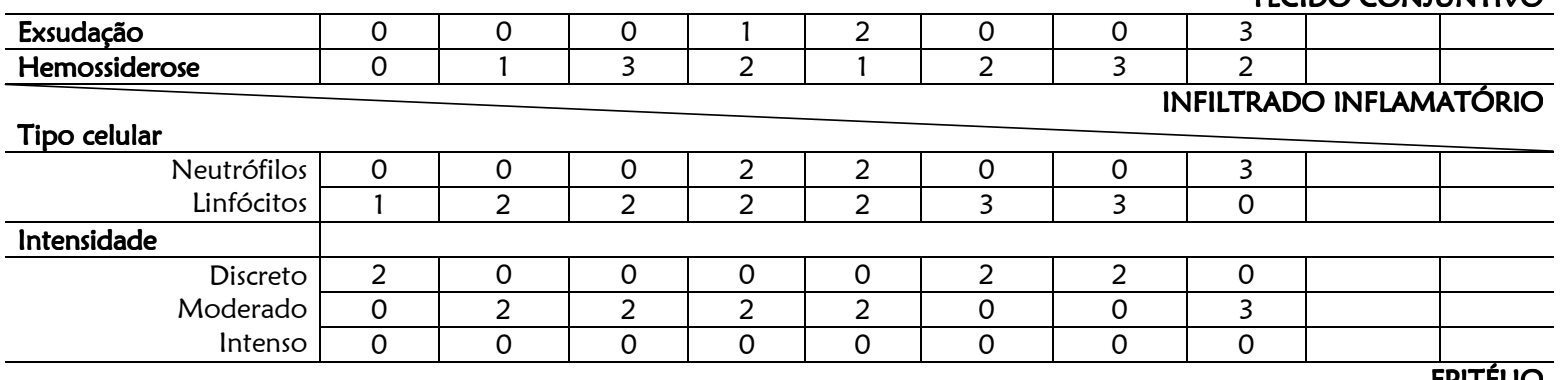

\begin{tabular}{l|l|l|l|l|l|l|l|l|l|l}
\hline Hiperplásico & 3 & 0 & 2 & 2 & 3 & 2 & 2 & 2 & & \\
\hline Atrófico & 0 & 0 & 2 & 0 & 0 & 0 & 0 & 0 & & \\
\hline Ulcerado & 0 & 0 & 0 & 3 & 3 & 0 & 0 & 3 & & \\
\hline
\end{tabular}

Escores: 0 = ausente; 1 = escasso; 2 = moderado; 3 = freqüente. 


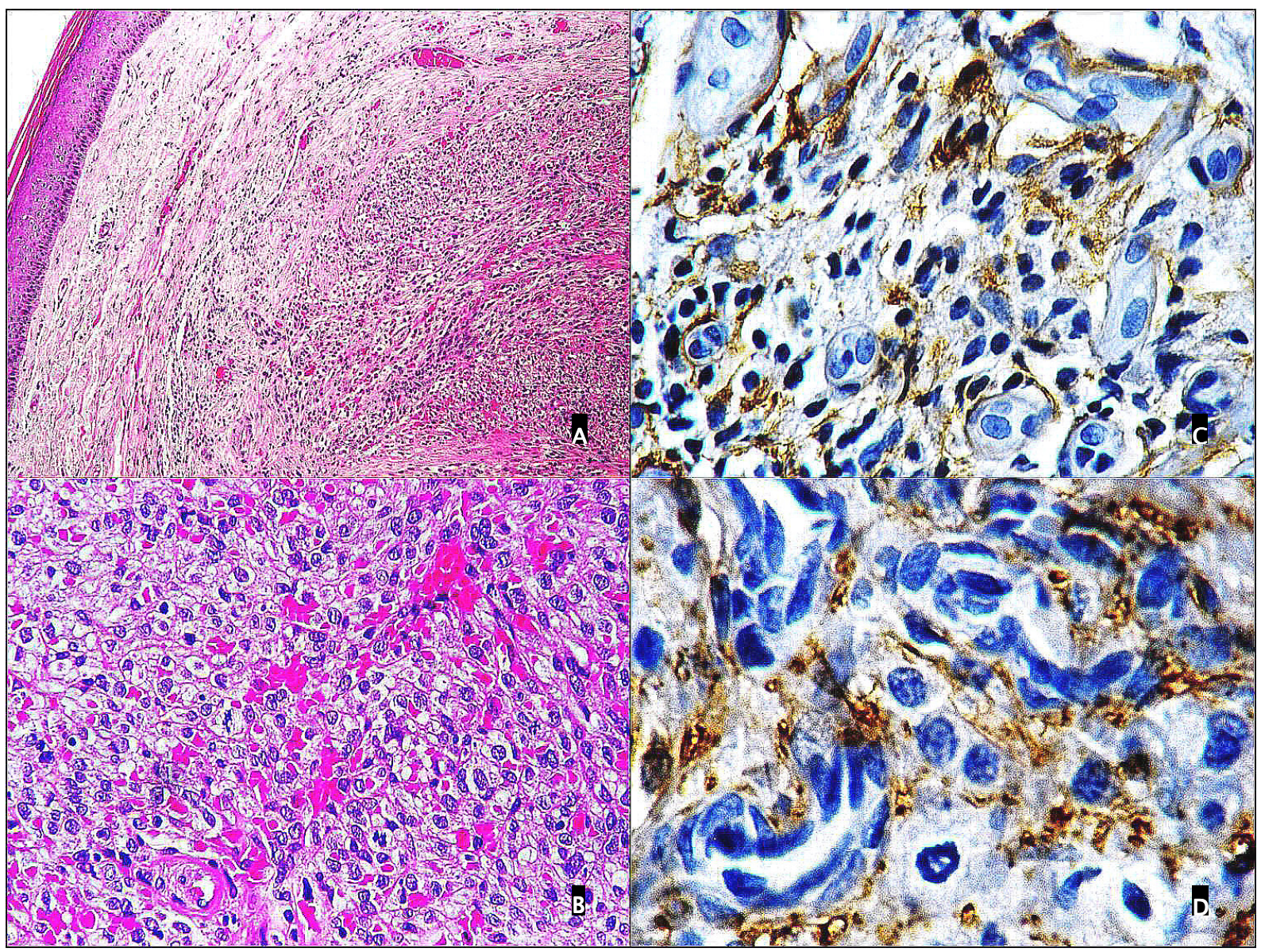

Figura 19 - Sarcoma de Kaposi cutâneo. Em (A) observam-se elementos neoplásicos dispostos na derme reticular paralelamente à superfície epidérmica. A imagem (B) destaca intensa proliferação de células neoplásicas com citoplasma vacuolar, bem como discretas fendas preenchidas por hemácias. $O$ corte (C) demonstra imunoreatividade focal para $\mathrm{p} 75^{\mathrm{NTR}}$ na superfície de algumas das células. A imagem (D) demonstra vasos tortuosos com células endoteliais atípicas com positividade parcial para p75 ${ }^{\mathrm{NTR}}$. [HE (A e B) e IHQ (C e D). Objetivas 10X (A), 40X (B) e 100X $(C$ e D $)]$ 


\section{4 - Análise Estatística Comparativa}

A partir da classificação morfológica dos espécimes da amostra foram calculadas as medianas dos grupos (Tabela 28) e o teste estatístico de Dunn para comparações individuais foi empregado com nível de significância estabelecido em $5 \%$. Todos os critérios morfológicos foram analisados e nenhum deles demonstrou diferença estatisticamente significante entre as lesões bucais e cutâneas.

Para a análise estatística dos resultados imuno-histoquímicos, foram obtidas as medianas dos grupos (Gráficos 3 e 4) e aplicado o teste estatístico de Dunn, com nível de significância em 5\%. A comparação entre os granulomas piogênicos bucais e cutâneos resultou em diferenças estatisticamente significantes em relação à marcação de p75 NTR e FGFb. Outras diferenças significantes quanto ao padrão de expressão de $\mathrm{p} 75^{\mathrm{NTR}}$ e FGFb incluíram os grupos de hemangiomas arteriovenosos e malformações venosas. Em valores percentuais, as lesões bucais tiveram maior expressão de FGFb enquanto que as cutâneas apresentaram maior expressão de p75 NTR (Tabelas 29 e 30). Nos controles negativos não se observou reatividade imuno-histoquímica para os mediadores estudados e nos controles positivos externos e internos o sinal imuno-histoquímico apresentou-se intenso e bem localizado, conforme as áreas previamente padronizadas. 
Tabela 28 - Medianas dos escores morfológicos da amostra de lesões angioproliferativas bucais e cutâneas. Escores: $0=$ ausente; $1=$ escasso; $2=$ moderado; 3 = freqüente

\begin{tabular}{|c|c|c|c|c|c|c|c|c|c|c|c|c|}
\hline $\mathrm{N}$ & 10 & 10 & 10 & 10 & 10 & 10 & 10 & 10 & 10 & 10 & 2 & 8 \\
\hline \multirow{2}{*}{ Grupo } & \multicolumn{2}{|c|}{ I } & \multicolumn{2}{|c|}{ II } & \multicolumn{2}{|c|}{ III } & \multicolumn{2}{|c|}{ IV } & \multicolumn{2}{|c|}{ V } & \multicolumn{2}{|c|}{$\mathrm{VI}$} \\
\hline & MVB & MVC & MLB & MLC & GPB & GPC & HCPB & HCPC & HAVB & HAVC & SKB & SKC \\
\hline Capilar & 2 & 2 & 2 & 2 & 3 & 3 & 3 & 2 & 2 & 1,5 & 3 & 3 \\
\hline Vênula & 3 & 3 & 2 & 1 & 3 & 2 & 2 & 3 & 3 & 2,5 & 2 & 2 \\
\hline Arteríola & 1 & 1 & 0 & 0 & 2 & 0,5 & 1 & 1 & 2 & 2,5 & 1 & 1 \\
\hline Veia & 0 & 0 & 0 & 0 & 0 & 0 & 0 & 0 & 0 & 0 & 0 & 0 \\
\hline Artéria & 0 & 0 & 0 & 0 & 0 & 0 & 0 & 0 & 0 & 0 & 0 & 0 \\
\hline Linfático & 0 & 0 & 3 & 3 & 0 & 0 & 0 & 0 & 0 & 0 & 1 & 0 \\
\hline Lobular & 0 & 0 & 0 & 3 & 2 & 3 & 3 & 2,5 & 0 & 0 & 1,5 & 1 \\
\hline Cordonal & 1,5 & 0 & 0 & 0 & 1 & 0,5 & 3 & 0 & 0 & 0 & 0 & 0 \\
\hline Fasciculado & 0 & 0 & 0 & 0 & 0 & 0 & 0 & 0 & 0 & 0 & 1,5 & 1 \\
\hline Aleatório & 0 & 2 & 3 & 0 & 2 & 0 & 3 & 0 & 3 & 3 & 1,5 & 1 \\
\hline Localizada & 1 & 0 & 0 & 3 & 0 & 0 & 1,5 & 1,5 & 0 & 1,5 & 1,5 & 0 \\
\hline Multifocal & 0 & 3 & 3 & 0 & 2 & 3 & 1,5 & 0 & 3 & 1,5 & 0 & 0 \\
\hline Disseminada & 0 & 0 & 0 & 0 & 3 & 0 & 0 & 0 & 0 & 0 & 1,5 & 3 \\
\hline Epitelióide & 0 & 3 & 1 & 0 & 3 & 3 & 3 & 0,5 & 0,5 & 0 & 3 & 3 \\
\hline Fusiforme & 3 & 3 & 3 & 3 & 1 & 1 & 2 & 3 & 2,5 & 2 & 0,5 & 2 \\
\hline Arredondada & 1,5 & 1 & 0 & 0,5 & 2 & 2 & 1,5 & 2 & 2 & 2 & 2 & 2 \\
\hline Pleomórfica & 0 & 0 & 0 & 0 & 0 & 0 & 1 & 0 & 0 & 0 & 2,5 & 2 \\
\hline Mitoses típicas & 0 & 0 & 0 & 0 & 3 & 0,5 & 0,5 & 0 & 0 & 0 & 0 & 2 \\
\hline Mitoses atípicas & 0 & 0 & 0 & 0 & 0 & 0 & 0 & 0 & 0 & 0 & 1,5 & 1,5 \\
\hline LIC* & 0 & 0 & 0 & 0 & 1,5 & 0 & 0 & 0 & 0 & 0 & 2 & 3 \\
\hline Dilatação & 3 & 3 & 3 & 3 & 3 & 3 & 3 & 3 & 2 & 3 & 2 & 2,5 \\
\hline Congestão & 3 & 3 & 3 & 3 & 3 & 2 & 2 & 3 & 2 & 2,5 & 2 & 2,5 \\
\hline Trombose & 0 & 3 & 0 & 0 & 0 & 0 & 0 & 0 & 0 & 0 & 0 & 0 \\
\hline Inflamação & 1 & 2 & 3 & 3 & 3 & 3 & 2 & 1 & 2 & 3 & 2 & 2 \\
\hline Hemossiderose & 1 & 2 & 2 & 3 & 2 & 1 & 2 & 0 & 3 & 2 & 3 & 3 \\
\hline Ulceração & 0 & 3 & 2 & 0 & 3 & 3 & 1 & 0 & 2 & 0 & 2 & 3 \\
\hline
\end{tabular}

*LIC = lumes intracitoplasmáticos. 


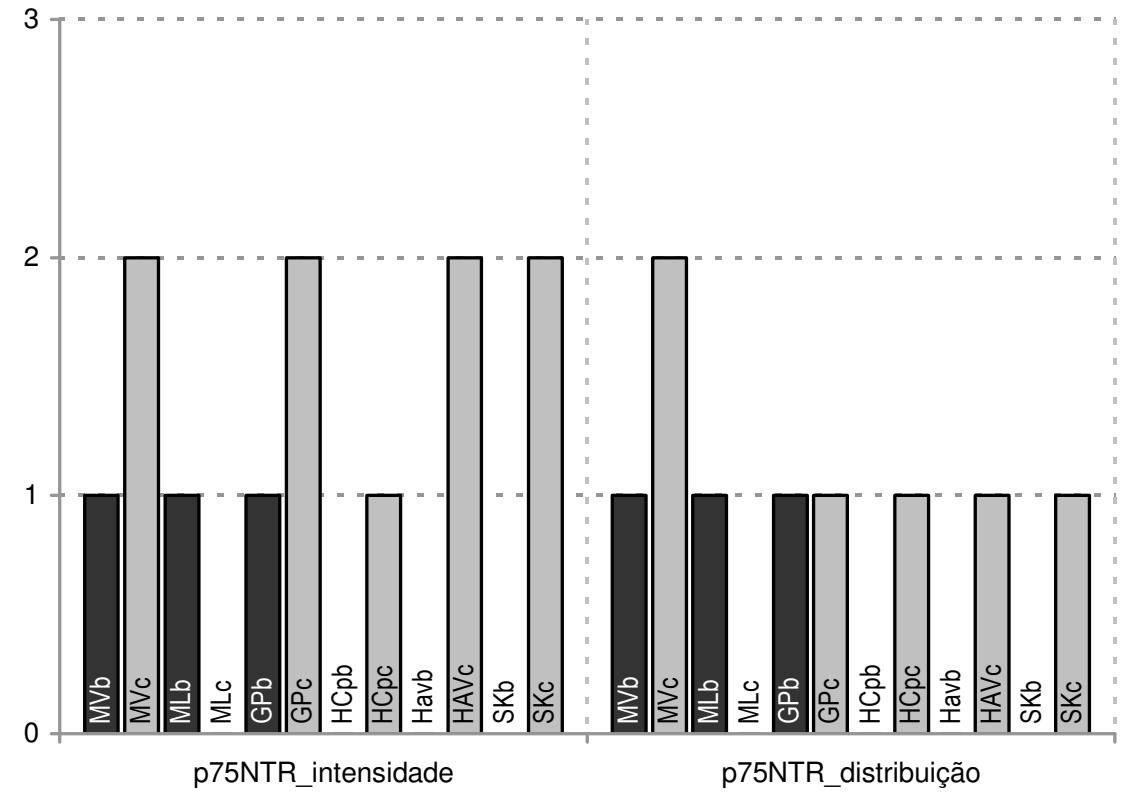

Gráfico 3 - Medianas da expressão do mediador p75 NTR no endotélio de lesões angioproliferativas bucais e cutâneas. Valores atribuídos em escores qualitativos: (0) = ausente; $(1)$ = fraco/focal; (2) = moderado/multifocal; (3) = intenso/difuso

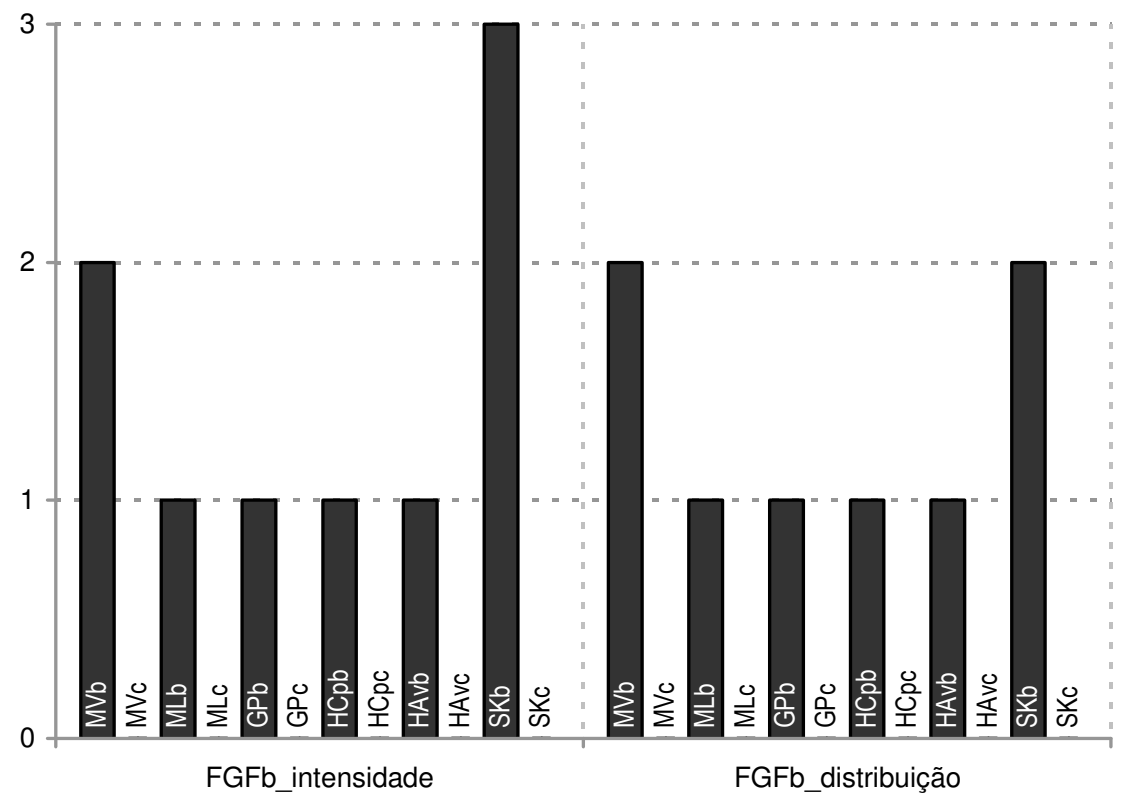

Gráfico 4 - Medianas da expressão do mediador FGFb no endotélio de lesões angioproliferativas bucais e cutâneas. Valores atribuídos em escores qualitativos: (0) = ausente; $(1)$ = fraco/focal; $(2)=$ moderado/multifocal; $(3)=$ intenso/difuso 
Tabela 29 - Escores da expressão de p75 NTR nas lesões angioproliferativas bucais e cutâneas representados em valores percentuais

\begin{tabular}{|c|c|c|c|c|c|c|c|c|c|c|c|c|c|c|c|c|c|c|c|c|c|c|c|c|}
\hline \multirow{3}{*}{ 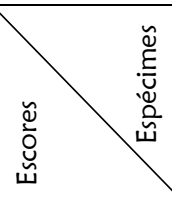 } & \multicolumn{4}{|c|}{$\mathrm{Gl}$} & \multicolumn{4}{|c|}{ Gll } & \multicolumn{4}{|c|}{ GIII } & \multicolumn{4}{|c|}{ GIV } & \multicolumn{4}{|c|}{ GV } & \multicolumn{4}{|c|}{ GVI } \\
\hline & \multicolumn{2}{|c|}{ MVB } & \multicolumn{2}{|c|}{ MVC } & \multicolumn{2}{|c|}{ MLB } & \multicolumn{2}{|c|}{ MLC } & \multicolumn{2}{|c|}{ GPB } & \multicolumn{2}{|c|}{ GPC } & \multicolumn{2}{|c|}{$\mathrm{HCPB}$} & \multicolumn{2}{|c|}{$\mathrm{HCPC}$} & \multicolumn{2}{|c|}{ HAVB } & \multicolumn{2}{|c|}{ HAVC } & \multicolumn{2}{|c|}{ SKB } & \multicolumn{2}{|c|}{ SKC } \\
\hline & 1 & D & 1 & $D$ & 1 & $D$ & 1 & D & 1 & $D$ & 1 & $D$ & 1 & $D$ & 1 & $D$ & 1 & $D$ & 1 & $D$ & 1 & D & 1 & $D$ \\
\hline 0 & $40 \%$ & $40 \%$ & $10 \%$ & $10 \%$ & $60 \%$ & $60 \%$ & 0 & 0 & $87,5 \%$ & $87,5 \%$ & $20 \%$ & $20 \%$ & $33,3 \%$ & $33,3 \%$ & 0 & 0 & $71,5 \%$ & $71,5 \%$ & $33,3 \%$ & $33,3 \%$ & $50 \%$ & $50 \%$ & $25 \%$ & $25 \%$ \\
\hline 1 & $10 \%$ & $60 \%$ & $90 \%$ & $80 \%$ & $40 \%$ & $40 \%$ & $14,4 \%$ & $42,8 \%$ & 0 & $12,5 \%$ & 0 & $50 \%$ & $55,5 \%$ & $55,5 \%$ & $25 \%$ & $62,5 \%$ & 0 & 0 & $44,4 \%$ & $44,4 \%$ & $50 \%$ & $50 \%$ & $25 \%$ & $50 \%$ \\
\hline 2 & $20 \%$ & 0 & 0 & $10 \%$ & 0 & 0 & $42,8 \%$ & $57,2 \%$ & $12,5 \%$ & 0 & $80 \%$ & $30 \%$ & $11,2 \%$ & $11,2 \%$ & $50 \%$ & $37,5 \%$ & $28,5 \%$ & $14,2 \%$ & $22,3 \%$ & $22,3 \%$ & 0 & 0 & 0 & 0 \\
\hline 3 & $30 \%$ & 0 & 0 & 0 & 0 & 0 & $42,8 \%$ & 0 & 0 & 0 & 0 & 0 & 0 & 0 & $25 \%$ & 0 & 0 & $14,2 \%$ & 0 & 0 & 0 & 0 & $50 \%$ & $25 \%$ \\
\hline $\mathrm{N}$ & & 0 & 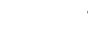 & & & & & & & & 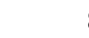 & & 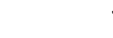 & 7 & & 9 & $\varepsilon$ & & 1 & & 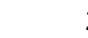 & & 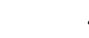 & 4 \\
\hline
\end{tabular}

Tabela 30 - Escores da expressão de FGFb nas lesões angioproliferativas bucais e cutâneas representados em valores percentuais

\begin{tabular}{|c|c|c|c|c|c|c|c|c|c|c|c|c|c|c|c|c|c|c|c|c|c|c|c|c|}
\hline \multirow{3}{*}{ 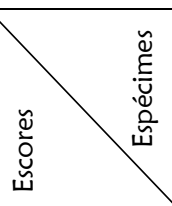 } & \multicolumn{4}{|c|}{$\mathrm{Gl}$} & \multicolumn{4}{|c|}{ GII } & \multicolumn{4}{|c|}{ GIII } & \multicolumn{4}{|c|}{ GIV } & \multicolumn{4}{|c|}{ GV } & \multicolumn{4}{|c|}{ GVI } \\
\hline & \multicolumn{2}{|c|}{ MVB } & \multicolumn{2}{|c|}{ MVC } & \multicolumn{2}{|c|}{ MLB } & \multicolumn{2}{|c|}{ MLC } & \multicolumn{2}{|c|}{ GPB } & \multicolumn{2}{|c|}{ GPC } & \multicolumn{2}{|c|}{ HCPB } & \multicolumn{2}{|c|}{ HCPC } & \multicolumn{2}{|c|}{ HAVB } & \multicolumn{2}{|c|}{ HAVC } & \multicolumn{2}{|c|}{ SKB } & \multicolumn{2}{|c|}{ SKC } \\
\hline & 1 & $\mathrm{D}$ & 1 & $\mathrm{D}$ & 1 & $\mathrm{D}$ & 1 & $\mathrm{D}$ & 1 & $\mathrm{D}$ & I & $\mathrm{D}$ & I & $\mathrm{D}$ & 1 & $\mathrm{D}$ & 1 & $\mathrm{D}$ & 1 & $\mathrm{D}$ & 1 & $\mathrm{D}$ & 1 & $\mathrm{D}$ \\
\hline 0 & $10 \%$ & $10 \%$ & $85,72 \%$ & $85,72 \%$ & $10 \%$ & $10 \%$ & $80 \%$ & $80 \%$ & 0 & 0 & $100 \%$ & $100 \%$ & $42,8 \%$ & $42,8 \%$ & $100 \%$ & $100 \%$ & $25 \%$ & $25 \%$ & $100 \%$ & $100 \%$ & 0 & 0 & $100 \%$ & $100 \%$ \\
\hline 1 & $30 \%$ & $20 \%$ & $14,28 \%$ & 0 & $60 \%$ & $70 \%$ & 0 & $20 \%$ & $55,5 \%$ & $55,5 \%$ & 0 & 0 & $28,6 \%$ & $28,6 \%$ & 0 & 0 & $62,5 \%$ & $50 \%$ & 0 & 0 & 0 & $50 \%$ & 0 & 0 \\
\hline 2 & $50 \%$ & $50 \%$ & 0 & $14,28 \%$ & $20 \%$ & $20 \%$ & $20 \%$ & 0 & $44,5 \%$ & $33,4 \%$ & 0 & 0 & $14,3 \%$ & $14,3 \%$ & 0 & 0 & 0 & $25 \%$ & 0 & 0 & 0 & 0 & 0 & 0 \\
\hline 3 & $10 \%$ & $20 \%$ & 0 & 0 & $10 \%$ & 0 & 0 & 0 & 0 & 11,11 & 0 & 0 & $14,3 \%$ & $14,3 \%$ & 0 & 0 & $12,5 \%$ & 0 & 0 & 0 & $100 \%$ & $50 \%$ & 0 & 0 \\
\hline$N$ & & 0 & & 7 & & 0 & 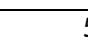 & 5 & 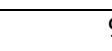 & & 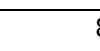 & 3 & 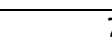 & 7 & 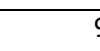 & & 8 & & 1 & 0 & 2 & & & 4 \\
\hline
\end{tabular}




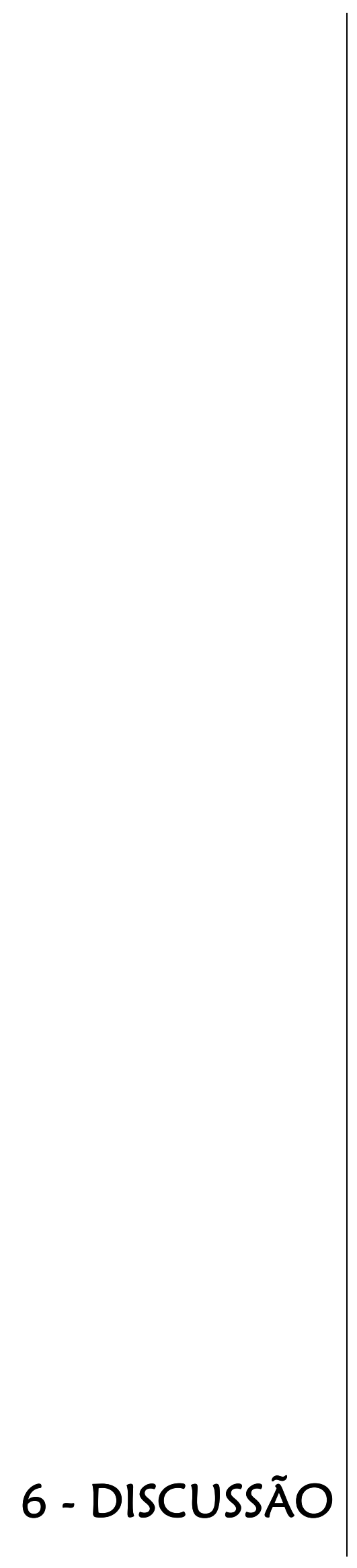




\section{6 - DISCUSSÃO}

A mucosa bucal e a pele são envolvidas por distúrbios angioproliferativos com certa freqüência. As características fisiopatológicas dessas lesões resultam de alterações moleculares que geram características clínicas próprias e norteiam parâmetros de classificação. Apesar de vários sistemas de classificação já haverem sido divulgados, poucos trabalhos com esse tipo de abordagem enfatizam as lesões vasculares proliferativas da mucosa bucal. As implicações clínicas e diagnósticas relativas à deficiência de critérios adequados são reais e não podem ser negligenciadas. Tais constatações motivaram a realização de uma análise comparativa das lesões angioproliferativas bucais em relação às mesmas lesões cutâneas, que já contam com sistemas de classificação organizados.

Nesse trabalho, optou-se por compilar os casos de lesões angioproliferativas bucais diagnosticadas na Faculdade de Odontologia de Bauru, entre os anos de 1971 a 2002, e compará-los com as lesões angioproliferativas cutâneas do Instituto Lauro de Souza Lima, diagnosticadas no mesmo período. Após o levantamento retrospectivo foram selecionados os casos mais comuns de lesões angioproliferativas dos arquivos de ambos os Serviços de Anatomia Patológica. Houve exceção apenas para os espécimes de sarcoma de Kaposi que, apesar de não serem comuns, representam as neoplasias vasculares malignas mais freqüentes, além da importância epidemiológica que adquiriram ao longo das décadas que sucederam à pandemia da Síndrome da Imunodeficiência Adquirida (AIDS).

Seguindo-se à amostragem, os espécimes obtidos foram classificados quanto às respectivas características etiopatogênicas em: malformações vasculares; hiperplasias; neoplasias benignas e neoplasias vasculares malignas. Posteriormente, a amostra foi dividida conforme seu sítio anatômico de ocorrência, sendo que 398 espécimes apresentavam-se na mucosa bucal e 340 na pele. Os dados clínicos das amostras foram registrados com o intuito de melhor caracterizá-las. 
Das 738 lesões angioproliferativas selecionadas, as mais freqüentes foram os granulomas piogênicos. HARRIS et al. ${ }^{35}$ realizaram, em 2000, um estudo epidemiológico sobre granulomas piogênicos bucais e cutâneos. Constataram que entre os 325 granulomas piogênicos obtidos em levantamento epidemiológico, $86 \%$ se apresentou na pele ${ }^{35}$. Nosso trabalho demonstrou índices percentuais diferentes. O total de granulomas piogênicos foi de 413 espécimes e desses; $66 \%$ foram lesões bucais e 34\%, cutâneas.

Os dados clínicos desse estudo em relação aos granulomas piogênicos conferem com os achados de outros trabalhos, os quais relatam a maior incidência dessas lesões na terceira década de vida, em pacientes do gênero feminino, sendo que a gengiva é o sítio anatômico mais acometido ${ }^{88}$. A ocorrência dos granulomas piogênicos em outras mucosas não é comum, mas já foram relatados casos de granulomas piogênicos nas mucosas nasal e genital ${ }^{80}$. Na pele, os granulomas piogênicos podem ser observados com maior freqüência nos dedos e na face ${ }^{70,88}$, o que está de acordo com nossa amostra de lesões cutâneas.

Os granulomas piogênicos, sendo bucais ou cutâneos, desenvolvem-se por meio de estádios evolutivos ${ }^{97}$. Essa característica patogênica é compartilhada com hemangiomas infantis. As lesões precoces dos granulomas piogênicos apresentam-se geralmente ulceradas, sob as quais se observam inúmeros capilares em proliferação, bem como intenso infiltrado inflamatório misto permeando um interstício edematoso. As células endoteliais das áreas superficiais encontram-se circundadas por uma lâmina de membrana basal e por esparsos pericitos ASMA-negativos, confirmando tratar-se de estruturas vasculares capilares. Os lóbulos vasculares em profundidade são, por sua vez, compostos por estruturas predominantemente venulares circundadas por miócitos ASMA-positivos. Nas lesões com desenvolvimento já estabelecido, os grupamentos venulares passam a ser interceptados por feixes de fibras colágenas cada vez mais densos. O infiltrado inflamatório e o exsudato tendem a se restringir. A maturação dos granulomas piogênicos é acompanhada pela reepitelização da área ulcerada ${ }^{45}$. 
Os granulomas piogênicos bucais desse trabalho apresentaram-se como lesões em curso de desenvolvimento adiantado. Apesar do padrão nodular não ser marcante como nas lesões cutâneas, os seguimentos principais demonstraram edema moderado, restrição do infiltrado inflamatório e pouca fibrose, além de pequenos vasos com uma uniformidade característica de estruturas pré e póscapilares. Esses achados foram compatíveis com estudos histopatológicos prévios sobre os granulomas piogênicos ${ }^{88,76}$. A despeito dos granulomas piogênicos bucais de nossa amostra não se apresentarem como leões precoces, o processo de angiogênese foi indicado pela demonstração difusa do mediador FGFb no endotélio vascular. A expressão do receptor p $75^{\text {NTR }}$ nos granulomas piogênicos bucais esteve restrita a focos de discreta imunoreatividade.

Os cortes microscópicos dos granulomas piogênicos cutâneos demonstraram formações lobulares marcantes e densos septos colagênicos, apesar do infiltrado inflamatório ainda se apresentar intenso em algumas áreas. Os achados morfológicos dos espécimes cutâneos indicaram tratar-se de lesões mais maduras que as bucais e a quase ausência de marcação imuno-histoquímica para FGFb nos espécimes cutâneos, contribuiu para validar tal consideração. O receptor p75 ${ }^{\text {NTR }}$ foi expresso na superfície das células endoteliais das inúmeras vênulas dispostas em lóbulos pelo interstício dos granulomas piogênicos cutâneos.

A expressão do receptor p75 NTR na superfície endotelial dos granulomas piogênicos e a maturidade morfológica da maioria dos granulomas piogênicos da amostra sugere que receptor $\mathrm{p} 75^{\mathrm{NTR}}$ esteja sinalizando a regressão do processo proliferativo desses espécimes. Por outro lado, a presença de p75 ${ }^{\text {NTR }}$ em localização periendotelial sugere possível influência das neurotrofinas sobre miócitos ASMA+, contribuindo para a organização dos futuros lóbulos vasculares nas lesões precoces.

Ainda com relação à prevalência, observou-se que além dos granulomas piogênicos bucais, as malformações venosas foram os tipos de lesões bucais mais comuns desse estudo (14\%). KABAN; MULLIKEN ${ }^{41}$ consideraram as malformações vasculares como os distúrbios endoteliais mais comuns do complexo 
bucomaxilofacial. MATHES et al. $.^{53}, 2004$, ao descreverem o escopo de trabalho da Vascular Anomalies Clinic da cidade de San Francisco (USA), relatam que a maioria dos pacientes estudados apresentava malformações venosas e os casos de anomalias vasculares na região de cabeça e pescoço eram os mais numerosos. Estes dados estão de acordo com os achados de nosso trabalho e com os da literatura científica ${ }^{53,54}$. No entanto, SPETIC ${ }^{78}, 2001$, sugerem com base em seus achados microscópicos e imuno-histoquímicos que algumas das lesões bucais classificadas como hemangiomas cavernosos sejam na verdade hemangiomas capilares em fase de regressão, o que poderia alterar a freqüência das malformações venosas no que se refere às lesões de mucosa bucal.

As características morfológicas das malformações vasculares bucais e cutâneas desse trabalho nos permitiram classificá-las como malformações venosas. Tanto as lesões bucais quanto as cutâneas demonstraram vasos irregulares com paredes endoteliais delgadas, compostas por células planas e por vezes arredondadas. Foi observado, ainda, discreto infiltrado inflamatório crônico, tromboflebolítos e alguns focos de hemossiderose no interstício. O tecido conjuntivo subendotelial demonstrou com freqüência musculatura lisa delicada ou mesmo ausente. Os achados para p75NTR se concentraram em áreas de organização de trombos e na musculatura lisa ao redor dos vasos. A presença do fator de crescimento fibroblástico entre as malformações venosas foi demonstrada somente nos espécimes bucais de trabalho, principalmente nos trombos em organização e nos núcleos de algumas células endoteliais.

Algumas isoformas de FGF não são secretadas e localizam-se nos núcleos das células, porém a metodologia adotada nesse estudo não nos permitiu especificar quais isoformas estariam expressas no núcleo das células endoteliais das malformações venosas. Sabe-se que as formas com massa molecular alta possuem distribuição citosólica e as de baixa massa, localizam-se no núcleo das células, onde se ligam à cromatina e modulam a transcrição gênica ${ }^{49}$. Sugere-se que a apresentação tanto citosólica quanto nuclear do FGF indique maior potencial proliferativo nas células. No entanto, a expressão imunofenotípica desse fator de 
crescimento pode simplesmente indicar que as células envolvidas estão estocando o FGF, como parece ser o caso das malformações venosas estudadas aqui.

As malformações linfáticas integraram o grupo das malformações vasculares desse estudo; representando 6\% das lesões bucais e 6\% das lesões cutâneas de toda amostra obtida. Essas malformações apresentaram-se compostas por canais sem conexão direta com grandes vasos linfáticos. As malformações linfáticas superficiais, como as selecionadas para esse estudo, podem ocorrer congenitamente e aumentar de volume em conseqüência de infecções. Não há evidencias sobre o caráter hereditário das malformações linfáticas superficiais. Se existem alterações genéticas nessas lesões, as mesmas devem resultar de defeitos somáticos localizados"1.

Os achados morfológicos referentes às malformações linfáticas desse trabalho estiveram de acordo com relatos prévios e a ausência dos marcadores imunohistoquímicos estudados indica a falta de atividade proliferativa dessas lesões. Consideramos que as áreas restritas nas malformações linfáticas bucais, nas quais se observou expressão de FGFb e p75, correspondiam a pequenos vasos sanguíneos adjacentes às malformações, que foram evidenciados por apresentarem ativação em resposta ao processo inflamatório de alguns espécimes. Ressaltamos, ainda, que as lesões angioproliferativas bucais e cutâneas de nosso estudo, diagnosticadas como linfangiomas e hemangiomas cavernosos, não são neoplasias benignas e devem ser classificadas como malformações linfáticas e venosas, respectivamente.

Observaram-se nesse estudo, que as neoplasias vasculares cutâneas foram mais freqüentes que as bucais, mesmo havendo mais lesões bucais $(n=398)$ do que cutâneas $(n=340)$. Os hemangiomas capilares cutâneos que se apresentaram em alta freqüência, localizaram-se principalmente no tronco de indivíduos do gênero masculino com média de idade de 54 anos, enquanto que os hemangiomas capilares bucais prevaleceram nos lábios de pacientes do gênero feminino com média de 25 anos de idade. O comportamento biológico dos hemangiomas capilares é definido por três períodos diferentes. A fase proliferativa dos hemangiomas capilares é caracterizada pela proliferação das células endoteliais, que 
aumentam o diâmetro dos vasos permitindo a formação de lumes e a perfusão sanguínea. Durante essa fase de rápida proliferação os hemangiomas aumentam a expressão de mediadores angiogênicos como VEGF, FGFb e metaloproteinases. Com exceção ao FGFb, a concentração tecidual desses mediadores decresce conforme as lesões entram em regressão. A fase regressiva dos hemangiomas capilares demonstra gradativamente uma organização arquitetural em lóbulos, separados por septos fibrosos, com vasos cada vez mais ectásicos. Nessa fase podem ser evidenciadas duas proteínas relacionadas ao processo de apoptose, o citocromo B mitocondrial e a proteína homer-2a, ${ }^{87}$.

Os hemangiomas infantis podem ser considerados arquétipos de hemangiomas de capilares. São lesões que aparecem logo após o nascimento, crescem rapidamente $\mathrm{e}$ a seguir regridem quase sem deixar seqüelas. Os hemangiomas capilares de nossas amostras, bucal e cutânea, ocorreram em pacientes jovens e adultos, exceto em um paciente de um ano de idade com a lesão excisada do rebordo alveolar; caracterizada como um hemangioma infantil de fato. Alternativamente ao hemangioma infantil, foram classificadas duas formas de hemangiomas capilares já presentes ao nascimento ${ }^{54}$. Os hemangiomas congênitos são similares aos infantis em alguns aspectos histopatológicos embora demonstrem fenótipo e evolução diferentes. O hemangioma congênito rapidamente involutivo tem um padrão de regressão muito mais rápido que o infantil; esse tipo de lesão não foi detectado em nosso estudo. Em contraste, pareceu-nos adequado sugerir que os hemangiomas bucais e cutâneos de nossa amostra fossem designados como hemangiomas congênitos não involutivos ou não progressivos ${ }^{23,59}$, uma vez que as características histopatológicas e proliferativas dos mesmos estiveram de acordo com essas variantes.

KAPLAN et al. ${ }^{42}$, estudaram, em 1998, hemangiomas capilares labiais e notaram que as características microscópicas dessas lesões eram as mesmas que as dos hemangiomas infantis. Porém, com diferenças em relação ao desenvolvimento dessas lesões, como a ausência de regressão com o avançar da idade dos 
pacientes $^{42}$. Talvez as lesões estudadas por esses autores também fossem hemangiomas capilares congênitos não involutivos.

Os aspectos morfológicos dos hemangiomas capilares bucais e cutâneos analisados em nosso estudo apresentaram algumas diferenças entre si. Os espécimes obtidos de mucosa bucal demonstraram lesões com predominância de células endoteliais volumosas, constituindo pequenos vasos sanguíneos por vezes dispostos difusamente pela submucosa. A maioria dos espécimes cutâneos apresentou lesões com aspecto regressivo, com vasos de contornos regulares separados por septos de fibras colágenas além do endotélio composto por células arredondadas e pouco volumosas. As diferenças na expressão dos marcadores imuno-histoquímicos empregados nesse estudo corroborou os achados microscópicos. O mediador angiogênico FGFb foi evidenciado nos hemangiomas capilares bucais, indicando tratar-se de lesões em crescimento ou em início de involução, mas não totalmente

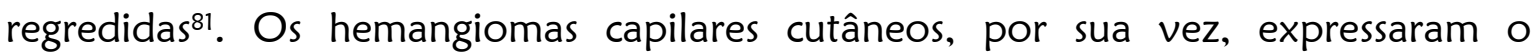
receptor p75 NTR nas células endoteliais e foram negativos para FGFb, indicando um estádio avançado de maturação. A presença do receptor p75 NTR talvez sinalize a regressão das lesões por meio da morte celular, mas esse fenômeno não pôde ser registrado com a metodologia aqui adotada e requer estudos adicionais mais específicos.

As variações na expressão de um mesmo mediador analisado em locais distintos, como a mucosa bucal e a pele, sugerem a influência da fisiologia local sobre o comportamento biológico dessas lesões. Tal constatação se aplica em alguns dos espécimes desse estudo, como os hemangiomas arteriovenosos. Os espécimes de mucosa bucal expressaram FGFb no endotélio, denotando caráter proliferativo em alguns deles, embora a presença do fator de crescimento no núcleo das células endoteliais dessas lesões possa simplesmente refletir seu potencial de produzir FGFb. Em mais esse grupo de lesões angioproliferativas os espécimes cutâneos foram negativos para FGFb e apresentaram expressão do receptor p75 para neurotrofinas. Porém, no caso dos hemangiomas arteriovenosos, a presença desse receptor pode ser esperada devido à densidade de musculatura lisa perivascular que 
reconhecidamente sofre a influência das neurotrofinas e seus receptores ${ }^{13}{ }^{14}$. Alguns dos achados microscópicos contribuíram para entender porque as lesões cutâneas apresentaram maior expressão de p75 do que as bucais. Notou-se que nessas últimas as paredes musculares dos vasos encontravam-se menos espessas que as paredes dos hemangiomas arteriovenosos de pele.

No expressivo estudo de BARRET et al. ${ }^{6}$, em 2000, os hemangiomas arteriovenosos bucais apresentaram três padrões arquiteturais distintos: Difuso, lobular e tortuoso. Nas lesões bucais e cutâneas aqui analisadas, os arranjos citados pelos autores puderam ser constatados, mas o padrão mais encontrado na amostra de mucosa bucal foi o difuso. Os demais aspectos histopatológicos e clínicos demonstrados pelos autores foram semelhantes aos discutidos aqui e aos dados encontrados na literatura ${ }^{36,46}$, permitindo-nos classificar as lesões de nossa amostra como hemangiomas arteriovenosos superficiais.

As neoplasias malignas, representadas em nosso estudo pelos sarcomas de Kaposi, demonstraram sinais positivos para ambos os marcadores imunohistoquímicos avaliados. Semelhante a algumas das lesões proliferativas anteriormente citadas, o diferencial em relação à expressão desses mediadores se deu entre os espécimes bucais e cutâneos. Ficou evidente que as lesões angioproliferativas bucais expressam FGFb no endotélio, em detrimento do mediador p75NTR, que também participa da angiogênese como co-fator, estimulando a expressão de TrkA77. Em contrapartida, as lesões cutâneas apresentaram pouca positividade para FGFb em comparação com a expressão de p75 ${ }^{\text {NTR }}$. Nos sarcomas de Kaposi cutâneos, o anticorpo anti-p75 NTR foi evidenciado focalmente, de forma intensa. Esse receptor apresenta papéis antagônicos na biologia de diferentes tipos celulares ${ }^{18,} 48,49$, portanto não se pode descartar 0 envolvimento do p75 ${ }^{\mathrm{NTR}}$ no crescimento desses tumores. Além das características histopatológicas dessas lesões angioproliferativas, as atividades diversificadas do receptor $\mathrm{p} 75^{\mathrm{NTR}}$ poderiam ser avaliadas com mais exatidão, por meio da expressão de co-receptores e ligantes específicos na indução de repostas endoteliais ${ }^{50}$. 
Consideramos particularmente interessante a possibilidade de investigação do potencial pleiotrópico presente em vários fatores de crescimento e seus receptores, como o FGFb e o p75 ${ }^{\mathrm{NTR}}$, lembrando que a resposta biológica a essas moléculas depende de sua associação com vários co-fatores e de parâmetros cinéticos que determinem sinais alternativos de indução. Desse modo, a compreensão do papel de importantes mediadores angiogênicos, como FGFb e p75 ${ }^{\text {NTR }}$, virá principalmente da análise molecular dos diferentes tipos de complexos formados e de avaliações sobre a interação entre esses complexos e suas vias de sinalização intracitoplasmática $31,39,40$.

A intrigante disparidade de expressão fenotípica dos mediadores FGFb e p75NTR, em tipos iguais de lesões bucais e cutâneas, leva-nos a refletir sobre a preponderância de diferentes estimuladores dos distúrbios angiogênicos sediados em ambientes anatomofisiológicos distintos. Mesmo nos distúrbios angioproliferativos não neoplásicos, compreender a ação dos mediadores vasculares abre perspectivas para futuras pesquisas e para abordagens clínicas baseadas em terapêuticas moleculares, como $\mathrm{O}$ emprego de mediadores angiogênicos e antiangiogênicos na inibição da progressão ou na indução da regressão de lesões vasculares proliferativas.

Conforme características histopatológicas constatadas nos grupos de angioproliferativas desse trabalho, podemos sugerir que abordagens clínicas $e$ terapêuticas podem ser adotadas sob os mesmos algoritmos. Contudo, o diagnóstico clínico e microscópico das lesões angioproliferativas bucais e cutâneas deve seguir parâmetros criteriosos. Algumas semelhanças ilusórias podem mascarar diagnósticos diferenciais e dificultar a condução de adequados protocolos de tratamento. 
7 - CONCLUSÃO 


\section{7 - CONCLUSÃO}

Após a interpretação e discussão dos resultados concluiu-se, conforme a metodologia adotada, que:

( As malformações venosas e linfáticas, granulomas piogênicos, hemangiomas capilares e sarcomas de Kaposi bucais e cutâneos apresentaram semelhanças histopatológicas que permitem classificá-los sob os mesmos parâmetros etiopatogênicos.

( Algumas das referidas lesões angioproliferativas bucais e cutâneas do mesmo tipo, analisadas nesse estudo, apresentaram padrões de expressão distintos em relação aos mediadores FGFb e p75 ${ }^{\text {NTR }}$, sugerindo que a evolução e a regressão dessas lesões possam mediadas por fatores distintos. 


\section{REFERÊNCIAS BIBLIOGRÁFICAS*}

1. ABLASHI, D. V. et al. Spectrum of Kaposi's sarcoma-associated herpes virus or human herpesvirus-8 diseases. Clin Microb Rev, v.15, n.3, p.439-64, July 2002.

2. ACIKCOZ, A. et al. Rare benign tumors of oral cavity. Capillary haemangioma of palatal mucosa: a case report. Int J Paediatr Dent, v.10, n.2, p.161-5, June 2000.

3. ALABDULHADI, $K$. et al. Extensive tongue hemangiopericytoma in a child: modified combined modality of treatment to preserve well functioning tongue. Int J Pediatr Otorhinolaryngol, v.68, n.2, p.211-9, Feb. 2004.

4. AL-KHATEEB, T; ABABNEH, K. Oral pyogenic granuloma in Jordanians: a retrospective analysis of 108 cases. J Oral Maxillofac Surg, v.61, n.11, p.1285-8, Nov. 2003.

5. BAKAEEN, $G$ et al. Congenital macroglossal angiodysplasia: "Lymphangioendotheliomatosis." Arch Pathol Lab Med, v.124, n.9, p.13491351, Sept. 2000.

6. BARRET, W. A; SPEIGHT, P. M. Superficial arteriovenous hemangioma of the oral cavity. Oral Surg Oral Med Oral Pathol, v.90, n.6, p.731-8, Dec. 2000.

7. BIELENBERG, D. R. et al. Progressive growth of infantile hemangiomas is directly correlated with hyperplasia and angiogenesis of adjacent epidermis

\footnotetext{
- Normas recomendadas para uso no âmbito da Universidade de São Paulo, com base no documento "Referências Bibliográficas: exemplos", emanados do Conselho Supervisor do Sistema Integrado de Bibliotecas da USP, em reunião de 20 de setembro de 1990.
} 
and inversely correlated with expression of the endogenous angiogenesis inhibitor, IFN- $\beta$. Int J Oncol, v.14, n.3, p.401-8, Mar. 1999.

8. BOYE, E. et al. Clonality and altered behavior of endothelial cells from hemangiomas. J Clin Invest, v.107, n.6, p.745-52, Mar. 2001.

9. BOON, L. M. et al. Glomuvenous malformation (Glomangioma) and venous malformation: Distinct Clinicopathologic and genetic entities. Arch Dermatol, v.140, n.8, p.971-6, 2004.

10. BRENNAN, T. D; MILLER A. S; CHEN S. Y. Lymphangiomas of the oral cavity: a clinicopathologic, immunohistochemical, and electron-microscopic study. J Oral Maxillofacial Surg, v.55, n.9, p.932-5, Sept. 1997.

11. BROUILLARD, P; VIKKULA, M. Vascular malformations: localized defects in vascular morphogenesis. Clin genet, v.63, n.340-51, May 2003.

12. CALONJE, E; FLETCHER, C. D. M. A distinctive benign vascular neoplasm within the group of cavernous hemangioma. Am J Surg Pathol, v.15, p.130-5, Dec. 1991.

13. CAMPAGNOLO, L. et al. Mesenchymal cell precursors of peritubular smooth muscle cells of the mouse testis can be identified by the presence of the p75 neurotrophin receptor. Biol Reprod, v.64, n.2, p.464-72, Feb. 2001.

14. CANTARELLA, $G$. Nerve growth factor - endothelial cell interaction leads to angiogenesis in vitro and in vivo. FASEB J, v. 16, p. 1307-9, 2002.

15. CAO, R. et al. Comparative evaluation of FGF-2, VEGF-A and VEGF-Cinduced angiogenesis, lymphangiogenesis, vascular fenestrations, and permeability. Circulation, v.94, p.664-70, 2004. 
16. CHANG Y. et al. Identification of herpes virus-like DNA sequences in AIDSassociated Kaposi's sarcoma. Science, v.266, n.1865-9, 1994.

17. CHEN-TSAI C. P. et al. Correlation among neural cell adhesion molecule, nerve growth factor and its receptors, trkA, trkB, trkC e p75 invasion by basal cell and cutaneous squamous cell carcinomas. Dermatol Surg, v.30, n.7, p.1009-16, 2004.

18. CHESA, P. G. et al. Immunohistochemical analysis of nerve growth factor receptor expression in normal and malignant human tissues. J Histochem Cytochem, v. 36, n.4, p.383-9, 1988.

19. CHILLER K. G; PASSARO D; FRIEDEN I. J. Hemangiomas of infancy. Clinical characteristics, morphologic subtypes, and their relationship to race, ethnicity, and sex. Arch Dermatol, v.138, p.1567-76, 2002.

20. Delbem A. C; CORREIA, M. G; PUGliesi, D. M; CRIVEliNI M. M. Palatal lymphangioma: a case report. ASDC J Dent Child, v.68, n.5/6, p.344-6, Sept, /Dec. 2001.

21. DONOVAN, M. J. et al. Brain derived neurotrophic factor is an endothelial cell survival factor required for intramyocardial vessel stabilization. Development, v.127, p. 4531-40, 2000.

22. EMANUELI, $C$. et al. Nerve growth factor promotes angiogenesis and arteriogenesis in ischemic hindlimbs. Circulation, v.106, p.2257-62, 2002.

23. ENJOLRAS $\mathrm{O}$, et al. Noninvoluting congenital hemangioma: a rare cutaneous anomaly. Plast Reconstr Surg, v.107, p. 1647-54, 2001.

24. ENJOLRAS, O. et al. Arteriovenous malformations: a study of 200 cases. Ann Dermatol Venereol, v.127, n.1, p.17-22, Jan. 2000. 
25. ENZINGER, F. M; WEISS, S. W. Soft Tissue Tumors. St. Louis: Mosby, 2001.

26. EZEKOWITZ, R. A. B; MULLIKEN, J. B; FOLKMAN, J. Interferon alfa-2a therapy for life-threatening hemangiomas of infancy. New England J Med, v.32, n.22, p.1456-63, 1992.

27. FICARRA, G; MERRELL, P. W; JOHNSTON, W. H; HANSEN L. S. Intraoral solitary glomus tumor (glomangioma): case report and literature review. Oral Surg Oral Med Oral Pathol, v.62, n.3, p.306-11, Sept. 1986.

28. FLUGEL, A. et al. Anti-inflammatory activity of nerve growth factor in experimental autoimmune encephalomyelitis: inhibition of monocyte transendothelial migration. Eur J Immunol, v.31, p.11-22, 2001.

29. FOLKMAN, J; KLAGSBRUN, M. Angiogenic Factors. Nature, v.235, n.4787, p.442-7, Jan. 1987.

30. FOLPE, A. L. et al. Vascular endothelial growth factor receptor-3 (VEGFR-3): A marker of vascular tumors with presumed lymphatic differentiation, including Kaposi's sarcoma, kaposiform and Dabska-type hemangioendotheliomas and a subset of angiosarcomas. Mod Pathol, v. 13, n.2, p.180-5, 2000.

31. FOROUGH, R. et al. Differential transforming abilities of non-secreted and secreted forms of human fibroblast growth factor-1. J Biol Chem, v. 268, n.4, p.2960-8, 1993.

32. GIAVAZZI, R. et al. Distinct role of fibroblast growth factor-2 and vascular endothelial growth factor on tumor growth and angiogenesis. Am J Pathol, v.162, n.6, p.1913-25, 2003. 
33. GRÜTZKAU, A. et al. Synthesis, storage and release of vascular endothelial growth factor/vascular permeability factor (VEGF/NPF) by human mast cells: Implications for the biological significance of VEGF. Mol Biol Cell, v.9, p.87584, 1998.

34. HAGIWARA, K. et al. Mast cell "densities" in vascular proliferations: a preliminary study of pyogenic granuloma, port wine stain, cavernous hemangioma, cherry angioma, Kaposi's sarcoma and malignant hemangioendothelioma. J Dermathol, v.26, p.577-86, 1999.

35. HARRIS, M. N. et al. Lobular capillary hemangiomas: an epidemiologic report, with emphasis on cutaneous lesions. J Am Acad Dermatol, v.42, p.1012-6, 2000.

36. HASSARD, A. D; BYRNE, B. D. Arteriovenous malformations and vascular anatomy of the upper lip and soft palate. Laryngoscope, v.95, n.7, p.829-32, 1985.

37. JACKSON, I. T; CARRENO, R; POTPARIC, Z; HUSSAIN, K. Hemangiomas, vascular malformations, and lymphovenous malformations: classification and methods of treatment. Plast Reconstr Surg, v.91, n.7, p.1216-30, June 1993.

38. JANG, Y-C. et al. Changes in matrix composition during the growth and regression of human hemangiomas. J Surg Res, v.80, n.1, p.9-15, 1998.

39. JAVERZAT, $S$. et al. The role of fibroblast growth factors in vascular development. Trends in Mol Med, v.8, n.10, p.483-9, 2002.

40. JOHNSON, D. et al. Expression and structure of the human NGF receptor. Cell, v.47, p.545-54, 1986.

41. KABAN, L. B; MULLIKEN, J. B. Vascular anomalies of the maxillofacial region. J Oral Maxillofac Surg, v.44, p.203-13, 1986. 
42. KAPLAN, I; MASS, E; LITTNER, M. A study of small superficial capillary hemangiomas on the lips in children. Pediatr Dent, v.20, n.3, p.188-91, 1998.

43. KAPOSI, M. K. Idiopathisches multiples Pigmentsarkom der Haut. Archiv für Dermatologie und Syphilis, v. 4, p.265-73, 1872.

44. KASABACH, H. H; MERRITT, K. K. Capillary hemangioma with extensive purpura: report of a case. Am J Dis Child, v.59, p.1063-70, 1940.

45. KEMPSON, R. L. et al. Atlas of Tumor Pathology: Tumors of the Soft Tissues. Armed Forces institute of Pathology, Bethesda, Maryland 2001.

46. KHONG, P-L. et al. Fast-flow lingual vascular anomalies in the young patient: is imaging diagnostic? Pediatr Radiol, v.33, p.118-22, 2003.

47. KOHOUT, M. P; HANSEN, M; PRIBAZ, J. J; MULLIKEN, J. B. Arteriovenous malformations of the head and neck: natural history and management. Plast Reconstr Surg, v.102, n.3, p.643-54, Sept. 1998.

48. KHWAJA, F; TABSSUM, A; ALLEN, J; DJAKIEW, D. The p75 (NTR) tumor suppressor induces cell cycle arrest facilitating caspase mediated apoptosis in prostate tumor cells. Biochem Biophys Res Commun, v.341, n.4, p.1184-92, March 2006.

49. LARA, V. S. Estudo comparativo da expressão de triptase de mastócitos, de fator de crescimento fibroblástico básico (bFGF) e do receptor do fator de crescimento neural (NGFR) em lesões neurais bucais. Bauru-SP, 2003. 75p. Tese [Livre Docência] - Faculdade de Odontologia de Bauru. 
50. LINGGI, M. S. et al. Neurotrophin receptor interacting factor (NRIF) is an essential mediator of apoptotic signaling by the p75 neurotrophin receptor. J Biol Chem, v.280, n.14, p.13801-8, Apr. 2005.

51. MAAITA, J. K. Oral tumors in children: a review. J Clin Ped Dent, v.24, n.2, p.134-7, 2000.

52. MARGIOTTA, V; FlORENA, A. M; GIULIANA, G. Primary angiosarcoma of the alveolar mucosa in a hemodialysis patient: case report and discussion. J Oral Pathol Med, v. 23, n.9, p.429-31, Oct. 1994.

53. MATHES E. D. et al. Clinical characteristics and management of vascular anomalies: Findings of a Multidisciplinary vascular anomalies clinic. Arch Dermatol, v.140, n.8, p.979-83, 2004.

54. MULLIKEN, J. B; ENJOLRAS, O. Congenital hemangiomas and infantile hemangiomas: Missing links. J Am Acad Dermatol, v.50, n.6, p.875-82, 2004.

55. MULLIKEN, J. B; GLOWAKI, J. Hemangiomas and vascular malformations in infants and children: a classification based on endothelial characteristics. Plast Reconstr Surg, v.69, n.3, p.412-22, Mar. 1982.

56. MULLIKEN, J.B; YOUNG, A. E. Vascular birthmarks: hemangiomas and vascular malformations. Philadelphia: WB Saunders, 1988.

57. MURATA, M; HARA, K; SAKU, T. Dynamic distribution of basic fibroblast growth factor during epulis formation: an immunohistochemical study in an enhancing healing process of gingiva. J Oral Pathol Med, v.26, p.224-32, 1997. 
58. NORDELL, V. L; LEWIS, D. K; BAKE, S; SOHRABJI, F. The neurotrophin receptor p75NTR mediates early anti-inflammatory effects of estrogen in the forebrain of young adult rats. BMC Neurosci, v.6, p.58, Sept. 2005.

59. NORTH, P. E. et al. Congenital nonprogressive hemangioma. A distinct clinicopathologic entity unlike infantile hemangioma. Arch Dermatol, v.137, p.1607-20, 2001.

60. OZCAN, C; APA, D. D; GORUR, K. Pediatric lobular capillary hemangioma of the nasal cavity. Eur Arch Otorhinolaryngol, v.261, n.8, n.449-51, 2004.

61. PARK, Y. W. et al. Lymphangioma involving the mandible: immunohistochemical expressions for the lymphatic proliferation. J Oral Pathol Med, v.31, n.5, p.280-3, May 2002.

62. PROCHAZKOVA, L. Arteriovenous malformations of the orofacial area. Acta Chir Plast, v.42, n.2, p.55-9, 2000.

63. PROPHET, E. B. et al. Métodos Histotecnológicos. AFIP, Washington, D. C. 1995.

64. PUIG, $S$ et al. Classification of venous malformations in children and implications for sclerotherapy. Pediatr Radiol, v.33, p.99-103, 2003.

65. QU, Z. et al. Mast cells are a major source of basic fibroblast growth factor in chronic inflammation and cutaneous hemangioma. Am J Pathol, v.147, n.3, p.564-5, 1995.

66. RAYCHAUDHURI, S. K. et al. Effect of nerve growth factor on endothelial cell biology: proliferation and adherence molecule expression on human dermal microvascular endothelial cells. Arch Derm Res, v.293, p. 291-5, 2001. 
67. REIS-FILHO, J. S. et al. Distribution and significance of nerve growth factor receptor (NGFR/p75NTR) in normal, benign and malignant breast tissue. Mod Pathol, v.19, n.2, p.307-19, Feb. 2006.

68. REIS-FILHO, J. S; SOUTO-MOURA, C; LOPES, J. M. Classic Kaposi's sarcoma of the tongue: case report with emphasis on the differential diagnosis. J Oral Maxillofac Surg, v.60, p.951-4, 2002.

69. REQUENA, L; SANGUEZA, O. Cutaneous vascular anomalies. Part I. Hamartomas, malformations and dilatation of preexisting vessels. J Am Acad Dermatol, v.37, n.4, p.523-49, 1997.

70. REQUENA, L; SANGUEZA, O. Cutaneous vascular proliferations. Part II. Hyperplasias and benign neoplasms. J Am Acad Dermatol, v.37, n.6, p.887920, 1997.

71. REQUENA, L; SANGUEZA, O. Cutaneous vascular proliferations. Part III. Malignant neoplasms, other cutaneous neoplasms with significant vascular component and disorders erroneously considered as vascular neoplasms. J Am Acad Dermatol, v.38, n. 2, p.143-75, 1998.

72. RIBATTI, D. et al. Alterations of blood vessel development by endothelial cells overexpressing fibroblast growth factor 2. J Pathol, v.189, n.4, p.590-9, 1999.

73. RITTER, M. R. et al. Insulin-like factor 2 and potential regulators of hemangioma growth and involution identified by large-scale expression analysis. PNAS, v.99, n.11, p.7455-60, 2002.

74. ROGELJ, $S$, et al. Basic fibroblast growth factor is an extracellular matrix component required for supporting the proliferation of vascular endothelial cells and the differentiation of PC12 cells. J Cell Biol, v.109, n.2, p.823-31, 1989. 
75. ROTHE, M. J. et al. The mast cells in health and disease. J Am Acad Dermatol, v.23, n.4, p.615-24, 1990.

76. SANGÜEZA, O. P; REQUENA, L. Pathology of vascular skin lesions. Humana Press, NJ, 2003.

77. SCHOR, N. F. The p75 neurotrophin receptor in human development and disease. Prog Neurobiol, v.77, n.3, p.201-14, Oct. 2005.

78. SPETIC, M. B. da S. A. Avaliação da presença de mastócitos em hemangiomas e granulomas piogênicos bucais. Bauru-SP, 2001. 119p. Dissertação [Mestrado] - Faculdade de Odontologia de Bauru.

79. STAVRI, G. T. et al. Fibroblast growth factor upregulates the expression of vascular endothelial growth factor in vascular smooth muscle cells: Synergistic interaction with hypoxia. Circulation, v.92, n.1, p.11-4, 1995.

80. SUNDERKÖTTER, C. et al. Macrophages and angiogenesis. J Leukoc Biol, v.55, p.410-22, 1994.

81. TAKAHASHI K. et al. Cellular markers that distinguish the phases of hemangioma during infancy and childhood. J Clin Invest, v.93, n.2357-64, 1994.

82. TAKENAKA, H; YASUNO, H; KISHIMOTO, S. Immunolocalization of fibroblast growth factor receptors in normal and wounded skin. Arch Dermatol Res, v.294, p. 331-8, 2002.

83. TALKS, A. L; HARRIS, A. L. Current status of antiangiogenic factors. Brit J Haematol, v.109, p.477-89, 2000. 
84. TAN, S. T. et al. Cellular and extracellular markers of hemangioma. Plast Reconstruct Surg, v.106, n. 3, p.529-37, 2000.

85. TANAKA, A. et al. Na autocrine function of nerve growth factor for cell cycle regulation of vascular endothelial cells. Biochem Biophys Res Commun, v. 313, n.4, p. 1009-14, 2004.

86. TEN CATE, R. Oral histology. Development, structure and function. 50ed. St. Louis: Mosby, 2003.

87. TILLE, J. C; PEPPER, M. S. Hereditary vascular anomalies. New insight into their pathogenesis. Arterioscler thromb vasc biol, v.24, p.1578-90, 2004.

88. TOIDA, M. et al. Lobular capillary hemangioma of the oral mucosa: Clinicopathological study of 43 cases with a special reference to immunohistochemical characterization of the vascular elements. Pathology International, v.53, p.1-7, 2003.

89. URMACHER, C. Normal skin. In: STERNBERG, S. S. Histology for pathologists. New York, Raven Press, 1992.

90. VAN DOORNE, L. et al. Diagnosis and treatment of vascular lesions of the lip. Brit J Oral Maxillofac Surg, v.40, p.497-500, 2002.

91. VIKKULA, M. et al. Vascular dysmorphogenesis caused by an activating mutation in the receptor tyrosine-kinase TIE2. Cell, v.87, p.1181-90, 1996.

92. VLODAVSKY, I. et al. Endothelial cell-derived basic fibroblast growth factor: synthesis and deposition into subendothelial extracellular matrix. Proc Natl Acad Sci U S A, v.84, n.8, p.2292-6, 1987. 
93. WAKULICH, C. et al. Immunohistochemical localization of growth factors fibroblast growth factor-1 and fibroblast growth factor-2 and receptors fibroblast growth factor receptor-2 and fibroblast growth factor receptor-3 in normal oral epithelium, epithelial dysplasias and squamous cell carcinoma. J Oral Pathol Med, v.93, n.5, p.573-9, 2002.

94. WAUTIER, M. P. et al. Cultured endothelial cells from human arteriovenous malformations have defective growth regulation. Blood, v.94, p.2020-8, 1999.

95. WANER, M; SUEN, J. Y. Hemangiomas and vascular malformations of the head and neck. New York: Wiley-Liss, 1999.

96. YU H.J. et al. Localized multiple glomus tumors of the face and oral mucosa. J Dermatol, Mar. 2000.

97. YUAN, K; LIN, M. T. The roles of vascular endothelial growth factor and angiopoietin-2 in the regression of pregnancy pyogenic granuloma. Oral Diseases, v.10, p.179-85, 2004. 


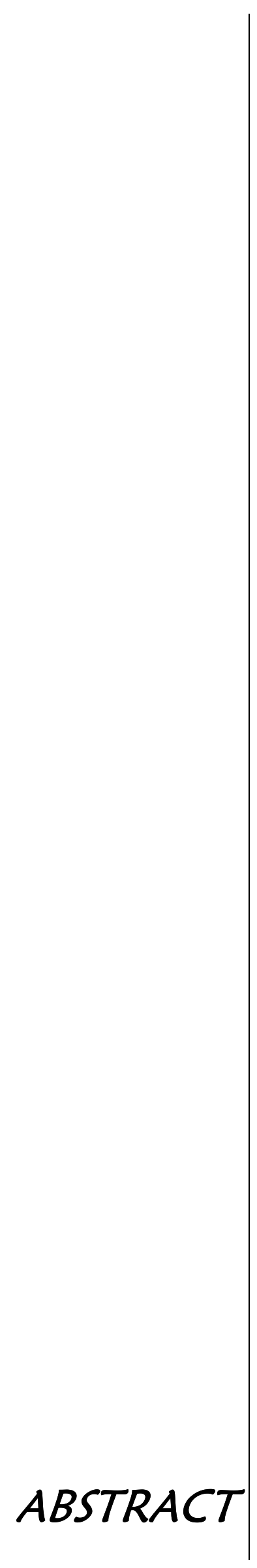




\section{ABSTRACT}

\section{Oral and Cutaneous Angioproliferative Diseases: Histopathologic CORRELATIONS AND EXPRESSION OF ANGIOGENIC MEDIATORS}

The oral mucosa and the skin may present proliferative vascular diseases with varied biological behavior. To classify such lesions, pathogenic criteria were adopted in specific groups of vascular lesions. The objective of this retrospective study was to characterize the main oral vascular lesions, comparing them with the same types of cutaneous lesions. The histopathologic findings were compared, as well as the endothelial expression of basic fibroblastic growth factor (FGFb) and p75 neurotrophin receptor ( $p 75^{\text {NTR }}$ ). Paraffin embedded specimens were purchased and divided, according to microscopic diagnostic, into six groups: (I) venous malformations; (II) lymphatic malformations; (III) pyogenic granulomas; (IV) capillary hemangiomas; (V) arteriovenous hemangiomas; (VI) Kaposi sarcomas. Each group was divided in two subgroups of oral and cutaneous location. The microscopic data demonstrated that oral and cutaneous vascular lesions, in our sample, are similar and they can be classified under the same parameters. However, some groups presented differences related to maturation stage, incidence, and expression FGFb and p75 NTR. These differences allowed us to conclude that the evolution of angiogenic process inside oral mucosa and in the skin, not necessarily is mediated by the same biological factors. Such differences open perspectives for future researches and therapeutic approaches, based on molecular technologies. 